\title{
Detailed anatomy of the braincase of Macelognathus vagans Marsh, 1884 (Archosauria, Crocodylomorpha) using high resolution tomography and new insights on basal crocodylomorph phylogeny
}

\author{
Juan Martin Leardi ${ }^{\text {Corresp.. }}{ }^{1}$, Diego Pol ${ }^{2}$, James Matthew Clark ${ }^{3}$ \\ ${ }^{1}$ CONICET, Instituto de Estudios Andinos “Don Pablo Groeber" (IDEAN), Facultad de Ciencias Exactas y Naturales, Departamento de Ciencias Geológicas, \\ Universidad de Buenos Aires, Buenos Aires, Argentina \\ 2 CONICET, Museo Paleontológico Egidio Feruglio, Trelew, Chubut, Argentina \\ 3 Department of Biological Sciences, George Washington University, Washington DC, United States of America \\ Corresponding Author: Juan Martin Leardi \\ Email address: jmleardi@gl.fcen.uba.ar
}

Background. Macelognathus vagans Marsh, 1884 from the Late Jurassic Morrison Fm. of Wyoming was originally described as a dinosaur by Marsh and in 1971 Ostrom suggested crocodilian affinities. In 2005, Göhlich and collaborators identified new material of this species from Colorado as a basal crocodylomorph. However, a partial skull found in association with mandibular and postcranial remains was not described.

Methods. Due to the small size and delicate structures within the braincase, micro CT studies were performed on this specimen. The new anatomical information was incorporated in a phylogenetic dataset, expanding both character and taxon sampling.

Results. This new material reinforces the non-crocodyliform crocodylomorph affinities of Macelognathus as it bears a large otic aperture, unfused frontals and lacks ornamentation on the dorsal cranial bones. The internal structures also support these affinities as this specimen bears traits (i.e., heavily pneumatized and expanded basisphenoid; the presence of additional pneumatic features on the braincase; and the otoccipital-quadrate contact) not present in most basal crocodylomorphs.

Furthermore, the presence of a wide supraoccipital and a cranioquadrate passage are traits shared with Almadasuchus from the early Late Jurassic of Argentina. Macelognathus was recovered as one of the closest relatives of crocodyliforms, forming a clade (Hallopodidae) with two other Late Jurassic taxa (Almadasuchus and Hallopus).

Discussion. The clade formed by Almadasuchus + Hallopus + Macelognathus, the Hallopodidae, is characterized by a higher degree of suturing of the braincase, posteriorly closed otic aperture (paralleled in mesoeucrocodylians) and cursorial adaptations. Also, the phylogenetic position of this lineage of derived crocodylomorphs as the sister group of Crocodyliformes implies a large amount of unsampled record (ghost lineage), at least 50 million years. 
1 Detailed anatomy of the braincase of Macelognathus vagans Marsh, 1884 (Archosauria,

2 Crocodylomorpha) using high resolution tomography and new insights on basal

3 crocodylomorph phylogeny

4 Juan Martín Leardi ${ }^{*}$, Diego Pol$^{2}$, and James Matthew Clark ${ }^{3}$

$5{ }^{1}$ Universidad de Buenos Aires, CONICET, Instituto de Estudios Andinos "Don Pablo Groeber"

6 (IDEAN), Facultad de Ciencias Exactas y Naturales, Departamento de Ciencias Geológicas,

7 Intendente Güiraldez 2160, Ciudad Universitaria - Pabellón 2, Buenos Aires, C1428EGBA,

8 Argentina

9 2Museo Paleontológico Egidio Feruglio, CONICET, Avenida Fontana 140, Trelew 9100,

10 Chubut, Argentina

$11{ }^{3}$ Department of Biological Sciences, George Washington University, 2029 G St. NW,

12 Washington, DC, 20052, U.S.A

13

14 Corresponding author:

15 Juan Leardi ${ }^{1}$

17 Email address: jmleardi@gl.fcen.uba.ar 
19 Abstract

20 Background.Macelognathus vagans Marsh, 1884 from the Late Jurassic Morrison Fm. of

21 Wyoming was originally described as a dinosaur by Marsh and in 1971 Ostrom suggested

22 crocodilian affinities. In 2005, Göhlich and collaborators identified new material of this species

23 from Colorado as a basal crocodylomorph. However, a partial skull found in association with

24 mandibular and postcranial remains was not described.

25 Methods.Due to the small size and delicate structures within the braincase, micro CT studies

26 were performed on this specimen. The new anatomical information was incorporated in a

27 phylogenetic dataset, expanding both character and taxon sampling.

28 Results. This new material reinforces the non-crocodyliform crocodylomorph affinities of

29 Macelognathus as it bears a large otic aperture, unfused frontals and lacks ornamentation on the

30 dorsal cranial bones. The internal structures also support these affinities as this specimen bears

31 traits (i.e., heavily pneumatized and expanded basisphenoid; the presence of additional

32 pneumatic features on the braincase; and the otoccipital-quadrate contact) not present in most

33 basal crocodylomorphs. Furthermore, the presence of a wide supraoccipital and a cranioquadrate

34 passage are traits shared with Almadasuchus from the early Late Jurassic of Argentina.

35 Macelognathus was recovered as one of the closest relatives of crocodyliforms, forming a clade

36 (Hallopodidae) with two other Late Jurassic taxa (Almadasuchus and Hallopus).

37 Discussion.The clade formed by Almadasuchus + Hallopus + Macelognathus, the Hallopodidae,

38 is characterized by a higher degree of suturing of the braincase, posteriorly closed otic aperture

39 (paralleled in mesoeucrocodylians) and cursorial adaptations. Also, the phylogenetic position of 
40 this lineage of derived crocodylomorphs as the sister group of Crocodyliformes implies a large 41 amount of unsampled record (ghost lineage), at least 50 million years. 
42

43

44

45

46

47

\section{Introduction}

Macelognathus vagans Marsh, 1884 was originally described by Marsh (1884), and since then it has been surrounded by several controversies. The holotype specimen was recovered in 1880 at Como Bluff (Wyoming, USA), in levels belonging to the Morrison Formation. Based on the isolated mandibular symphysis that bears no teeth, Marsh (1884) assigned this taxon to a chelonian reptile. However, several authors questioned Marsh's assignment and referred the type specimen of Macelognathus vagans to Dinosauria, either as a coelurosaur (Theropoda; Baur, 1897) or even as an ornithischian (Simpson, 1926; Von Huene, 1956). Later, Ostrom (1971) reexamined the holotype specimen (YPM 1415), and based on the anatomical evidence reidentified Macelognathus vagans as a crocodilian.

Exploration of other outcrops of the Morrison Formation in Colorado (Brushy Basin Member; Fruita Paleontological Area) during the late 70s and early 80 s retrieved additional material of Macelognathus. Göhlich et al. (2005) established that this material belongs to Macelognathus based on the presence of mandibular remains with the same peculiar anatomy of the type specimen: a spatulate anterior end that lacks any teeth. In that contribution, Göhlich et al. (2005) described new cranial and postcranial materials of the taxon and concluded, based on that material, that Macelognathus has non-crocodyliform crocodylomorph affinities. However, given the incomplete nature of the remains, no clear relationship among basal crocodylomorphs was claimed. Later on, Pol et al (2013) described a new taxon from the Late Jurassic of Argentina (Almadasuchus) and noted some similarities between the femur of this new taxon and Macelognathus, but the large amount of missing data precluded the finding of a stable phylogenetic placement for the latter. 
64

65

66

67

68

69

70

71

72

73

74

75

76

77

78

Upon personal examination (JML and DP) of the collections of the Los Angeles County Museum (LACM), we were able to find a partial braincase among the material of Macelognathus retrieved from the Fruita Paleontological Area (Fig. 1A-D). The objective of the present contribution is to describe this new material and to evaluate its phylogenetic affinities. We use high-resolution computed tomography (CT) to study the internal anatomy of Macelognathus (Fig. 2A-E). This contribution represents the first study of CT scans from a non-crocodyliform crocodylomorph, a group whose internal braincase anatomy is highly relevant to their evolution (Clark, 1986; Walker, 1990; Wu \& Chaterjee, 1993; Pol et al., 2013).

\section{Materials and Methods}

\section{CT analysis}

The skull of Macelognathus (LACM 5572/150148) was scanned at the Microscopy and Imaging Facility of the American Museum of Natural History, using a high resolution CT scanner (GE Phoenix v|tome|x s 240). The partial skull was scanned in the transverse plane, resulting in a total of 982 slices, each with a slice thickness of $0.038 \mathrm{~mm}$, with interslice spacing of 0.038 , and a pixel resolution of $782 \times 722$. The matrix was eliminated and the individual bones were segmented using the Mimics software (V 16; Materialise, Belgium). Slice archive data is available online (http://morphobank.org/permalink/?P2550).

\section{Systematic Paleontology}

Archosauria Cope, 1869

Crocodylomorpha Hay, 1930, sensu Walker, 1970 
87

\section{Hallopodidae Marsh, 1881}

Discussion: This family has been little used since its initial erection, and then only as a monotypic taxon. Here we apply this taxon to the clade found by our phylogenetic analysis comprising Hallopus victor (Marsh, 1890), Macelognathus vagans, and Almadasuchus figarii figarii Pol, Rauhut, Lecuona, Leardi, Xu \& Clark 2013. We redefine it here as all taxa more closely related to Hallopus victor (Marsh, 1890) than to Protosuchus richardsoni Brown, 1933 or to Dibothrosuchus elaphros Simons, 1965.

Diagnosis: Hallopodidae can be diagnosed by the following synapomorphies: the presence of a cranioquadrate passage that is not in the lateral border of the skull; femoral head and distal condyles of the femur having parallel long axes; a trochanteric crest on the femur; and, a pseudointernal trochanter in the posterolateral end of the proximal end of the femur (paralleled in Kayentasuchus + Dromicosuchus). Other traits that might diagnose the clade include: greatly elongated radiale (only preserved in Almadasuchus and Hallopus, paralleled in Junggarsuchus); dorsoventrally large otic appertures (present in Almadasuchus and Macelognathus, also paralleled in Junggarsuchus), and, a quadrate-laterosphenoid contact but leaving the prootic exposed within the supratemporal fossa (only known in Almadasuchus).

Macelognathus vagans Marsh, 1884

Holotype: YPM 1415, articulated anterior portions of both dentaries, which lack teeth on the anterior end.

$$
\text { Referred materials: LACM 5572/150148, left dentary, partial braincase, and postcranial }
$$
remains including dorsal vertebrae, a partial left ilium, partial femora, and other elements of the 
110 hindlimbs; LACM 4684/128271, partial right and left hindlimbs; LACM 4684/128272, a left

111 femur which may belong to LACM 4684/128271; LACM 5572/150211, both calcanea, and

112 metatarsal III; LACM 4684/133772, a portion of the right maxilla, and both dentaries. For a

113 more detailed explanation of the elements included the reader is encouraged to refer to Göhlich

114 et al.'s (2005) paper.

115 Horizon and locality: The holotype specimen was recovered from Como Bluff, Albany

116 County, Wyoming (USA); the referred specimens were found in the Fruita Paleontological Area,

117 Mesa County, Colorado (USA). In both of these localities the fossils derive from the Brushy

118 Basin Member in the upper part of the Morrison Formation (Upper Jurassic, Kimmeridgian-early

119 Tithonian; Foster, 2003).

120 Emended diagnosis: A non-crocodyliform crocodylomorph with dorsoventrally flattened

121 and anteriorly edentulous dentary*, heterodont dentition, and tooth crowns devoid of mesial and

122 distal serrations; dentary lacking caniniform teeth; maxilla with laterally concave and ventrally

123 sinuous alveolar margin; lateral longitudinal ridge above alveolar margin of maxilla; at least two

124 enlarged anterior maxillary teeth; enlarged maxillary teeth serrated only distally; quadrate with

125 five pneumatic cavities; laterally closed cranioquadrate passage; large otic aperture two-thirds of

126 the height of the quadrate; quadrate contacts the otoccipital; wide supraoccipital in posterior

127 view; posterior bony ring on the basisphenoid, allowing the precarotid recess to open

128 posteriorly*; internal carotids exit anteroventrally from the hypophyseal fossa*; presacral

129 vertebrae with large neural canals (almost as large as the centrum); ilium without supraacetabular

130 crest; ventral margin of preacetabular process of ilium thickened and medially projecting; round

131 femoral head oriented medially and separated from proximal end by a distinct neck; proximal

132 facet of tibia distinctly slanted laterally; longitudinal groove on proximoanterior end of fibula; 
133 calcaneum with a completely flat distal surface; strong medioplantar crest on medial base of

134 calcaneal tuber*; overlapping proximal ends of metatarsals. Autapomorphies are marked with an 135 asterisk $(*)$.

137 Results

138

139

General features

The cranium of Macelognathus vagans (LACM 5572/150148) was first described by 141 Göhlich et al. (2005). In this contribution, the maxilla was carefully described, but the posterior region of the braincase (mislabeled in that paper as LACM 4684/133772) was only briefly mentioned. In particular, the parietal was the only element described of the posterior specimen, highlighting two details: the presence of a weak sagittal crest and a concave nuchal crest that delimited the occipital surface of the skull. With later mechanical preparation of the specimen, the parietal was disarticulated and is no longer associated with the rest of the skull. No further details were given about the rest of the braincase of Macelognathus by Göhlich et al. (2005). the anterior end of the frontals (Figs. 1A-D, 2A-E), being anteroposteriorly shorter than the 150 length of the mandibular symphysis of the holotype specimen (YPM 1415, approximately $58 \mathrm{~mm}$ 151 [Göhlich et al., 2005]). Thus LACM 5572/150148 probably belonged to a small juvenile 152 individual, an idea further reinforced by the strongly convex skull roof (Figs. 1C-D, 2C). This 153 fossil preserves a partial posterior region of the skull including partial remains of the braincase.

154 The braincase of this specimen is poorly exposed, so in order to recover more information from 155 this region a high resolution CT scan was performed (see Materials and Methods). 
Other crocodylomorph remains were recovered from the same outcrop, including 157 crocodyliforms (Goniopholis [Göhlich et al., 2005] and Fruitachampsa [Clark, 2011]). The

158

159

160

161

162

163

164

165

166

167

168

169

170

171

172

173

174

175

176

177

178

\section{Description}

Both prefrontals are preserved on LACM 5572/150148, but they are only represented by the dorsal process of this bone (Fig. 3A-D). The prefrontal contacts medially with the anterolateral edge of the frontal only. This is rare condition among crocodylomorphs, as the frontals usually contact also with the posterolateral edge of the nasals. However, no partial remains of the nasals could be identified on the anteriormost end of LACM 5572/150148, but this possibility should not be discarded as this region is badly preserved, bearing many cracks and fissures. Where this contact is better preserved, on the right side of the skull, the suture is almost straight (Fig. 3A). The prefrontals are anteroposteriorly elongate in dorsal view and they form the anteromedial border of the orbit. Anteriorly, the prefrontals are almost laminar, while posteriorly they have a higher dorsoventral development. In dorsal aspect, the prefrontal has a posterior process projected posterolaterally (Fig. 3A-B). The posterolateral edge of the prefrontals is broadened in many basal crocodylomorphs (Pseudhesperosuchus, Dromicosuchus, Hesperosuchus agilis [CM 29894], Terrestrisuchus, Saltoposuchus, Litargosuchus, Sphenosuchus, Dibothrosuchus, Junggarsuchus), but only in Macelognathus does it form a 
179 distinct process. The CT data exposed the internal morphology of the right prefrontal. The 180 posterior region of the right prefrontal bears a triangular pneumatic recess, with the apex pointed

181 posterodorsally, and increases in size towards the anteroventral region of the prefrontal (Fig. 3B-

182 D). Ventral to this pneumatic recess a posteroventral bulge is partially preserved, which 183 represents the descending process of the prefrontal, but its ventral end is not preserved.

184 The frontals are paired and have a clear median suture between them along their entire 185 length (Fig. 3A-B). The frontals are separated from each other anteriorly (where both frontals 186 barely touch each other) but they are tightly joined to each other along the posteriormost region 187 of the dorsal surface of the frontals. The dorsal surface of the frontals is smooth (Fig. 3A) as in most non-crocodyliform crocodylomorphs (e.g., Hesperosuchus, Sphenosuchus, Litargosuchus) with the exception of Almadasuchus, which is sculpted, and Dibothrosuchus, which has three longitudinal ridges. The frontals are rectangular in dorsal view, although their anterior end is lateromedially narrower than the posterior one, and convex in lateral view, but to a lesser extent than the parietals (see below). The frontals wedge between the prefrontals (see above), displaying a rather anteroposteriorly elongated contact. The prefrontal-frontal contact extends approximately along one third of the preserved length of the frontals. Just anterior to the midlength of the frontals as preserved, a constriction is present on the left element (damaged on the right one) that is here interpreted as the dorsal margin of the orbits. Unlike the condition of most eusuchians and some close relatives of that clade (Glen Rose Form, Bernissartia, Shamosuchus), the dorsal margin of the orbits is not dorsally projected (Fig. 3C).

The posteroventral margins of the frontals have ventrally directed flanges, the cristae crania (Fig. 3B-C). These flanges contact the anterodorsal end of the laterosphenoids, as in most archosauriforms. Even though these crests are only partially preserved, they deeply project 
202 ventrally, as in most non-crocodyliform crocodylomorphs. The posteromedial region of both

203 frontals is not preserved. Partial remains of the parietals are preserved on their posterolateral

204 ends allowing the observation of the lateral region of the frontoparietal suture, which has its main

205 axis anterolaterally oriented (Fig. 2A and C). Anterior to this region a slightly depressed area is

206 delimited anteriorly by a curved crest. This crest is continuous with a crest present on the parietal

207 (see below), so it is interpreted as the anterior border of the supratemporal fossa.

208 The ventral surface of the frontals bears two wide grooves that extend anteroposteriorly 209 along its anterior half, interpreted here as the depression for the olfactory bulbs (Fig. 3B). These 210 grooves are deep, limited laterally by the cristae cranii, and attenuate approximately at the level

211 of the posterior end of the orbit. The division in two grooves is given by a well-developed and

212 ventrally projected crest located medially at the interfrontal suture. This crest would imply a 213 partially divided (or bilobed) olfactory bulb, and is much more developed than in crocodyliforms 214 (e.g., Araripesuchus gomesii Price, 1959 [AMNH 24450]; Sebecus icaeorhinus Simpson, 1937; 215 Crocodylus acutus Cuvier, 1807 [Colbert, 1946]). The frontals of Macelognathus also have two 216 elongated depressions on the posterior half of the ventral surface of the frontals, which are 217 interpreted here as the impressions of the cerebral hemispheres (Fig. 3B). These depressions 218 have a considerable anteroposterior development, occupying $25 \%$ of the total length of the 219 frontal.

A fragment of bone is preserved articulated to right frontal along its mid-length, interpreted as part of the postorbital (Fig. 3A-C). The region preserved corresponds to the postorbital plate, just anterior to the descending process.

The parietals are badly damaged, with almost the whole left part of the bone missing

(Fig, 4A-B). The almost complete lack of the left half of the bone precludes determining if the 
225 parietals were fused. The central right half of the parietal was already described previously

226 (Göhlich et al., 2005; see above), and for additional information on that region the reader is

227 referred to that contribution. Thus, most of the description of the parietal will be based on the

228 right half of this element. Most crocodylomorphs have the parietals fused as a single element,

229 with the exception of Hesperosuchus, Pseudhesperosuchus, Dromicosuchus, Terrestrisuchus and

230 Saltoposuchus (Clark, Sues \& Berman, 2000); although in some cases this could be due to the

231 early ontogenetic stage of the specimens. The parietal is strongly convex in lateral view, a

232 condition that is more evident at its contact with the supraoccipital (Fig. 1C-D, 2C-E). The dorsal

233 surface of the parietal is smooth, as in most basal crocodylomorphs (Hesperosuchus,

234 Pseudhesperosuchus, Dromicosuchus, Terrestrisuchus, Saltoposuchus, Litargosuchus,

235 Kayentasuchus, Sphenosuchus, Dibothrosuchus, Junggarsuchus and Almadasuchus), contrasting

236 with the ornamented condition present in crocodyliforms (e.g., Protosuchus richardsoni Brown, 237 1933).

238 Anteriorly, only the lateral regions of the sutures of the parietals with the frontals were 239 preserved. This anterolateral border is oriented obliquely, as described above, with the 240 lateralmost end projected more anteriorly than the medial one. At the midpoint of this suture an 241 acute anterior process is present in both parietals. This process bears a well-developed 242 anteroposteriorly oriented crest on its dorsal surface (Fig. 4B). The dorsal crest of the anterior 243 acute process of the parietal is anteroposteriorly short, disappearing at approximately one quarter 244 of the total length of the parietal. Lateral to this crest the surface of the parietal bears a concavity 245 that occupies almost two thirds of the total length of the bone. This region is identified as the 246 supratemporal fossa. Its great anteroposterior development is consistent with the condition of 
247 most basal crocodylomorphs, in which the supratemporal fossae are very large and occupy

248 almost the entire dorsal surface of the parietal.

Along its ventral edge, the parietal contacts the laterosphenoid and the prootic. The contact with the former is extended through the anterior $75 \%$ of the ventral margin of the parietal

251

252

253

254

255

256

257

258

259

260

261

262

263

264

265

266

267

268

269

along a straight suture (Fig. 4B). The posterior fourth of the ventral border of the parietal contacts the prootic. Posteriorly, the parietal is very fragmentary, thus its contact with the supraoccipital is not preserved. The internal surface of the parietal is concave, which is especially marked on the posterolateral region of the medial surface of the parietal, near the sutural contact with the laterosphenoids. This depressed internal surface, which continues on to the laterosphenoids, is interpreted as the posterolateral expansion of the cerebral hemispheres.

The quadrate, despite being damaged in many regions, is one of the most complete bones of the skull. Both quadrates are preserved in LACM 5572/150148, although the right one is better preserved than the left one, as with most elements of the skull (Fig. 2A-E). The quadrate body is curved posteriorly in lateral view, being markedly convex anteriorly. One of the most notable features of the right quadrate is the presence of a large otic aperture on its main body (Fig. 5A-B). The quadrate only forms the ventral and anterior borders of this fenestra. Despite being incomplete (as the squamosal is not preserved) we can infer its size, which is approximately two thirds of the dorsoventral length of the quadrate. The presence of a large otic aperture, where the quadrate forms the anteroventral borders of a well-delimited fenestra, is a feature shared with Almadasuchus and Junggarsuchus. In these taxa the otic aperture is also dorsoventraly large, attaining at least half of the height of the quadrate body. In other known non-crocodyliform crocodylomorphs (Hesperosuchus "agilis”, Pseudhesperosuchus, Dromicosuchus, Terrestrisuchus, Sphenosuchus, Dibothrosuchus), the otic aperture is not such a 
270 circumscribed fenestra as the otic aperture lies posterior to the quadrate body and it is not closed

271 posteriorly (see below). However, this condition is unknown in Kayentasuchus and

272 Litargosuchus as the posteroventral region of their quadrates are not well preserved.

273 Anterior to the otic aperture, on the posterior surface of the quadrate body, a crest is 274 present (Fig. 5D). Given its anterior position to the otic aperture, this crest is here identified as 275 the tympanic crest. The lateral surface of the main body of the quadrate of Macelognathus is 276 slightly concave and this concavity is limited anteriorly by an oblique oriented crest. On the 277 anterolateral border of the body of the quadrate an elongated and obliquely oriented facet can be 278 seen. This facet is for the articulation of the quadratojugal on the quadrate (Fig. 5A). The precise 279 dorsal extent of this facet is unknown, but it seems not to reach the dorsalmost end of the 280 quadrate anterolateral surface. Thus, the quadrate participates in the posterodorsal border of the 281 infratemporal fenestra as in most non-crocodyliform crocodylomorphs (e.g., Dromicosuchus, 282 Dibothrosuchus, Sphenosuchus, Almadasuchus). In crocodyliforms (e.g., P. richardsoni, 283 Edentosuchus) the quadrate is excluded from the margin of the infratemporal fenestra, as the 284 quadratojugal covers all the anterior surface of the quadrate that could be exposed in this 285 fenestra.

Also on the anterior margin of the quadrate body, and dorsal to the facet for the 287 quadratojugal the posterior border of an elongated rounded fenestra is present (Fig. 5A and C). 288 This quadrate fenestra is located at the dorsoventral midpoint of the anterolateral surface of the 289 quadrate and appears to be pneumatic, as it connects with the internal space of this bone (see 290 below). Among non-crocodyliform crocodylomorphs, pneumatic quadrate fenestrae are also

291 present in simple form in Terrestrisuchus and more complexly in Junggarsuchus and 292 Almadasuchus. These pneumatic fenestrae are always located on the main body of the quadrate 
293 and anterior to the tympanic crest. However, there is a great deal of variation in the shape and

294 size of these fenestrae among different taxa. The borders of the quadrate fenestra of

295 Terrestrisuchus have at least some participation with the quadratojugal on the anterior end

296 (Crush, 1984), while in Dibothrosuchus, Junggarsuchus, Almadasuchus and crocodyliforms

297 (e.g., Protosuchus richardsoni, Gobiosuchus) the quadrate fenestrae are completely surrounded

298 by the quadrate. As was previously mentioned, this condition cannot be precisely known in

299 Macelognathus due to the incomplete preservation of the quadrate fenestra. Furthermore, these

300 fenestrae are variable in size and in most taxa are small, while the quadrate fenestrae of

301 Terrestrisuchus and Almadasuchus are elongated and quite large, being at least half of the

302 dorsoventral height of the quadrate body. Junggarsuchus is unusual also in this aspect, as at least

303 two fenestrae are identified on its quadrate (Klein et al., in prep). This condition is similar to the

304 one present in basal crocodyliforms which have multiple quadrate fenestrae (e.g., Protosuchus

305 richardsoni). Finally, the condition of Dibothrosuchus deserves mention. This structure was not

306 described in the original paper (Wu and Chaterjee, 1993), but upon personal examination (DP),

307 we identified what could be interpreted as the posterior border of a large quadrate fenestra on the

308 left quadrate. The anterolateral margin of the quadrate of the skull of the referred specimen

309 (IVPP V 7907) bears an elongate, rounded border on its anterior end, and thus can be interpreted

310 as the posterior border of a pneumatic quadrate fenestra. The quadratojugal is very incompletely

311 preserved and its relationships with neighboring elements are unclear (Wu \& Chaterjee, 1993).

312 The orbital process of the quadrate is preserved on the right quadrate on its dorsomedial

313 region (Fig. 5B-D). The orbital process of the quadrate is a lateromedially thin and medially

314 projected process that contacts the dorsolateral region of the prootic. The articular surface for the

315 prootic is exposed only medially (or slightly dorsomedially). The quadrate-prootic contact is 
316 anteroposteriorly long, extending through almost the entire length of the prootic as in most

317 crocodylomorphs (Fig. 2C). The dorsolateral region of the quadrate is not preserved in any of the

318 elements, precluding observation of the primary head of the quadrate.

319 Medially, on the lateral surface of the adductor chamber, the anterior surface of the 320 quadrate is slightly convex and mediolaterally wide (Fig. 5C). Although this region is badly

321 preserved, no crest can be observed on the anterior surface of the quadrate, just anterodorsal to

322 the quadrate condyles. A broad and relatively short pterygoid ramus of the quadrate is present in

323 the ventromedial region of the adductor chamber. The distal end of the pterygoid ramus of the

324 quadrate is asymmetrical, being more expanded dorsally. The ventral region of the pterygoid

325 ramus of the quadrate seems to be separated from the most dorsal part by an anteromedial notch.

326 A similar condition is present in Almadasuchus, where the quadrate is greatly expanded medially

327 and this notch represents the lateral border of the passage for the middle cerebral vein (sensu

328 Walker, 1990). The distal end of the left quadrate bears well-preserved distal condyles, which are

329 divided by a shallow intercondylar groove. The lateral condyle is mediolaterally broader than the

330 medial one, while the latter is slightly more distally projected.

331 The body of the quadrate and the distal condyles are heavily pneumatized, being hollow

332 internally with thin walls. The body of the quadrate is internally divided from dorsal to ventral in

333 a series of individualized interconnected chambers. A total of five (5) internal divisions, which

334 increase in volume towards the distal condyles, can be identified in the quadrate (Fig. 5C). The

335 first chamber, located on the most dorsal region of the quadrate is approximately triangular in

336 dorsal view. The exact size of this chamber cannot be precisely known, as the dorsal region of

337 the quadrate is incomplete. The dorsal chamber is separated from the second one by a thin bony

338 septum only developed on the posterior half of the inner cavity of the quadrate. The second 
339 chamber is parallelogram shaped in dorsal view and is dorsoventrally higher than

340 anteroposteriorly long. The second chamber communicates with the central chamber via several

341 passages on its ventral septum. One is located on the posterior border (the largest one) and three

342 on the anteromedial border (the medial most is the largest of these). The third and central cavity

343 is volumetrically smaller than the second, being dorsoventrally flat when it is compared with the

344 other internal divisions of the quadrate. The bony septum dividing the central chamber of the

345 fourth chamber seems to be complete, whereas the incompleteness on the anterolateral region

346 could be attributed to preservational features. The communication with the ventral chamber is

347 across a small foramen located on the anteromedial border of the chamber. The fourth chamber is

348 dorsoventrally higher than the third, even though it is lateromedially wider than its dorsoventral

349 development. The posteromedial border appears to be open, as it is confluent with the cavity

350 formed within the quadrate and limited externally by the otic aperture (middle ear). This fourth

351 chamber is also externally connected via the pneumatic quadrate foramen described above

352 (usually called the quadrate fenestra in most crocodylomorphs). The fourth chamber is separated

353 from the ventralmost one by an incomplete septum which has three communicating foramina,

354 one posteriorly and two anteriorly. Finally, the largest pneumatic chamber in the quadrate is the

355 ventral one. This chamber occupies the whole interior volume of the distal body of the quadrate,

356 including the pterygoid process of the quadrate. Pneumaticity invades the distal condyles via

357 three lateral diverticula. The ventral chamber is open ventrally as in other derived non-

358 crocodyliform crocodylomorphs (e.g., Almadasuchus and Dibothrosuchus).

359 On the posterodorsal region of the quadrate a large, pointed and dorsomedially directed

360 process is present (Fig. 5D). This process forms the posterior border of the otic aperture and

361 contacts through its medial surface the ventrolateral margin of the otoccipital. The quadrate- 
362 otoccipital contact is also present in Junggarsuchus, Almadasuchus and crocodyliforms, but not 363 in more basal "sphenosuchians" (Pol et al., 2013). However, the morphology of this region of the 364 quadrate is unknown in some of the other non-crocodyliform crocodylomorphs. The dorsal 365 surface of the posterodorsal process of the quadrate of Macelognathus bears a dorsomedially 366 oriented furrow (Fig. 5A and D). The position and direction of this groove and the fact that the 367 quadrate forms its ventral border are consistent with the cranioquadrate passage. Such passages 368 are absent in most "sphenosuchians" and even basal crocodyliforms (Protosuchus richardsoni 369 and Orthosuchus). On the other hand, cranioquadrate passages are present in Almadasuchus and 370 in the vast majority of crocodyliforms (such as Gobiosuchus, Sichuanosuchus and all 371 mesoeucrocodylians).

372 The prootic, although damaged, is preserved almost complete on the right side of the 373 skull (Figs. 2A-E, 6A-B). The left prootic only preserves part of its ventral region and the 374 ventrolateral flange (see below). The protic is a dorsoventrally high bone when it is compared 375 with its lateromedial development (Fig. 7A-D). As in most non-crocodyliform crocodylomorphs 376 (e.g., Hesperosuchus, Sphenosuchus, Dibothrosuchus, Almadasuchus) and thalattosuchians [e.g., 377 Cricosaurus araucanensis (Gasparini \& Dellapé, 1976)] the prootic is exposed on the posterodorsal region of the supratemporal fossa. In Macelognathus the prootic is verticalized on the supratemporal fossa, with the exposed surface facing anteriorly, a similar condition to the one observed in Dibothrosuchus, Sphenosuchus and Kayentasuchus. On the other hand, the prootic is exposed facing anterodorsally within the supratemporal fossa in Almadasuchus, Litargosuchus preserved) and anteriorly the parietal along its medial margin. 
The dorsal region of the prootic is more lateromedially developed, and houses a large

385

386

387

388

390

391

392

393

394

395

396

397

398

400

401

402

403

404

405

406

mastoid antrum (Fig. 7A and C). This pneumatic cavity is subrectangular in shape and is restricted to the prootic, although the squamosal (not preserved) might form the dorsal roof of the mastoid antrum. The mastoid antrum appears to communicate with the middle ear via at least two large foramina on the dorsolateral surface of the prootic: a larger one located on the anterior half and a smaller, more elongated one, located on the posterior half of this surface (Fig. 6C-D). One or more ventral openings could be present on the anteroventral surface of the mastoid antrum, but these may have been caused by breakage of the specimen. Also, the presence of such ventral apertures of the mastoid antrum would depend on the particular shape of the unpreserved contact with the pterygoids. Multiple lateral openings of the mastoid antrum into the middle ear cavity are present in Kayentasuchus, Dibothrosuchus and P. haughtoni; while in Sphenosuchus the mastoid antrum opens through a unique undivided foramen.

Anteroventral to the mastoid antrum the prootic is damaged, preserving the articulation with the laterosphenoid only anteriorly. Thus, the structure of the trigeminal recess is unknown. The anteroventral region of the prootic has many discontinuities on its lateral wall, but interpreting these as evidence of the exit of cranial nerves would be equivocal. However, in the central region of this area, ventral to the mastoid antrum, and near the posterior edge of the prootic a rounded foramen is present within the prootic (Fig. 7A-B). The placement of this foramen, anteroventral to the fenestra ovalis (see below), and its orientation indicates it is the exit of the facial nerve (VII). The structure of this foramen closely resembles the one present in Protosuchus haughtoni (Busbey \& Gow, 1984) as it is dorsoventrally oriented, while in Sphenosuchus (Walker, 1990) an oblique groove is associated with the exit of the VII. Posterodorsal to this area and ventral to the posterolateral opening of the mastoid antrum of 
407 Macelognathus is a small anteroposteriorly oriented foramen that continues posteriorly as a 408 groove. The groove associated with the foramen continues its straight path onto the otoccipital.

409 The foramen continues anteriorly as a passage to reach an expanded cavity, located dorsal to the 410 exit of the VIIth nerve. This configuration is consistent with its assignment as the groove and 411 bony canal of the lateral semicircular canal of the inner ear that has been exposed laterally by 412 breakage of the specimen; while the enlarged cavity located anterior to it is interpreted as the 413 ampulla of the lateral and rostral semicircular canals. Furthermore, from the anterodorsal end of 414 the expanded cavity (ampulla) a dorsally directed canal arises and continues its path dorsally, 415 just medial to the mastoid antrum. Upon reaching the anterodorsal end of the prootic, it turns posteriorly very abruptly, leaving a groove on the dorsal surface of the prootic. This groove 417 continues posteriorly on the medial aspect of the supraoccipital (see below). These traits are consistent with the identification of this structure as the rostral semicircular canal.

Ventral to the region of the mastoid antrum and the groove for the lateral semicircular canal, in the central region of the posterior margin of the prootic, a rounded notch is present (Fig. 7A). The shape of this notch is due to the lack of preservation of the anteriormost area of the otoccipital. The position and the bones that form this notch (i.e., the prootic forms its anterior and dorsal margins) help us to identify it as the fenestra ovalis. Ventral to the fenestra ovalis, the prootic bears a large laterally projected flange (prootic-basisphenoid flange sensu Walker [1990] or crista prootica). This flange extends to the ventral margin of the prootic and continues also on the dorsal region of the basisphenoid, as in Sphenosuchus. The otoccipital contacts the prootic427 basisphenoid flange along the posterior margin of its prootic part. The prootic-otoccipital contact 428 also involves the posterior surface of the prootic (excluding the region of the fenestra ovalis), 429 although the central region of the prootic is not preserved. This contact is preserved on the dorsal 
430 and ventral region of the posterior surface of the prootic. This double contact involving the 431 otoccipital and the prootic encloses a dorsoventrally oriented pyramidal cavity interpreted as the 432 cochlear recess $(=$ lagena). Further ventrally the prootic contacts the basisphenoid through its 433 posteroventral margin, and as a result closes the cochlear recess ventrally.

The medial surface of the prootic is damaged, exposing parts of the bony labyrinth medially. Dorsal to the bony canal of the lateral semicircular canal and its associated ampulla a strongly projected medial bony flange is present. This flange is sigmoidal in medial view and it limits ventrally a deep depression. This depression is capped dorsally by the supraoccipital. A similar depression has been observed in medial view of the braincase of Sphenosuchus and has been interpreted as the auricular (or floccular) recess of the cerebellum (Walker, 1990) (Fig. 6A and 7B). Medial views of the braincases of other basal crocodylomorphs are rare, precluding the observation of this feature.

The opisthotics and exoccipitals are fused constituting an otoccipital. The right otoccipital preserves part of the subcapsular buttress, the otic capsule, the distalmost part of the ventrolateral part of the parocipital process and the dorsal region of the bone (just dorsally to the otic capsule) (Fig. 6A-B). The subcapsular buttress of the otoccipital is a rounded eminence limiting the posteroventral region of the otic capsule forming the lateral and posterior walls of 447 the cochlear recess (Fig. 8A-B). The subcapsular buttress of the otoccipital contacts the crista 448 prootica anteriorly to form the crista interfenestralis, which is only preserved at its base on this specimen. The posterior border of the subcapsular buttress represents the ventral border of the metotic fissure, from where the cranial nerves IX-XI exit the endocranial cavity. Internally, this region is divided in two elongated slits by a lamina of the otic capsule, also formed by the

452 otoccipital (Fig. 8B). The dorsal slit, located at the posterior border of the metotic fissure is 
453 interpreted as the exits of the cranial nerves X-XI and the posterior cerebral vein; while the

454 ventral slit, located at the ventral border of the metotic fissure, is interpreted as the exit of cranial

455 nerve IX. A similar division is also present in Sphenosuchus (Walker, 1990: Fig. 24), although

456 this region of the braincase is not that well exposed in other crocodylomorphs. On the dorsal

457 border of the otic capsule a posteriorly directed groove is observed, the extension of the groove

458 conducting the lateral semicircular canal observed in the prootic (Fig. 8C). This groove continues

459 medially up to the level of the otic capsule, and at the posterior border of the capsule it expands

460 into the ampulla of the caudal semicircular canal. Dorsal to this region an oblique groove runs

461 through the dorsomedial surface of the otoccipital, medial to mastoid antrum. This groove

462 continues anteriorly on the ventral surface of the supraoccipital and represents the caudal

463 semicircular canal.

464 Dorsal to the otic capsule, the otoccipital is heavily pneumatized (Fig. 8A-B). This

465 pneumatic cavity is completely separated from the mastoid antrum by a bony wall formed by the

466 posterodorsal region of the prootic. The otoccipital also contributes to this separation, as a thin

467 bony lamina that articulates anterodorsally with posterior bony septum of the mastoid antrum

468 formed by the prootic. The position of this pneumatic cavity, located dorsal to the otic capsule

469 and to the metotic fissure, is consistent with its identification as the posterior tympanic recess

470 (PTR sensu Wu \& Chaterjee, 1993). A slight posterior tympanic recess is present in

471 Sphenosuchus, being represented by a shallow groove between the prootic-opisthotic suture. A

472 heavily pneumatized cavity in this same area is present in Dibothrosuchus and P. haughtoni, thus

473 sharing the same condition with Macelognathus. The posterior tympanic recess of

474 Macelognathus is partially divided anteriorly by a bony pillar located near the suture with the

475 prootic. However, due to the almost complete lack of preservation of the paroccipital processes 
476 we are unable to evaluate if this pneumatic cavity penetrates these processes as in

477 Dibothrosuchus and P. haughtoni.

478 Ventromedially the otoccipital contacts the basioccipital on the lateral region of the floor 479 of the endocranial cavity. Posteriorly, the otoccipital has a medially projected process that 480 excludes the basioccipital from the ventrolateral border of the foramen magnum. Therefore, the 481 otoccipital forms the entire lateral margin of this foramen (Fig. 6A). The otoccipital-basioccipital 482 contact reaches the occipital condyle, and as result the otoccipital participates in the dorsolateral 483 margin of it. Finally, only the ventralmost part of the right paroccipital process is preserved. The 484 fragment preserved is exposed posteroventrally and separates the basioccipital from the quadrate 485 in this view. This region of the paroccipital process contacts with the quadrate laterally; 486 anteriorly and medially with the basioccipital.

The supraoccipital is present between the foramen magnum and the parietals. Only the right half of the supraoccipital is preserved (Fig. 2A-E; Fig. 6A-B). The preserved half is 489 rectangular in external view (Fig. 9A-B), thus the full element would have a quadrangular shape in occipital view. This condition is similar to the one present in Litargosuchus, Junggarsuchus, 491 Almadasuchus and crocodyliforms that have a wide supraoccipital, unlike the dorsoventrally 492 elongated supraoccipitals of other crocodylomorphs (Pseudhesperosuchus, Terrestrisuchus, Kayentasuchus, Sphenosuchus, Dibothrosuchus). Anteroventrally, the supraoccipital bears a ventral bulge that is pyramidal shaped and with its apex oriented ventrally, giving this region a higher dorsoventral development than the rest of the supraoccipital (Fig. 9C). The anteromedial region of the anteroventral bulge bears a very deep concavity, which is the part of the auricular

497 (or floccular) recess that extends into the supraoccipital. Dorsal to this recess a shallow groove 498 can be observed. This groove continues on the dorsal border of the anteroventral bulge, just 
499 ventral to the dorsal plate of the supraoccipital. As mentioned above, this groove is interpreted as

500 for the caudal semicircular canal.

501 As in all "sphenosuchians" where this condition has been properly explored, the

502 supraoccipital of Macelognathus does not participate in any pneumatic cavity (i.e., transverse

503 canal communicating the mastoid antra from both sides) (Fig. 6A-B), unlike the condition seen

504 in crocodyliforms (e.g., P. richardsoni [Clark, 1986], P. haugthoni [Busbey \& Gow, 1984]) with

505 the exception of thalattosuchians (e.g., Pelagosaurus [Pierce, Williams \& Benson, 2016];

506 Steneosaurus [Brusatte et al., 2016]. In previous contributions, a transverse canal communicating

507 both mastoid antra was mentioned to be present in Dibothrosuchus (Wu \& Chaterjee, 1993),

508 however this condition cannot be observed in the external view of the skull material known for

509 this taxon (IVPP V 7907; JMC pers. obs.). Posterolaterally, the supraoccipital articulates with the

510 otoccipital on its posterior third through an oblique interdigitated suture (Fig. 2A).

511 Anterolaterally, the supraoccipital contacts the prootic on its anterior two thirds through an

512 interdigitated suture on the anteroventral bulge.

513 The basioccipital forms the floor of the posterior half of the endocranial cavity, while the 514 anterior half is formed by the basisphenoid (Fig. 6A-B). Anteriorly, the median region of the

515 basioccipital is divided by a short posterodorsal process of the basisphenoid. Lateral to this area, 516 the basioccipital-basisphenoid articulation is straight, through a transverse suture (Fig. 10A-C).

517 On the anterolateral corner of the endocranial cavity, the basioccipital bears a posteroventrally 518 elongated and obliquely oriented facet for the prootic (Fig. 10B-C). Posterior to this facet, and 519 along its dorsolateral surface, the basioccipital contacts the subcapsular buttress of the 520 otoccipital. On the central region of the dorsal aspect of the basioccipital, this element has lateral 
521 expansions that contact the medial wall of the subcapsular buttress and the otic capsule. These

522 lateral flanges contract before reaching the occipital condyle.

523 The occipital condyle of the basioccipital is rugose and has the articular surface for the

524 atlas-axis complex oriented posteriorly, but slightly inclined dorsally. The occipital condyle is

525 projected ventrally, delimiting a ventral rim around this area (Fig. 10B and D). On the ventral

526 surface of the basioccipital, anterior to the occipital condyle, the basioccipital tubera are partially

527 preserved. These are laminar as in most crocodylomorphs (Nesbitt, 2011) and are separated from

528 the occipital condyle by a shallow groove (Fig. 10A). Only the right basioccipital tuber and

529 partial remains of the medial lamina uniting both tubera are preserved. A wide depressed area is

530 present on the ventral surface of the basioccipital, the basioccipital recess. This wide recess is

531 present in almost all non-crocodyliform crocodylomorphs (e.g., Hesperosuchus, Dromicosuchus,

532 Sphenosuchus, Dibothrosuchus, Almadasuchus), but is absent in Junggarsuchus and

533 crocodyliforms (e.g., P. richardsoni, P. haughtoni, Orthosuchus). A wide crest projects

534 anteriorly from the anteroventral surface of the medial lamina joining both basioccipital tubera

535 throughout all the ventral surface of the basioccipital, dividing the basioccipital recess. Two

536 posteriorly directed blind tubes excavate the posterior region of the basioccipital recess. These

537 additional depressions on the posterior surface of the basioccipital are also present in

538 Almadasuchus and Dibothrosuchus, while they are lacking in other basal crocodylomorphs.

539 Anteriorly, the basioccipital bears two ventral flanges that project posterolaterally. The

540 anterodorsal surface of these flanges is deeply excavated by two parallel rounded depressions

541 (Fig. 10B-C). These depressions do not perforate the basioccipital, and are limited anteriorly by

542 the basisphenoid, which articulates with this region of the basioccipital. These expanded cavities

543 are located posteroventral to the cochlear recess, in a similar fashion to the placement of the 
544 rhomboidal sinus (Colbert, 1946; Walker, 1990). Thus, we interpret them as such. Despite that

545 the posteroventral region of the basisphenoid is not preserved (see below), the rhomboidal sinus

546 seems to open directly to the pharynx. Given this morphology, we can conclude that

547 Macelognathus lacks well-developed bony passages for Eustachian tubes, which are present in

548 Crocodyliformes (e.g., P. richardsoni [Clark, 1986]).

549 In addition to the dorsal contact with the otoccipital along the endocranial cavity, the 550 basioccipital has a contact with the otoccipital. This contact is between the distal end of the 551 anteroventral flanges of the basioccipital and the paroccipital process (Fig. 10A).

552 The basisphenoid, although damaged and incomplete ventrally, is fairly well preserved.

553 The basisphenoid is greatly expanded lateromedially in ventral view (Fig. 2B) as in

554 Junggarsuchus, Almadasuchus and basal crocodyliforms (e.g., P. richardsoni), unlike the more 555 compressed basisphenoids present in Terrestrisuchus, Sphenosuchus and Dibothrosuchus. CT 556 data of the central region of the basisphenoid allowed the observation of the highly pneumatized 557 nature of this region (Fig. 11A-D), a condition also shared with Almadasuchus, Junggarsuchus 558 and Crocodyliformes.

559 Internally, the basisphenoid is a very complex bone formed by a series of bony struts and 560 laminae that enclose various recesses and pneumatic cavities. The remaining part of the 561 description of the basisphenoid will be done excluding the posterolateral laminae contacting the 562 otoccipital and the quadrate. The posterior surface of the body of the basisphenoid is 563 subrectangular in posterior view, with a ventral constriction present on its center (Fig. 10A-B, 564 D). This constriction is caused by a pointed, posteriorly projected process of the basisphenoid 565 that wedges into the anterodorsal region of the basioccipital (see basioccipital above). Lateral to 566 this process there is a flat, dorsally exposed area on each side of this median process that 
567 represents the articular facet for the basioccipital. However, the basioccipital does not contact 568 this whole surface, as it leaves the medialmost region exposed posteriorly. These free surfaces 569 cap the parallel rounded depressions of the basioccipital (see above). The basioccipital also 570 contacts the basisphenoid on its ventrolateral margin, as the ventrolateral flanges of the 571 basioccipital articulate on this area. The facet for these flanges is very elongated, almost ridge572 like. The dorsolateral region of the posterior edge of the basisphenoid articulates with the prootic 573 through a dorsally exposed facet (Fig. 11A-B). Thus, there is a triple contact involving the 574 basioccipital, basisphenoid, and the prootic (Fig. 6D). As was previously mentioned, this triple 575 contact closes the ventralmost end of the cochlear recess (see prootic). Additional participation in 576 this contact by the otoccipital is possible, as the ventrolateral region of the cochlear recess is not 577 preserved.

Anteriorly, the basisphenoid of Macelognathus is "W"-shaped, comprising a dorsal basisphenoid plate and a central carotid pillar, which conveyed the internal carotids (Fig. 11C). The carotid pillar can be divided into the dorsal postcarotid recess and the ventral precarotid recess (Walker, 1990). The basisphenoid plate is directed anterodorsally and continues anteriorly 582 up to the level of the hypophyseal fossa (Fig. 11A). Due to the fragmentary preservation of LACM 5572/150148 it is not possible to establish if the basisphenoid plate formed a continuous

584 bony sheet. On the anterolateral ends of the basisphenoid plate, two elongated oblique facets for 585 the laterosphenoids are present (Fig. 11B). Ventromedial to these facets two anterolaterally 586 directed grooves, which have an associated foramen (only preserved on the left side) can be seen. 587 These represent the exits for the abducens cranial nerve (VI).

Just medial to the grooves for the abducens nerve, the basisphenoid plate forms the 589 dorsum sellae, the dorsal roof of an anteriorly placed hypophyseal fossa (Fig. 11B-C). The 
590 hypophyseal fossa is not bounded anteriorly, as in other basal crocodylomorphs (e.g., 591 Sphenosuchus, Almadasuchus) and crocodyliforms. Although not well-preserved (only on the 592 right side), bulges are present lateral to the hypophyseal fossa. Anteroventrally an anteriorly 593 exposed bony plate is present that is pierced by two foramina, the exit for the internal carotid 594 arteries (Fig. 11C). This condition is very unusual among crocodylomorphs, as in taxa where this 595 trait is known the exit of the internal carotids is located on the ventrolateral surface of the 596 hypophyseal fossa (e.g., Sphenosuchus, Dibothrosuchus, P. haughtoni). The bony plate bears a 597 dorsal bulge and, separated from it, the base of the basisphenoid rostrum is preserved. Thus the 598 base of the basisphenoid rostrum is located well ventral to the base of the hypophyseal fossa, as 599 in Sphenosuchus, contrasting with the condition present in Almadasuchus and Crocodyliformes 600 (e.g., P. haughtoni, Caiman yacare Daudin, 1802). In these taxa the hypophyseal fossa is 601 bounded anteroventrally by the basisphenoid rostrum, and in crocodyliforms this anterior process 602 expands dorsally forming the anterior wall of the fossa. On the posterior surface of the anteriorly 603 exposed bony plate and ventral to the hypophyseal fossa, an elliptical, lateromedially elongated 604 recess is present. A similar rostral recess is also present in Sphenosuchus, but the structure of this 605 region is not known in other basal crocodylomorphs. these struts, both carotid pillars are preserved on their posterior region (Fig. 11C). These have an 608 internal hollow structure for the passage of the internal carotids. Unlike the condition present in Sphenosuchus, the carotid pillars completely enclose the internal carotids, at least in their 610 posterior part, while in the latter taxon they run dorsally on the carotid pillar leaving a dorsally 611 open groove (Walker, 1990). Dorsal to the carotid pillar, the postcarotid recess is only partially 612 preserved. Posteriorly this recess bears two parallel posteriorly projected depressions that 
613 excavate this surface. Ventral to the carotid pillar the precarotid recess is also partially preserved 614 on its posterior region where it has a bony ring delimiting a circular passage (Fig. 11D). Thus, 615 the precarotid recess seems to be posteriorly open, unlike the condition in Sphenosuchus where 616 this recess is closed.

617 Two anterolaterally oriented bony struts arise from the ventral surface of the posterior 618 region of the basisphenoid, ventrolateral to the carotid pillars (Fig. 11A). The lateral surface of 619 the bony struts bears a foramen that divides in two rami, an anteriorly directed ramus and an 620 anteroventrally oriented one. The anterior ramus of this foramen communicates with the carotid 621 pillar, representing the initial passage where the internal carotid enters the basisphenoid. The 622 anteroventral ramus is only formed by a dorsal bony bridge and then continues anteroventrally 623 through a slight groove. The path described by the initial part of the foramina, and then by the 624 groove, is consistent with the identification of this structure as representing the branching of the 625 internal carotid into the palatine artery. The two lateroventral bony struts branch out rapidly 626 towards the ventral surface of the basisphenoid, within the highly pneumatized ventral region of 627 this bone. These branches expand distally to form the ventrally expanded plate of the 628 basisphenoid.

629 Posteroventral to the posterior edge of the basisphenoid are two isolated bony laminae 630 (Fig. 2B and D). These posterolateral laminae contact the posteromedial process of the quadrate 631 and the paroccipital processes of the ottocipital. Given their topological position these are 632 interpreted as fragmentary remains of the pterygoids, particularly the quadrate ramus of that 633 bone.

634 Although elements from both sides are preserved, the laterosphenoids are poorly 635 preserved (Fig. 2). The laterosphenoids articulate posteriorly with the prootics through a straight 
636 overlapping suture (Fig. 12A). Posteroventrally the laterosphenoid contacts the basisphenoid

637 dorsolateral to the hypophyseal fossa via an elongated facet (see basisphenoid above) (Fig. 12C).

638 The region in between these sutures is missing, precluding evaluating the shape of the trigeminal

639 foramen. Most of the dorsal edge of the laterosphenoid contacts the parietal through a straight

640 suture. The anterodorsal end of the laterosphenoid articulates with the frontals, having short

641 capitate processes located on its anteriormost end (only preserved on the right side).

642 The lateral surface does not seem to have any crest on its external surface, as in most

643 basal crocodyliforms (Pol et al., 2014) and "sphenosuchians" where this region is preserved (i.e.,

644 Sphenosuchus, Dibothrosuchus, Junggarsuchus and Almadasuchus). The lateral surface of the

645 laterosphenoid is convex in general, as it forms the anterolateral border of the lateral wall of the

646 forebrain. This convexity is particularly developed anteriorly, where it is markedly beveled. On

647 the posterior half of the lateral surface an elongated, foramen leading dorsally into the bone is 648 present (Fig. 12C). However, this foramen does not communicate with the neurocranial cavity as 649 it is closed by a medial lamina.

650

\section{Phylogenetic relationships}

In order to evaluate the affinities of Macelognathus the latter taxon was included in a

653 phylogenetic dataset. The chosen dataset was the one used by Pol et al. (2013), as this matrix

654 includes the highest amount of "sphenosuchian" taxa and also has an expanded crocodyliform

655 sampling when it is compared to other datasets (e.g., Clark, Sues \& Berman, 2000; Clark et al.,

656 2004; Nesbitt, 2011). However, considering recent contributions on crocodylomorph phylogenies

657 (Nesbitt, 2011; Zanno et al., 2015) we expanded this matrix including new characters and new

658 taxa. As a result, our new dataset is composed of 39 taxa and 138 characters. 
659

660 Taxon sampling

661

The new taxa incorporated are: the paracrocodylomorph Saurosuchus galilei Reig, 1959;

662

and the crocodylomorphs CM 73372 (see Nesbitt, 2011), Carnufex carolinensis Zanno, Drymala,

663 Nesbitt \& Scheider, 2015, Redondavenator quayensis Nesbitt, Irmis \& Lucas, 2005, Trialestes

664 romeri (Reig, 1963), Hallopus victor, Macelognathus vagans, and Hemiprotosuchus leali

665 Bonaparte, 1969. Saurosuchus is added to increase the number of outgroups in the analysis, as

666 Wilberg (2015) noted that the inclusion of more outgroups might affect the results. Also,

667 Saurosuchus represents a very well-known paracrocodylomorph with both reported cranial

668 (Alcober, 2000) and postcranial remains (Troteyn, Desojo \& Alcober, 2011).

669

Among the crocodylomorphs included, CM 73372 was recently found as the one of the

670

basalmost members of the clade (Nesbitt, 2011), and thus is relevant to the following analysis.

671 Other taxa relevant in this matter are two putative crocodylomorphs relatively recently

672 published: Redondavenator quayensis (Nesbitt et al., 2005) and Carnufex carolinensis (Zanno et

673 al., 2015; Drymala \& Zanno, 2016). In Zanno et al.’s (2015) original analysis Carnufex was

674 recovered at the base of Crocodylomorpha, in a polytomy with CM 73372, while

675 Redondavenator was depicted as the sister taxon of Sphenosuchus. The sister group relationship

676 between Sphenosuchus and Redondavenator was supported by a single synapomorphy: an

677 elongated maxillary process on the premaxilla (Nesbitt, 2011; char. 2-1). It is important to

678 consider that this character cannot be scored in Sphenosuchus, as Walker stated in his seminal

679 paper that the dorsal end of this process is not preserved (Walker, 1990, p. 12; SAM-PK 3014). 
680 However, in a second analysis including both Carnufex and Redondavenator Drymala \& Zanno 681 (2016) recovered both taxa at the base of Crocodylomorpha together with CM 73372. almost the past 30 years. Only Trialestes was incorporated in the precursor dataset of Benton and

684

685

686

687

688

689

690

691

692

693

694

695

696

697

698

699

700

701

702

Clark (1988). Finally, Macelognathus was added in Pol et al.’s (2013) dataset, but it was

recovered as a wildcard taxon in that analysis and was removed from the consensus. However,

Pol et al. (2013) mentioned that Macelognathus was recovered as the sister group of

Almadasuchus, Terrestrisuchus + Litargosuchus or Saltoposuchus on the different most

parsimonious trees obtained in their analysis. Those topologies were mostly supported by

femoral characters, as the braincase of Macelognathus was not yet described. Hemiprotosuchus

leali represents the only crocodyliform added in this analysis as it represents the oldest record of

the clade (Late Triassic; Los Colorados Formation, La Rioja, Argentina; Bonaparte, 1972a).

Finally, it is relevant to discuss which materials were considered for some of the operational taxonomical units (OTUs) of our analysis. For a full list of the specimens examined the reader is referred to the Supplementary Information. The two most taxonomically controversial taxa are Trialestes romeri and Hesperosuchus agilis. Trialestes has been involved in a controversy since its original description by Reig (1963). Two specimens have been assigned to this taxon (PVL 2561, 3889), but other authors recognized that one specimen could represent a dinosaur (Clark, Sues \& Berman, 2000) or even another crocodylomorph (Ezcurra, Lecuona \& Irmis, 2008). In consequence, to avoid future problems with our codifications of the taxon, we restrict our scorings of Trialestes to the type specimen (PVL 2561), which also preserves clear crocodylomorph synapomoporphies (e.g., elongated proximal carpals). The other controversial taxon is Hesperosuchus agilis Colbert, 1952, especially regarding its content. 
703 Colbert (1952) established the taxon on a well preserved but rather fragmentary specimen from

704 the lower part of the Chinle Formation. Later on, Clark, Sues \& Berman (2000) described a

705 much more complete individual from the upper part of the Chinle Formation and assigned it

706 Hesperosuchus. However, Nesbitt (2011) and Irmis, Nesbitt \& Sues (2013) thought this to be

707 unlikely as it would extend the range of the same species through the entire deposition of the

708 Chinle Formation, possibly as long as 20 million years. In later contributions other authors have

709 mentioned and even scored some differences between both specimens (Drymala \& Zanno, 2016).

710 However, we see little differences between both specimens and many of these morphological

711 differences are indeed present both in the type (AMNH FR 6756) and the referred specimen (CM

712 29894) (e.g., see characters 137 and 138). Furthermore, both specimens and another specimen

713 assigned to $H$. "agilis" (UCMP 129470) share the development of sharp postzygodiapophyseal

714 laminae, a trait not present in other North American "small" crocodylomorphs (i.e., not in

715 Carnufex). As a result, we base our scorings of Hesperosuchus agilis on both the type (AMNH

716 FR 6756) and the Carnegie Museum (CM 29894) specimens.

718 Character sampling

719 A total of 40 characters were added to Pol et al.'s (2013) dataset of 96 characters scored

720 for 32 taxa. Among these 13 are new and the remaining 27 are from other recent datasets, where

721 the majority of them come from Nesbitt's (2011) contribution on archosaurian relationships. As

722 new characters were formulated, and many of the characters from other contributions were

723 modified (either in their formulation or scorings), an explanation of them is given below. Our

724 focus on this discussion is on non-crocodyliform taxa, but for more information on the 
725 crocodyliform specimens used to evaluate these characters the reader is referred to the

726 Supplementary Materials.

727

97. Supraoccipital: fused with the exoccipital (0); or, as a separate ossification (1) (NEW)

728

(Fig. 13 A, C, and D). In basal pseudosuchians (Gracilisuchus, MCZ 4117; Stagonolepis,

729 Walker, 1961) and paracrocodylomorphs (Saurosuchus, PVSJ 32; Postosuchus [Weinbaum,

730 2011]) the supraoccipital is fused with the paroccipital processes, not being present as a separate

731 ossification. In crocodylomorphs where this region of the skull is known (e.g., Terrestrisuchus

732 [Crush, 1984], Kayentasuchus, UCMP 131830, Almadasuchus, MPEF-PV 3838; P. richardsoni,

733 UCMP 131827) the supraoccipital is a separate ossification.

98. Supraoccipital shape: narrow, being dorsoventrally taller than lateromedially wide

735

(0); or, wide, being lateromedially wider than dorsoventrally high (1) (NEW) (Fig. 13 A, C, and

736

D). In most crocodylomorphs the supraoccipital bone is rectangular in posterior view, as it is

737

taller than wide, such as Pseudhesperosuchus (PVL 3830), Hesperosuchus (CM 29894),

738

Terrestrisuchus (Crush, 1984), Kayentasuchus (UCMP 131830), Sphenosuchus (SAM-PK 3014),

Dibothrosuchus (IVPP V 7907) and Junggarsuchus (IVPP V 14010). On the other hand,

Almadasuchus (MPEF-PV 3838), Macelognathus (LACM 5572/150148, see description),

741

crocodyliforms (e.g., Protosuchus haughtoni [BP/1/4726, 4746, 4770], Gobiosuchus [Osmólska,

742 Hua \& Buffetaut, 1997]) and most thalattosuchians (e.g., Teleosaurus [Jouve, 2009];

743

Pelagosaurus [BSP 1890]; Metriorhynchus superciliosus Blainville, 1853 [AMNH 997];

744

Dakosaurus andiniensis Vignaud \& Gasparini, 1996 [Pol \& Gasparini, 2009]; Cricosaurus

745

araucanensis [MLP 72-IV-7-1]) have a wide supraoccipital bone, where this element is wider than

746 tall. 
99. Quadrate-Laterosphenoid contact: absent (0); or, present (1) (modified from Clark,

1986) (Fig. 13 B, and F). This character is a slight modification in its phrasing compared to how

it was originally stated, as it only made reference to the quadrate head. We agree with Clark's

(1986) observations, as it was scored as present in crocodyliforms with the exception of

751

thalattosuchians. Among sphenosuchians this condition is only present in Almadasuchus (MPEFPV 3838). See also character 104. internally. These are observed in Hesperosuchus (CM 29894), Sphenosuchus (SAM-PK 3014),

(MPEF-PV 3838). Crush (1984, p. 138) describes a well-developed basioccipital recess for

Junggarsuchus (IVPP V 14010) and crocodyliforms (e.g., P. richardsoni, UCMP 131827), although in the latter forms the posterior margin of the median Eustachian tubes. midlength of the supratemporal fenestra (0); or, long, exceeding the midlength of the supratemporal fenestra (1) (NEW) (Fig. 13 B, D, and F). As in most basal pseudosuchians posterodorsal process of the postorbital, very short and not exceeding the midlength of the supratemopral fenestra (e.g., P. richardsoni, MCZ 6727;P. haughtoni, BP/1/4726;Orthosuchus, 
770 SAM-PK 409, C. yacare). This condition is also present in the "sphenosuchians" Terrestrisuchus

771 (Crush, 1984) and Dibothrosuchus (IVPP V 7907). In Pseudhesperosuchus (PVL 3830),

772 Hesperosuchus (CM 29894), Sphenosuchus (SAM-PK 30141), Junggarsuchus (IVPP V 14010)

773 and Almadasuchus (MPEF-PV 3838) the posterodorsal process of the postorbital is posteriorly

774 elongated, reaching more than half the anteroposterior development of the supratemporal

775 fenestra.

102. Quadrate fenestra: with participation of the quadratojugal (0); or, exclusively

777 bounded by the quadrate (1) (NEW). Pneumatic quadrate fenestrae have been recognized in the

778 crocodylomorphs Terrestrisuchus, Junggarsuchus, Almadasuchus, Macelognathus and

779 Dibothrosuchus (see Description and char. 46 in the Supplementary Information). However,

780 besides size variation, there is variation in the contribution of the surrounding bones in the

781 different taxa. Terrestrisuchus (Crush, 1984) has at least some participation of the quadratojugal

782 on the anterior end; while in Junggarsuchus (IVPP V 14010), Almadasuchus (MPEF-PV 3838)

783 and crocodyliforms (e.g., Protosuchus richardsoni, UCMP 131827; Gobiosuchus [Omolska,

784 1997]) the quadrate fenestrae are completely surrounded by the quadrate. As previously

785 mentioned, this condition cannot be precisely known in Dibothrosuchus (IVPP V 7907) and

786 Macelognathus (LACM 5572/150148) due to the incomplete preservation of the quadrate

787 fenestra.

103. Number of quadrate fenestrae: one (0), or more than one (1) (Clark, 1994).

789 Crocodylomorphs that have quadrate fenestrae usually have one on the main body of the

790 quadrate. However, Junggarsuchus is unusual in this aspect, as at least two fenestrae are

791 identified on its quadrate (Klein et al., in prep). This condition is similar to the one present in 
792 basal crocodyliforms that have multiple quadrate fenestrae (e.g., Protosuchus richardsoni 793 [UCMP 131827]).

794

795

796

797

798

799

800

801

802

803

804

805

806

807

808

809

810

811

812

813

814

104. Prootic: exposed in dorsal view, on the supratemporal fossa (0); or not exposed in dorsal view (1) (NEW) (Fig. 13 B, D, and F). In basal pseudosuchians (Postosuchus [Weinbaum, 2011]; Saurosuchus, PVSJ 32; Gracilisuchus, MCZ 4117) and non-crocodyliform crocodylomorphs (e.g., Hesperosuchus, CM 29894;Litargosuchus, BP/1/5237; Dibothrosuchus, IVPP V 7907; Almadasuchus, MPEF-PV 3838) the prootic is exposed on the posterodorsal region of the supratemporal fossa. Most crocodyliforms lack the prootic exposed dorsally on the supratemporal fossa (e.g., P. richardsoni, UCMP 131827; Orthosuchus, SAM-PK 409) due to the broad contact of the quadrate with the laterosphenoid. However, Almadasuchus has a dorsally exposed prootic on the posterodorsal region of the supratemporal fossa, but has a quadrate-laterosphenoid contact (see char. 99). On the other hand, thalattosuchians (e.g.,

Cricosaurus araucanensis, MLP 72-IV-7-1; Teleosaurus [Jouve, 2009]; Pelagosaurus [Pierce \& Benton, 2006]) exhibit the same condition as in non-crocodyliform crocodylomorphs.

105. Exit of cranial nerves IX-XI: exit the braincase ventromedially (0); or, through a common foramen on the ventromedial region of the paroccipital process (vagus foramen) (1) (NEW) (Fig. 13 E). The primitive condition for Crocodylomorpha is the exit of the cranial nerves IX-XI through the ventrolateral region of the skull, thus not leaving any distinct foramen (e.g., Gracilisuchus, MCZ 4117; Postosuchus, [Weinbaum, 2011]; Saurosuchus, PVSJ 32). This condition is present in most "sphenosuchian" crocodylmorphs, like Pseudhesperosuchus (PVL 3810), Hesperosuchus (CM 29894; AMNH FR 6758), Terrestrisuchus (Crush, 1984), Litargosuchus (BP/1/5237), Kayentasuchus (UCMP 131830), Sphenosuchus (SAM-PK 3014), Dibothrosuchus (IVPP V 7907) and Junggarsuchus (IVPP V 14010). Almadasuchus (MPEF-PV 
815 3838) and crocodyliforms (e.g., P. richardsoni, UCMP 131827; Protosuchus haughtoni

$816[\mathrm{BP} / 1 / 4726,4746,4770]$, Orthosuchus, SAM-PK 409) exhibit a foramen on the ventrolateral

817 region of the paroccipital process that has been interpreted widely as the exit of the nerves IX-XI

818 (i.e., vagus foramen). This condition is also present in thalattosuchians (e.g., Pelagosaurus

819 [Clark, 1986; Pierce \& Benton, 2006]; Teleosaurus [Jouve, 2009]; Dakosaurus [Pol \& Gasparini, 820 2009]).

821 106. Postzygodiapophyseal laminae on the posterior cervical and anterior dorsal

822 vertebrae: absent or low (0); or, present as sharp lamina delimiting a pit posterior to them on the

823 neural arch (1) (NEW) (Fig. 14 B, and C). Sharp postzygodiapophyseal laminae are present on

824 the posterior cervical and anterior dorsal vertebrae of paracrocodylomorph archosaurs

825 (Saurosuchus, PVL 2198; Fasolasuchus, PVL 3950; Postosuchus [Long \& Murry, 1995]),

826 Carnufex (Drymala \& Zanno, 2016) and Hesperosuchus (AMNHFR 6576, CM 29894, UCMP

827 129470). Posterior to these laminae, a well-marked semicircular depression is limited.

828 Dibothrosuchus (IVPP V 7907) has a similar condition on its anterior dorsal vertebrae, although

829 the postzygodiapophyseal lamina is not as sharply projected as in Hesperosuchus.

830

107. Length of the radius: shorter than the humerus (0); or, longer than the humerus (1)

831 (NEW). This trait was originally highlighted by Clark, Sues \& Berman (2000) referring to the

832 particular elongation of the radius present in Trialestes. However, such elongation of the radius

833 is more widely distributed than previously reported. Besides Trialestes (PVL 2561), longer radii

834 than their respective humeri are also present in Litargosuchus (BP/1/5237), Dibothrosuchus

835 (IVPP V 7907), Dromicosuchus (NCSM 13733) and variably in Hesperosuchus (present in

836 AMNH FR 6758, while in CM 29894 the humerus is longer). On the other hand, most non-

837 crocodylomorph pseudosuchians (e.g., Gracilisuchus, MCZ 4117; Postosuchus, [Weinbaum, 
838 2011]; Saurosuchus, PVSJ 32), Saltoposuchus (SMNS 12597), Junggarsuchus (IVPP V 14010),

839 Hallopus (YPM 1914) and crocodyliforms (e.g., P. richardsoni, UCMP 131827; Protosuchus

840 haughtoni [BP/1/4726, 4746, 4770], Orthosuchus, SAM-PK 409) have longer humeri than their

841 radii. The relative length of the anterior zeugopodium seems not to be correlated with the lenghts

842 of the posterior one. Taxa such as Dromicosuchus (Sues et al., 2003) and Hallopus (Walker,

843 1970) have femora proximodistally shorter than the tibiae (see char. 32, Supplementary

844 Information), while their radii are longer than the humeri.

845 108. Proximomedial process of the radiale: absent (0); or, present (1) (NEW). Besides the

846 elongation present in this element (Clark, 1986; Benton \& Clark, 1988), crocodylomorphs are

847 also characterized by the presence of a proximomedial process on the radiale. This process

848 articulates with the ulna and the ulnare. As with the elongation on the proximal carpals, this

849 process is also lacking in CM 73372. The presence of the proximomedial process of the radiale

850 might be thought to be correlated with the elongation of the proximal carpals, as these traits have

851 the same distribution among crocodylomophs. However, this can be very useful in taxa where

852 the radiale is not preserved completely, and yet represents a crocodylomorph synapomorphy with

853 the exclusion of the CM 73372.

854 109. Anterior process of the squamosal: elongated, less than one third of the lateromedial

855 width of the supratemporal fossa (0); transversely broad, more than one third the width of the

856 supratemporal fossa (1); or, very broad, as wide as the width of the supratemporal fossa

857 (modified from Clark, 1986; Sereno \& Wild, 1992; Nesbitt, 2011) (Fig. 13 B, D, and F). Clark

858 (1986) recognized the lateromedially expanded anterior process of the squamosal as a

859 crocodylomorph synapomorphy. Sereno and Wild (1992) followed the same idea, and

860 established that unlike other pseudosuchians, in crocodylomorphs the anterior process of the 
861 squamosal was at least one third of the posterior width of the whole skull. Finally, Nesbitt (2011)

862 observed a similar, but more restricted variation among some crocodylomorphs (Litargosuchus,

863 P. richardoni, Orthosuchus and Alligator), where in these taxa the anterior process of the

864 squamosal was as transversely wide as the supratemporal fenestra. We integrated these

865 independent characters in a single, multistate character, and using as a comparative value the

866 width of the supratemporal fenestra. As previously noted, crocodylomorphs have a

867 lateromedially expanded anterior process of the squamosal. This condition is present in several

868 “sphenosuchians” (Pseudhesperosuchus, PVL 3810;Hesperosuchus, CM 29894; Sphenosuchus, 869 SAM-PK 3014; Dibothrosuchus, IVPP V 7907; Junggarsuchus, IVPP V 14010; Almadasuchus,

870 MPEF-PV 3838) and most crocodyliforms (Hsisosuchus [Li, Wu \& Li, 1994]; Sichuanosuchus

871 [Wu, Sues \& Dong, 1997]; Simosuchus, UA 8679). Finally Litargosuchus (BP/1/5237),

872 Terrestrisuchus (Crush, 1984), Protosuchus (P. richardsoni, UCMP 131827; Protosuchus

873 haughtoni [BP/1/4726, 4746, 4770]), Notosuchus (MACN-RN 1037) and Alligator (Iordansky,

874 1973) have a very wide anterior process of the squamosal, as this process is as wide as the

875 supratemporal fossa. Kayentasuchus (UCMP 131830) was scored as having an expanded anterior

876 process of the squamosal, but we could not determine to what extent (1/2), as the preservation of

877 the specimen does not allow it. Finally, we scored the condition of Orthosuchus as missing data,

878 as the anterior process of the squamosal is not completely preserved (SAM-PK 409).

879 110. Lateral extent of the paroccipital processes: ends lateral to the lateral border of the

880 supratemporal fenestra (including the fossa) (0); or, ends medial to or at the margin of the border

881 of the supratemporal fenestra (1) (modified from Nesbitt, 2011) (Fig. 13 A, C, and E). In

882 Nesbitt's study (2011) the derived condition was found in a group of derived crocodylomorphs,

883 which included Kayentasuchus, Litargosuchus, Protosuchus and Orthosuchus. However, due to 
884 difficulties in scoring this character we also included the lateral limit of the supratemporal fossa,

885 which was not stated in the original character. Without taking into account the supratemporal

886 fossa most crocodylomorphs would be scored as having the lateral end of the paroccipital

887 processes lateral to the border of the supratemporal fenestra/fossa, even some of them scored

888 otherwise by Nesbitt (2011). However, when the distribution of this character was revised

889 several differences were found. Paroccipital processes with short lateral projection (i.e., not

890 reaching the lateral border of the supratemporal fossa or fenestra) are present in

891 Pseudhesperosuchus (PVL 3810), Litargosuchus (BP/1/5237) and Hesperosuchus (CM 29894),

892 among non-crocodyliforms crocodylomorphs. Kayentasuchus (UCMP 131830) bears laterally

893 projected paroccipital processes, as these almost reach the lateralmost border of the skull in

894 occipital view (Clark \& Sues, 2002). Paroccipital processes that end more laterally than the

895 lateral edge of the supratemporal fossa/fenestra are also present in Protosuchus (P. richardsoni

896 [UCMP 131827; Protosuchus haughtoni $[\mathrm{BP} / 1 / 4726,4746,4770])$, as in this genus the

897 supratemporal fenestrae lack a fossa on their lateral part, thus having little lateral development.

898 Orthosuchus also has this state of the character, but unlike Protosuchus the paroccipital

899 processes have a great lateral projection reaching the lateral end of the skull in occipital view

900 (SAM-PK 409; Nash, 1975). Among crocodyliforms there is not a clear trend as laterally short

901 paroccipital processes are present in Zosuchus (Pol \& Norell, 2004), some notosuchians

902 (Baurusuchus [Carvalho, Campos \& Nobre, 2005]; Simosuchus [Kley et al., 2010]) and

903 thalattosuchians.

904 111. Anterior end of the dentaries: tapering to a point (0); or, dorsally expanded, forming

905 a distinct step (1) (modified from Nesbitt, 2011). This trait was used to refer CM 29894 to

906 Hesperosuchus by Clark, Sues \& Berman (2000). However this observation was questioned later 
907 as an anteriorly expanded dentary was also present in Postosuchus and Dromicosuchus (Nesbitt,

908 2011). We agree with the presence of such an expansion in Postosuchus (Weinbaum, 2011), but

909 on the other hand, this condition cannot be observed in Dromicosuchus (NCSM 13733) as the

910 mandibles are closed and articulated in the only known specimen. Trialestes (PVL 2561) also

911 has an anteriorly expanded dentary, but this condition should be handled with care considering

912 the aggressive mechanical preparation that specimen suffered.

913 112. Anterior part of the dentary: bears teeth (0); or, edentulous (1) (Parrish, 1994). Most

914 archosauriforms have teeth along their entire tooth row. Exceptions among pseudosuchians are

915 some poposauroids (Effigia [Nesbitt, 2007]; Lotosaurus [Nesbitt, 2011]), aetosaurs (Stagonolepis

916 [Walker, 1961]), and among crocodylomorphs Macelognathus (YPM 1415; LACM

$9175572 / 150148)$.

918 113. Acromial process of scapula: in the same plane of the proximal surface of the

919 scapula (0); or, distinctly raised, forming an abrupt step between the scapular blade and the 920 proximal end of the scapula (1) (modified from Nesbitt, 2011). Contrasting with the condition

921 present in basal archosauriforms, archosaurs have an expanded acromial process of the scapula,

922 where this region forms a distinct anterior step (Leardi, 2013). This condition is reversed in

923 paracrocodylomorph pseudosuchians (e.g., Effigia [AMNH 30587]; Postosuchus [Long \&

924 Murry, 1995]) and Hesperosuchus (AMNH 6758). Other crocodylomorphs where the proximal

925 end of the scapula is adequately known bear expanded acromial processes (e.g., Trialestes, PVL

926 2561; Pseudhesperosuchus, PVL 3810; Dibothrosuchus, IVPP V 7907; Orthosuchus, SAM-PK 927 409).

114. Coracoid posteroventral edge: smooth (0); or, with a groove (1) (Nesbitt, 2011). This

929 character evaluates the presence of a ventral groove on the distal end of the coracoids, which 
930 serves for the articulation of the interclavicle. This groove was noted in Postosuchus (missing in

931 other rauisuchids) and non-crocodyliform crocodylomorphs with the exception of Litargosuchus

932 (Nesbitt, 2011), with increased taxon sampling this groove is also observed to be absent in

933 Junggarsuchus (IVPP V 14010) and Dibothrosuchus (IVPP V 7907).

934 115. Scapular contribution to the glenoid: lesser than the coracoid contribution $(0)$; or,

935 equal or greater than the coracoid contribution (1) (NEW). In most archosauriforms the glenoid 936 is formed mostly by the coracoids, as can be seen in Riojasuchus (PVL 3827), Stagonolepis

937 (Walker, 1961), Prestosuchus (UFGRS PV 0629T), and Postosuchus (Weinbaum, 2002). In

938 crocodylomorphs, unlike other pseudosuchians, the glenoid is mostly formed by the scapula.

939 This condition can be observed in Pseudhesperosuchus (PVL 3810), Hesperosuchus (AMNH FR

940 6758), Terrestrisuchus (Crush, 1984), Sphenosuchus (SAM-PK 3014), Dibothrosuchus (IVPP V

941 7907), Junggarsuchus (IVPP V 14010), Protosuchus (P. richardsoni, UCMP 131827; P.

942 haughtoni $[\mathrm{BP} / 1 / 4726,4746,4770])$, among others.

943 116. Humeral proximal head: confined to the proximal surface $(0)$; or, posteriorly

944 expanded and hooked (1) (Nesbitt, 2011). Nesbitt (2011) formulated this character observing the

945 similarities among the posterior projection of the humeral heads in rauisuchids (e.g.,

946 Postosuchus) and crocodylomorphs. A hooked posteriorly projecting humeral head is also

947 present in basal crocodyliforms like Protosuchus and Orthosuchus, but not in more derived

948 forms (Alligator in that analyses). We agree with those observations, and also did not observe

949 that condition in other crocodyliforms.

950 117. Olecranon process on the ulna: present (0); or, absent or very low (1) (modified from

$951 \mathrm{Wu}$, Sues \& Dong, 1997). The olecranon process is present in the proximal end of the ulna in

952 most archosaurs (Leardi, 2013). This condition is maintained in most pseudosuchians (e.g., 
953 Stagonolepis [Walker, 1961]; Postosuchus [Weinbaum, 2002]) and "sphenosuchians"

954 (Hesperosuchus, AMNH 6758, CM 29894; Terrestrisuchus [Crush, 1984]; Dromicosuchus [Sues

955 et al., 2003]; Sphenosuchus, SAM-PK 3014; Dibothrosuchus, IVPP V 7907; Hallopus, YPM

956 1914). In crocodyliforms (e.g., P. richardsoni, AMNH FR 3024; Orthosuchus, SAM-PK 409;

957 Simosuchus, UA 8679; Alligator, MPEF AC 205) the olecranon process is absent or reduced, as

958 in these taxa there is no marked discontinuity between the proximal surface and the posterior end

959 of the proximal surface. A reduced olecranon process is also present in some non-crocodyliform

960 crocodylomorphs: Trialestes (PVL 2561), Pseudhesperosuchus (PVL 3810), Saltoposuchus

961 (SMNS 12597) and Junggarsuchus (IVPP V 14010).

962

118. Proximolateral process of the ulna: located at the midpoint of the proximolateral

963 surface of the ulna (0); or, anteriorly displaced, at the level of the anterior process of the ulna (1)

964 (NEW). The archosauriform ulna in proximal view has, generally, three proximal processes: an

965 anteromedial, a lateral and a posterior process (usually the olecranon, when it is proximally

966 projected). This condition is maintained in crocodylomorph outgroups (Stagonolepis [Walker,

967 1961]; Postosuchus [Weinbaum, 2002]). In crocodylomorphs the lateral process of the ulna is

968 displaced anteriorly, almost at the same level of the anterior process, leaving the articular surface

969 for the radius exposed anteriorly. Pseudhesperosuchus (PVL 3810), Hesperosuchus (AMNH FR

970 6758), Sphenosuchus (SAM-PK 3014) and Caiman (MPEF AC 205) are examples of this

971 condition among crocodylomorphs. In many taxa where the proximal surface of the ulna cannot

972 be observed due to preservational features, this trait can also be identified as the anteroproximal 973 end of the ulna is expanded.

974 119. Distal end of the ulna: anteroposteriorly compressed or rounded (0); or, with anterior

975 expansion (1) (Nesbitt, 2011). Nesbitt (2011) discussed that, unlike other archosaurs, rauisuchids 
976 (e.g., Postosuchus, Batrachotomus) have an anteriorly expanded distal end of the ulna. We agree

977 with that statement and the taxa in our analyses are coded that way.

978 120. Metacarpals II-V configuration: spreading (0); or, compact (1) (modified from

979 Clark, Sues \& Berman, 2000). We modified this character just focusing on the general

980 disposition of the metacarpals, eliminating the elongation part of the description. This character

981 was originally used by Sereno \& Wild (1992) and later modified by Clark, Sues \& Berman

982 (2000) to try to reflect the digitigrade configuration of the manus of several "sphenosuchians".

983 As also discussed in the latter paper, the digitigrady condition relies on an interpretative

984 reconstruction of the manus, and there is notable variation in the general configuration of the

985 metacarpals of "sphenosuchians", especially when compared with crocodyliforms. Also this

986 character seeks to replace the one referring to the proximal configuration of the metacarpals

987 (char. 30), which has proven to be controversial regarding its scorings, and recently no variation

988 among crocodylomorphs has been recognized (Nesbitt, 2011), thus making this character non-

989 informative. The main problem with how the character was restated is that it requires fairly

990 complete and articulated metacarpals to properly allow differentiating among the different

991 character states. In general, most pseudosuchians have a spreading configuration of their

992 metacarpus, in which the metacarpals diverge gradually from their proximally imbricated

993 proximal end towards their distal ends. This condition is present in aetosaurs (Stagonolepis

994 [Walker, 1961]; Longosuchus [TMM 31185-84a])] and Postosuchus (Peyer et al., 2008). The

995 condition of CM 73372 is dubious despite that it was scored in recent analyses as having

996 overlapping metacarpals (Nesbitt, 2011), as the metacarpus was disarticulated during mechanical

997 preparation. In non-crocodyliform crocodylomorphs where a manus was found articulated a

998 compressed metacarpus can be observed (Hesperosuchus, CM 29894; Saltoposuchus, SMNS 
999

1000

1001

1002

1003

1004

1005

1006

1007

1008

1009

1010

1011

1012

1013

1014

1015

1016

1017

1018

1019

1020

1021

12352, 12597; Terrestrisuchus, NHMUK R7557 [Crush, 1984]; Dibothrosuchus, IVPP V 7907;

Junggarsuchus, IVPP V 14010; and Hallopus, YPM 1914). In contrast, crocodyliforms have a spreading metacarpus (e.g., P. richardsoni, MCZ 6727; Orthosuchus, SAM-PK 409; Sichuanosuchus [Wu, Sues \& Dong, 1997]; Notosuchus, MACN-RN 1037; Caiman, MPEF AC 205).

121. Dorsoventrally oriented crest dorsal to the supraacetabular crest: absent $(0)$, or, present (1) (modified from Nesbitt, 2011). This character is a modification of a set of three characters postulated by Nesbitt (2011), which evaluated the presence, direction and thickness of a crest situated dorsally to the acetabulum (chars. 265-267). However, when taxon sampling is reduced to crocodylomorphs and outgroups, the morphological variation is reduced to a single morphology: a dorsoventrally oriented crest dorsal to the acetabulum. This crest is absent in basal pseudosuchians (Stagonolepis [Walker, 1961; Nesbitt, 2011]; Gracilisuchus, PVL 4597 [Lecuona \& Desojo, 2012]), but is present in paracrocodylomorphs (Saurosuchus [Nesbitt, 2011]; Postosuchus [Weinbaum, 2002]) and basal crocodylomorphs (CM 73372; Hesperosuchus, AMNH 6758; Terrestrisuchus [Nesbitt, 2011]; Dromicosuchus, NCSM 13733). This crest is absent Dibothrosuchus (IVPP V 7907), Macelognathus (LACM 5572/150148) and crocodyliforms (e.g., P. richardsoni [AMNH 3024], Orthosuchus [SAM-PK 409]).

122. Preacetabular process of the ilium: short and does not extend anteriorly to the acetabulum (0); or, elongated, but shorter than the postacetabular process (1) (modified from Galton, 1976; Clark, 1986; among others). An elongated preacetabular process (usually exceeding the anteriorly to the anterior border of the acetabulum) has been usually recognized as a crocodylomorph synapomorphy (Clark, 1986; Benton \& Clark, 1988; Nesbitt, 2011). This trait is also present in basal crocodyliforms like P. richardsoni (AMNH FR 3024) and Orthosuchus 
1022 (SAM-PK 409), but not in mesoeucrocodylians (e.g., Baurusuchus [Nascimento \& Zaher, 2010]; 1023 Alligator [Mook, 1921]) nor in the thalattosuchians sampled in our analysis (Andrews, 1913). 123. Ilium orientation: mainly vertical orientation $\left(0^{\circ}-20^{\circ}\right)(0)$; or, ventrolaterally

1025

1026

1027

1028

1029

1030

1031

1032

1033

1034

1035

1036

1037

1038

1039

1040

1041

1042

1043

1044

deflected about $45^{\circ}$ (1) (Benton \& Clark, 1988). Most archosauriforms have vertically oriented ilia. However, aetosaurs (e.g., Stagonolepis [Walker, 1961]) and paracrocodylomorphs (Saurosuchus, PVSJ unnumbered; Postosuchus [Weinbaum, 2002]) have been recognized to have ventrolaterally deflected ilia (Benton \& Clark, 1988). Nesbitt (2011) recognized this trait also in CM 73372, Dromicosuchus (NCSM 13733) and Kayentasuchus (UCMP 131830). Nesbitt scored a ventrolaterally oriented ilium in Hesperosuchus (AMNH FR 6758), but that specimens has a very badly preserved ilium and was scored as missing (?) in this analysis.

124. Ventral margin of the acetabulum: convex (0); or, concave (1) (modified from Nesbitt, 2011). Nesbitt (2011) erected this character as a modification of the classic character treating the perforate condition of the acetabulum (Bakker \& Galton, 1974). Convex ventral margin of the acetabulum is present in basal pseudosuchians (Gracilisuchus, PVL 4597 [Lecuona \& Desojo, 2012]; Stagonolepis [Walker, 1961]), Saurosuchus (Nesbitt, 2011), Postosuchus (Weinbaum, 2002), Hesperosuchus (Nesbitt, 2011) and Dromicosuchus (NCSM 13733). Other crocodylomorphs (e.g., Terrestrisuchus [Crush, 1984]; Dibothrosuchus, IVPP V 7907; Macelognathus, LACM 5572/150148) and crocodyliforms (e.g., P. richardsoni, AMNH 3024; Orthosuchus, SAM-PK 409) have concave ventral margins of the acetabulum.

125. Ilium dorsal margin dorsal to the supraacetabular rim: rounded or sharp (0); or, flat (1) (Nesbitt, 2011). Nesbitt proposed that the dorsal margin of the iliac blade in crocodylomorphs is flat when it is compared to more basal pseudosuchians (e.g., Saurosuchus, Postosuchus) and CM 73372. The only mesoeucrocodylian scored in that analysis has a rounded dorsal margin of 
1045 the iliac blade (Alligator). We agree with those scorings and incorporate Macelognathus, which

1046 has the "sphenosuchian condition". Furthermore, the dorsal margin of the ilia of Notosuchus

1047 (MACN-RN 1044) and Baurusuchus (UFRJ DG 285-R) are rounded.

1048 126. Obturator foramen on the pubis: present (0); or, absent (1) (modified form Sereno \&

1049 Wild, 1992). In previous contributions, the size of the obturator foramen has been recognized to

1050 vary among crocodylomorphs and closely related groups (Sereno \& Wild, 1992; Nesbitt, 2011).

1051 The main focus on this structure was the relative size of the obturator foramen, as it was noted

1052 that it was "enlarged" when it was compared to the condition present in rauisuchians and other

1053 pseudosuchians. However, this rather ambiguous state of character (the enlarged condition)

1054 raised some doubts about the scoring process and, also, is problematic when in a multistate

1055 character with absence of a foramen (Brazeau, 2011). In this analysis we chose a simpler

1056 solution, which is to simply score the presence of the obturator foramen. An obturator foramen is

1057 present in basal pseudosuchians (Gracilisuchus, PVL 4597 [Lecuona \& Desojo, 2012];

1058 Stagonolepis [Walker, 1961]), and Saurosuchus (Nesbitt, 2011). Among crocodylomorphs this

1059 foramen is also present in Hesperosuchus (YPM 41198), Saltoposuchus (SMNS 12596) and

1060 Terrestrisuchus (Crush, 1984). The pubis of Dromicosuchus (NCSM 13733) seems to have

1061 preserved the anterior margin of a foramen (the obturator foramen) on the proximal end of the

1062 pubis. However, to avoid speculation Dromicosuchus was still coded as unknown (?).

1063 Unfortunately, the data on the crocodylomorphs most closely related to crocodyliforms is

1064 lacking, as in these forms (Sphenosuchus, Dibothrosuchus, Junggarsuchus, Almadasuchus,

1065 Macelognathus, Hallopus) no remains of the proximal end of the pubis have been reported. In

1066 contrast, all known crocodyliforms lack an obturator foramen on their pubes (e.g., $P$.

1067 richardsoni, AMNH 3024; Orthosuchus, SAM-PK 409; Hsisosuchus, Li, Wu \& Li, 1994; 
1068 Simosuchus, FMNH PR 2596; Alligator [Mook, 1921]). Thalattosuchians also lack an obturator 1069 foramen (Andrews, 1913).

1070 127. Ischium medial contact with its antimere: all along its medial margin, but excluding 1071 the proximal end (0); or, restricted to the medial edge of the distal part (1) (modified from 1072 Nesbitt, 2011). This character was modified for use in the current study, as it had an extra state 1073 which was not informative in our analysis. Also, for the sake of clarity, state 1 (0 in Nesbitt, 1074 2011) was slightly restated. Paracrocodylomorphs (e.g., Saurosuchus [Nesbitt, 2011]; 1075 Postosuchus [Weinbaum, 2002]) have a very wide contact between the ischia, as it extends all 1076 along their medial margin only excluding the proximal ends. The same condition is observed in 1077 CM 73372 and in Terrestrisuchus (Crush, 1984). In Litargosuchus (BP/1/5237), thalattosuchians 1078 (Andrews, 1913; Pierce \& Benton, 2006) and crocodyliforms (e.g., P. richardsoni, AMNH FR 1079 3024; Orthosuchus, SAM-PK 409; Alligator [Mook, 1921]) the contact between the ischia is 1080 distally restricted, as it leaves a proximal portion (besides the proximal end) that is not involved 1081 in such contact. Unfortunately, the information available for non-crocodyliform 1082 crocodylomorphs is only known in the above mentioned taxa (CM 73372, Terrestrisuchus and 1083 Litargosuchus). noted that many paracrodylomorphs (Saurosuchus and Postosuchus in this study) and CM 73372 1086 had rounded distal ends of the ischia, unlike the condition in crocodylomorphs where the distal end of the ischium is lateromedially compressed. His codings are followed here. defined by Brochu (1992) and later incorporated as a character by Nesbitt (2011), the proximal 
1090 fold has been recognized in paracrocodylomorphs (including crocodylomorphs) but not in 1091 pseudosuchians outside this clade.

1092

1093

1094

1095

1096

1097

1098

1099

1100

1101

1102

1103

1104

1105

1106

1107

1108

1109

1110

1111

1112

130. Fibula, proximal end: rounded or elliptical (0); or, mediolaterally compressed (1)

(Nesbitt, 2011). Nesbitt (2011) recognized that a mediolaterally compressed proximal end of the fibula was a shared derived trait of Postosuchus + crocodylomorphs. We agree with those scorings and the observations from an expanded taxon sampling of crocodyliforms agrees with that observation.

131. Pedal digit IV, number of phalanges: five (0); or, four (1) (Parrish, 1993). Parrish (1993) recognized the presence of four phalanges in pedal digit four as a crocodylomorph synapomorphy. However, data on this character is very scarce among non-crocodyliform crocodylomorphs as it is only known in CM 73372 and Terrestrisuchus. CM 73372 has five phalanges on pedal digit five as in Stagonolepis (Walker, 1961), Postosuchus (Peyer et al., 2008). Terrestrisuchus is the only "sphenosuchian" where this condition is known, and it has four phalanges as in P. richardsoni and other crocodyliforms (Alligator [Mook, 1921]).

132. Pedal digit $\mathrm{V}$, number of phalanges: one or more $(0)$; or, none (1) (modified from Gauthier, 1986; Parrish, 1993). This character was modified as it is usually considered in large datasets where ornithodirans are also included (Gauthier, 1986; Parrish, 1993; Nesbitt, 2011; among others). Although the number of phalanges on digit $\mathrm{V}$ is rather difficult to evaluate, as these can be easily disarticulated, this character can also be evaluated when metatarsal V is wellpreserved. In taxa that lack phalanges on digit $\mathrm{V}$, metatarsal $\mathrm{V}$ tapers to a point and does not have a distal articular surface for the proximal phalanx. Presence of at least one phalanx in pedal digit V is widespread among pseudosuchians, such as Stagonolepis (Walker, 1961), Gracilisuchus (PVL 4597 [Lecuona \& Desojo, 2012]), Saurosuchus (PVL 2557) and 
1113 Postosuchus (Peyer et al., 2008). At least one phalanx is also present in pedal digit V in CM

1114 73372, Terrestrisuchus (Crush, 1984) and Hesperosuchus (YPM 41198, identified by the

1115 presence of a metatarsal $\mathrm{V}$ with a distal articular facet). On the other hand, Litargosuchus 1116 (BP/1/5237), Hallopus (YPM 1914), P. richardsoni (AMNH FR 3024), Orthosuchus (SAM-PK

1117 409) and other crocodyliforms (e.g., Simosuchus, Baurusuchus, Alligator) have no phalanges on 1118 pedal digit $\mathrm{V}$.

133. Ventrally open notch on ventral edge of rostrum at premaxilla-maxilla contact:

absent (0), present as a notch (1), or present as a large notch (2), or present as a notch that is closed ventrally (or largely constrained at its ventral edge) (3) (modified from Clark, 1994). The presence of a notch to accommodate an enlarged mandibular tooth (or even two in some taxa) at the premaxilla-maxilla contact is a highly variable trait among crocodylomorphs, which is reflected in the large number of states for this character. Taxa closely related to crocodylomorphs lack a notch on the ventral edge of the premaxilla-maxilla suture (e.g., Saurosuchus, PVL 32; Postosuchus [Weinbaum, 2011]). On the other hand, Hesperosuchus (CM 29894, YPM 41198), Kayentasuchus (UCMP 131830), Dibothrosuchus (IVPP V 7907), P. richardsoni (MCZ 6727) and Orthosuchus (SAM-PK 409) have large notches that are partially closed ventrally. In other non-crocodyliform crocodylomorphs this region is partially damaged, and this character cannot be scored properly. Junggarsuchus (IVPP V 14010) is unique in lacking the notch entirely.

1132 Nesbitt (2011) noticed that as in crocodylomorphs, in rauisuchians (represented by Postosuchus 1133 in our dataset) the suture between the nasals and frontals was not lateromedially straight, as the 1134 frontals wedged between the nasals and tapered to a point. In a few crocodyliforms this trait is 
1135 reversed to the primitive condition (Gobiosuchus [Osmólska, Hua \& Buffetaut, 1997];

1136 Simosuchus, UA 8679).

1137 135. Ectopterygoid: single head (0); or, double headed (1) (Weinbaum \& Hugerbühler,

1138 2007). The ectopterygoid of Postosuchus and some basal crocodylomorphs was noted to have a

1139 subdivided lateral head for the articulation with the maxilla and the jugal (Weinbaum \&

1140 Hungerbühler, 2007; Nesbitt, 2011).

1141 136. Ectepicondylar groove: present (0); or, absent (1) (Benton \& Clark, 1988). This

1142 character has been used in several archosaur studies (e.g., Benton \& Clark, 1988; Nesbitt, 2011).

1143 The absence of an ectepicondular groove has been previously recognized in crocodylomorphs

1144 (e.g., Trialestes, PVL 2561; Hesperosuchus, AMNH FR 6758, CM 28984; Sphenosuchus, SAM

1145 PK 3014; Junggarsuchus, IVPP V 14010; P. richardsoni AMNH FR 3024). With the increased

1146 taxonomical sample this distribution changes as an ectepicondilar groove is present in the

1147 referred specimen (NCSM 21623) the "large bodied" crocodylomorph CarnufexCarnufex

1148 (Drymala \& Zanno, 2016).

1149 137. Antorbital fossa: (0) well defined anterodorsally, yet not well defined along entire

1150 length of posterior process of maxilla; (1) well defined, forming complete circumference within

1151 the antorbital fenestra (modified from Drymala \& Zanno, 2016). This character was modified

1152 removing a state (poorly defined), as it can not be scored in any of the taxa included in our

1153 analysis. Drymala \& Zanno (2016) recognized the presence of a well defined antorbital fossa, all

1154 around its circumference, in what they defined as the "group H" which clustered the referred

1155 specimens of Hesperosuchus (H. "agilis" sensu Nesbitt, 2011 and Irmis et al., 2013) and

1156 Dromicosuchus. Among basal crocodylomorphs, this trait was also observed in Kayentasuchus

1157 (Drymala \& Zanno, 2016). Additionally, the holotype specimen of Hesperosuchus agilis 
1158 (AMNH FR 6758) was scored as having an antorbital fossa not well delimited on its

1159 posteroventral edge, and used to differentiate the type specimen from the referred ones as the

1160 they formed a paraphyletic group (Drymala \& Zanno, 2016). However, this trait can not be

1161 observed in the type specimen of $H$. agilis (AMNH FR 6758) as the posterior most region of the

1162 facial lamina of the maxilla is not preserved. In addition, the posterior part of the maxilla of the

1163 type specimen bears a well defined crest that can be interpreted as the border of the antorbital

1164 fossa (Fig. 14A). Thus, the differences noted on the antorbital fossa of the type and referred

1165 specimens of $H$. agilis are disregarded here.

1166 138. Radius, proximal end, medial process: (0) absent, giving the radius a symmetrical

1167 aspect in anterior view; (1) present, giving the radius an asymmetrical aspect in anterior view

1168 (modified from Drymala \& Zanno, 2016) (Fig. 14 D-E). Drymala \& Zanno (2016) erected this

1169 character based on the morphology of the referred specimen of H. agilis (CM 29894) and an as

1170 yet unpublished taxon. We modified the character in order to clarify the different states, as a

1171 distinct medial process of the proximal end of the radius was ambiguous. In most

1172 crocodylomorphs, the proximal end of the radius is almost symmetrical in anterior view (Fig.

1173 14D), while in CM 29894 the medial end is more expanded that the lateral one (Fig. 14F). Unlike

1174 Drymala \& Zanno's (2016) observations, the holotype specimen of H. agilis (AMNH FR 6758)

1175 also bears a well-projected proximomedial process of the radius, giving the proximal end of the

1176 radius an asymmetrical aspect in anterior view (Fig. 14E). As a result, all specimens of

1177 Hesperosuchus share this particular proximal radial morphology.

1178

Although it was not included in our analysis, it is worth discussing a character erected by

1179 Nesbitt (2011). Nesbitt's (2011) analysis and later datasets that use his matrix (Zanno et al.,

1180 2015; Drymala \& Zanno, 2016) recover Kayentasuchus as the sister taxon of Crocodyliformes, 
1181 with one of the synapomorphies that support this topology being the maxilla ventral to the

1182 antorbital fossa is of constant depth. However, the maxilla beneath the antorbital fenestra of

1183 Kayentasuchus is not of constant depth, it tapers posteriorly (Fig. 15B) (UCMP 131830; Clark \&

1184 Sues, 2002). This character is described as: "Maxilla, posterior portion ventral to the antorbital

1185 fenestra: (0) tapers posteriorly; (1) has a similar dorsoventral depth as the anterior portion ventral

1186 to the antorbital fenestra; (2) expands dorsoventrally at the posterior margin of the maxilla"

1187 (character 27; pp. 65-66). This character was recently revised slightly by Butler et al. (2014) but

1188 the scoring in crocodylomorphs was not changed. However, this character has some issues

1189 regarding the definition of its states. In particular the difference between the states "taper

1190 posteriorly" and "approximately constant in dorsoventral depth" is generally not distinct (Fig.

1191 15). Taxa such as Dromicosuchus (Sues et al., 2003), Hesperosuchus agilis (CM 29894) (Fig.

1192 15D) and Junggarsuchus (Fig. 15C) (IVPP V 14010; coded by Drymala and Zanno, 2016) were

1193 coded as having the condition "aproximately constant in depth" when the morphology is not

1194 significantly different from the one present in Litargosuchus (BP/1/5237) or Dibothrosuchus

1195 (Fig. 15A) (IVPP V 7907), which were scored as tapering posteriorly. Additionally, other taxa

1196 like Sphenosuchus (Nesbitt, 2011) and Carnufex (Zanno et al., 2015; Drymala \& Zanno, 2016)

1197 were scored as having maxillae with approximately constant depths. However, in both taxa this

1198 region is incompletely preserved (SAM-PK 3014; Drymala \& Zanno, 2016), and this character

1199 cannot be scored. Finally, the antorbital fenestra of crocodyliforms is much smaller than that of

1200 non-crocodyliforms, and it is not clear that the depth of the maxilla ventral to it is comparable in

1201 taxa with fenestrae of different sizes. After evaluating the morphology of non-crocodyliform

1202 crocodylomorphs, the only taxon that has a markedly different maxillary morphology ventral to

1203 the antorbital fossa is Kayentasuchus (Fig. 15B). In Kayentasuchus (UCMP 131830) the anterior 
1204 part of the maxilla ventral to the antorbital fossa is much taller dorsoventrally than the posterior

1205 part, as the anterior height is almost twice that of the posterior part. This morphology is unique to

1206 Kayentasuchus and seems to be an autapomorphy of the taxon. Thus, given the issues

1207 highlighted above we decided not to include this character in our analysis.

1208

1209 Phylogenetic analysis

1210

The resulting dataset was analyzed using TNT v 1.5 (Goloboff, Farris \& Nixon, 2008a,

1211

2008b). Unlike most previous analyses using this dataset, we used Gracilisuchus to root the trees

1212

given that it was recently recovered as one of the basal most suchians (Nesbitt, 2011; Butler et

1213

al., 2014). The analysis consisted of a heuristic search using 1000 RAS, saving up to ten equally

1214

parsimonious trees per replicate (hold $=10$ ), and the trees found were subjected to a final round

1215

of TBR. Ten most parsimonious trees (MTPs) were recovered $(\mathrm{L}=348 ; \mathrm{CI}=0.460 ; \mathrm{RI}=0.778)$,

1216

found in 735 of the 1000 replicates. The branch swapping of these trees found no additional

1217

MPTs, securing that all the optimal trees were recovered in the analysis. The only difference

1218

among the MPTs is related to the relationships among the three notosuchians included in the

1219

dataset and the relationships among basal crocodylomorphs involving the "large bodied

1220

crocodylomorphs" (Fig. 16). However, the polytomy recovered in our analysis at the base of

1221

Crocodylomorpha is similar to the one obtained by Drymala \& Zanno (2016), with the addition

1222

that Erpetosuchus is also involved in this uncertainty.

1223

Unlike previous analyses using this dataset (Clark et al., 2004; or with modifications in

1224 Pol et al., 2013) we recovered a well-resolved topology for basal crocodylomorphs. Also,

1225 consistent with previous more inclusive datasets (Nesbitt, 2011; Drymala \& Zanno, 2016)

1226 Saurosuchus was recovered at a more basal position than Postosuchus, and the latter 
1227 (representing the rauisuchids) is the sister taxon of crocodylomorphs + Erpetosuchus + 1228 CM73372 + Redondavenator + Carnufex. Our results support the hypothesis of most recent 1229 papers with a focus on the relationships of Crocodylomorpha (Clark et al., 2004; Nesbitt, 2011; 1230 Pol et al., 2013), as we recovered a paraphyletic Sphenosuchia. The taxon that is the focus of this 1231 contribution, Macelognathus, was recovered forming a group with Almadasuchus and Hallopus 1232 that is sister to Crocodyliformes, corroborating Pol et al.'s (2013) initial hypothesis (Fig. 16). 1233 The relationships among non-crocodyliform crocodylomorphs are consistent with most previous 1234 analyses (Clark, 2004; Pol et al., 2013), but contrast strongly with Nesbitt's (2011) and Drymala 1235 \& Zanno's (2016) results for crocodylomorphs, which did not include Macelognathus, 1236 Almadasuchus, or Hallopus and only the latter authors included Junggarsuchus. In those 1237 analyses, Litargosuchus and Kayentasuchus (and also Terrestrisuchus, either in a polytomy with 1238 or as the sister group of Dibothrosuchus) were found as successive sister groups of 1239 Crocodyliformes, while we recovered these taxa in much more basal phylogenetic positions 1240 within Crocodylomorpha. However, and as in the more inclusive analyses mentioned above 1241 (Nesbitt 2011; Drymala \& Zanno, 2016), we also recovered CM 73372, Carnufex and 1242 Redondavenator at the base of Crocodylomorpha. Synapomorphies supporting this topology are 1243 going to be treated on the following section.

1244 CM 73372, Redondavenator, and Carnufex are recovered as the most basal 1245 crocodylomorphs (using the stem-based definition of Nesbitt, 2011), placed in a basal polytomy 1246 with Erpetosuchus (Fig. 16). This lack of resolution is mainly due to the fragmentary nature of 1247 these taxa and the very little anatomical overlap between the known specimens of CM 73372 , 1248 Redondaventor, Carnufex and the Erpetosuchus specimens. The elongate preacetabular process 1249 of the ilium is not mapped as a synapomorphy grouping CM 73372 and crocodylomorphs, as the 
1250 unknown condition in Erpetosuchus of this character makes this ambiguous. Both

1251 synapomorphies retrieved in our analysis joining these taxa with crocodylomorphs are absent in

1252 CM 73372, as these are cranial: maxillae meet to form a secondary palate (char. 3-1; Clark, 1253 1994) and the absence of postfrontal bones (char. 8-1; Benton \& Clark, 1988). A group of large 1254 pseudosuchians has been recovered previously as basal crocodylomorphs ("large-bodied 1255 crocodylomorphs" sensu Drymala \& Zanno, 2016). In our strict consensus the smaller bodied 1256 Erpetosuchus is retrieved as a basal crocodylomorph, however this result should be considered 1257 preliminary, as our dataset lacks an extensive sampling of basal pseudosuchians and a detailed 1258 revision of the basal-most crocodylomorphs is still needed.

The derived features shared by taxa traditionally recognized as crocodylomorphs have been discussed extensively in various contributions (Walker, 1970; Clark, 1986; Benton \& Clark, 1988; among many others latter papers), and these will not be discussed here. However, typical crocodylomorph anatomical features are not recovered as synapomorphies in our anaylsis (e.g., the postglenoid process of the coracoids, elongated proximal carpals [see Supplementary Information]) due to the missing data in Erpetosuchus and the "large bodied" crocodylomorphs causing ambiguous optimizations of those characters. A single synapomorphy supports the node that groups the classic or "small-bodied" taxa plus crocodyliforms, which is the lack of an ectepicondylar groove in the humerus (char. 136-1; Benton \& Clark, 1988). resolution is observed in the strict consensus. However, this topology should be treated with caution, as many nodes are supported by a single synapomorphy, and the incorporation of new

1271 material or more characters might alter the topology. Near the base of Crocodylomorpha is a 1272 clade composed of Pseudhesperosuchus and Trialestes (Fig. 16). A basal position for 
1273 Pseudhesperosuchus has been previously suggested (Benton \& Clark, 1988; Wu \& Chaterjee,

1274 1993; Sues et al., 2003; Lecuona, Ezcurra \& Irmis, 2016), but its grouping at the base with

1275 Trialestes is new to this analysis. This clade is diagnosed by a single synapomorphy: the lack of

1276 a well developed olecranon process (char. 117-1). The basal position of these taxa is given by the

1277 presence of elongated anterior parts of the facial portion of the maxillae, unlike the condition in

1278 more derived forms where this region is shorter than the posterior one (char. 2-1; Clark, 1994).

1279 One node closer to crocodyliforms a clade composed of Saltoposuchus, Terrestrisuchus

1280 and Litargosuchus is recovered (Fig. 16). This clade could be identified as Saltoposuchidae

1281 Crush, 1984, if further corroborated. As previously mentioned this group is characterized by a

1282 single synapomorphy, which is a distally projected fibular condyle of the femur with respect to

1283 the medial one (char. 94-1; Pol et al., 2013). Terrestrisuchus and Litargosuchus are nested within

1284 this clade, more closely related than with Saltoposuchus, and this topology is supported by the

1285 following synapomorphies: a ridge along the border of the supratemporal fossa on the squamosal

1286 (char. 12-1; Clark, 1994); medial margins of the supratemporal fossae separated by a broad, flat

1287 area (char. 18-1; Clark, 1994); and, a very wide anterior process of the squamosal in dorsal view

1288 (char. 109-1).

1289

A clade of North American crocodylomorphs is recovered as more closely related to

1290

1291

1292

1293

1294

1295

crocodyliforms than the clade formed by Saltoposuchus, Terrestrisuchus and Litargosuchus (Fig.

16). The clade is formed by Hesperosuchus, Dromicosuchus and Kayentasuchus, with the inclusion of the latter being new to this analysis as it was recovered as the sister taxon of Crocodyliformes in some recent analyses (Nesbitt, 2011; Drymala \& Zanno, 2016). The presence of a crest on the dorsal surface of the frontal (char. 9-1; Clark, 1994), a ventral exposure of the splenials on the mandibular symphysis (char. 84-1; Ortega et al., 1996), and an elongated 
1296 posterodorsal process of the postorbital (char. 101-1) support this group as closer to 1297 crocodyliforms. This clade of North American crocodylomorphs is diagnosed by the presence of 1298 a dorsomedial projection of the articular (char. 27-1; Clark, 1986; paralleled in Protosuchus and 1299 unknown in Kayentasuchus), and a well-defined antorbital fossa all around its circumference 1300 (char. 137-1; Drymala \& Zanno, 2016). Dromicosuchus and Kayentasuchus are more closely 1301 related based on femoral characters: the presence of a pseudointernal trochanter (char. 92-1; Pol 1302 et al., 2013) and a ridge-like fourth trochanter (char. 93-1; Pol et al., 2013).

The topology that groups Sphenosuchus, Dibothrosuchus, Junggarsuchus and 1304 hallopodids with crocodyliforms is quite stable in this dataset and has been recovered in other 1305 analyses (Clark et al., 2004; Pol et al., 2013), even when the more basal nodes were very badly resolved. This contrasts with the more basal position recovered in Nesbitt's analysis (and analyses derived from that study [e.g., Lecuona, Ezcurra \& Irmis, 2016]), where Sphenosuchus was placeded more basally within Crocodylomorpha. The presence of completely sutured parietals (16-2; Clark, 1994), a sagittal crest separating the medial margin of the supratemporal fossae (char. 18-1; Clark, 1994), and a coracoid with a very elongated postglenoid process (char. 29-2; Clark, 1994) support this clade of derived crocodylomorphs. As in previous analyses (Pol et al., 2013), Junggarsuchus is recovered as the sister group of hallopoids (see below) + 1313 Crocodyliformes. This phylogenetic position is supported by the following synapomorphies: an 1314 expanded basisphenoid (char. 35-1; Clark, 1994); the exoccipitals contact the quadrate, enclosing 1315 the passage for the interal carotids (char. 36-1; Clark, 1994); large post-temporal fenestrae 1316 enclosed by the squamosal and the exoccipitals, with the lateral edge close to the supraoccipital 1317 (74-1; Pol et al., 2013); and, a radius shorter than the humerus (107-1). The later is new to this 
1318 analysis and is paralleled in Saltoposuchus and variably present in Hesperosuchus (see Character 1319 Sampling). Almadasuchus is found forming a clade with Macelognathus and Hallopus, the

1321

1322

1323

1324

1325

1326

1327

1328

1329

1330

1331

1332

1333

1334

1335

1336

1337

1338

1339

1340

Hallopodidae, which is the sister group of Crocodyliformes (Fig. 16). Most of the characters that support the position of this clade as the sister group of Crocodyliformes were already reviewed by Pol et al. (2013), who did not include Macelognathus and Hallopus in their analysis, nonetheless we identified three new characters supporting this topology: a wide supraoccipital in posterior view (char. 98-1), a quadrate-laterosphenoid contact (char. 99-1), and the cranial nerves IX-XI exiting through a common foramen (foramen vagi, char. 105-1). This clade of Late Jurassic forms can be diagnosed by the following synapomorphies: the presence of a cranioquadrate passage that is not in the lateral border of the skull (char. 77-2; Clark, 1994); femoral head and distal condyles of the femur having parallel long axes (char. 90-1; Pol et al., 2013); a trochanteric crest on the femur (char. 91-0; Pol et al., 2013); and, a pseudointernal trochanter in the posterolateral end of the proximal end of the femur (char. 92-1; Pol et al., 2013; paralleled in Kayentasuchus + Dromicosuchus). Unlike the Argentinean form, Macelognathus and Hallopus share the reduction of the fourth trochanter to a sharp ridge (char. 93-1; Pol et al., 2013; paralleled in Kayentasuchus + Dromicosuchus).

Support measures are all low, exhibiting Bremer values of one and jackknife/bootstrap values well below 50 on the internal nodes of Crocodylomorpha. However when the different positions of very incomplete taxa like Carnufex, Redondavenator, and Trialestes are ignored in the calculations, support measures increase significantly. Also if the different phylogenetic postions of Litargosuchus are ignored in suboptimal trees support measures increase significantly, as it was noted above that with two extra steps this taxon was positioned as the 
1341 sister group of Crocodyliformes. Under these circumstances the nodes that display a higher

1342 support (Bremer support = 3) are the one grouping the "small-bodied" crocodylomorphs, the one

1343 grouping the Jurassic non-crocodyliform crocodylomorphs (Sphenosuchus + Dibothrosuchus +

1344 Junggarsuchus + hallopoids + Crocodyliformes), Hallopodidae + Junggarsuchus +

1345 Crocodyliformes and other crocodyliform internal nodes. Another relatively well-supported node

1346 is the one grouping the North American crocodylomorphs (Hesperosuchus + Dromicosuchus +

1347 Kayentasuchus), as it shows Bremer values of 2. Unfortunately, the Hallopodidae only has a

1348 Bremer support of one (1), as in some suboptimal trees Almadasuchus is depicted as the sister

1349 taxon of Crocodyliformes

1350 To test the robustness of our analysis we considered different topologies obtained in 1351 recent analyses. First, we tried testing a monophyletic Sphenosuchia (Bonaparte, 1972b), forcing 1352 all non-crocodyliform crocodylomorph taxa to form the sister clade of Crocodyliformes. In order 1353 to retrieve such a monophyletic group (i.e., a clade including all non-crocodyliform 1354 crocodylomorphs) nine to eighteen extra steps are required, depending on whether CM 73372 is 1355 part of this artificial clade. Thus, the idea of a monophyletic Sphenosuchia is highly suboptimal 1356 in this dataset. On the other hand, our analysis differs from the results recently obtained by 1357 Nesbitt (2011), Zanno et al. (2015) and Drymala \& Zanno (2016). In these analyses 1358 Terrestrisuchus, Litargosuchus and Kayentasuchus were found as very closely related to 1359 Crocodyliformes, in particular the latter two where found as successive sister groups of 1360 Crocodyliformes. In our data set to set either Terrestrisuchus or Kayentasuchus as sister group to 1361 Crocodyliformes implies highly suboptimal hypothesis, as they require 10 and 8 extra steps 1362 respectively. However, a similar position solely for Litargosuchus is not a highly suboptimal 1363 topology, as 1 extra steps are required to place this taxon as the sister taxon of Crocodyliformes. 
1364 This hypothesis finds support from the conditions present in the squamosal (broad anterodorsal 1365 process), parietal (broad area separating the supratemporal fossae) and postcranial skeleton (the 1366 postglenoid process), among other characters, of Litargosuchus. Unfortunately, due to the 1367 preservation of the only known specimen, no data can currently be retrieved on the braincase of 1368 the specimen.

Finally, Wilberg (2015) has recently underscored the importance of taxon sampling of basal crocodylomorphs for inferring the position of thalattosuchians, noting the latter can be retrieved as the sister group of Crocodyliformes (rather than within it) in some cases. A critical review of Wilberg's data set is beyond the scope of the present paper but we have tested the impact of alternative positions of Thalattosuchia in the phylogeny of basal Crocodylomorpha within the context of our dataset. The basal position for Thalattosuchia as the sister group of Crocodyliformes requires 13 extra steps $(\mathrm{L}=361)$. Forcing this topology also implies great changes in the strict consensus, as under this constraint we recover a large clade formed by almost every "sphenosuchian" with the exception of Litargosuchus, Pseudhesperosuchus, Erpetosuchus and the "large bodied crocodylomorphs" (see Supplementary Information). However, it is important to note that two clades still remain from the optimal topology: the North American clade (Hesperosuchus + Dromicosuchus + Kayentasuchus) and Hallopodidae (with the possible inclusion of Junggarsuchus to this clade). A further similarity to the unconstrained 1382 analysis is the close relationship between the Sphenosuchus, Dibothrosuchus and the hallopodids + Junggarsuchus, however these do not form a monophyletic clade with the crocodyliforms as in 1384 the optimal topology.

1385

1386

\section{Discussion}




\section{Taxonomic status of Macelognathus vagans}

The taxonomic status of Macelognathus vagans has been subject to debate among recent years. Most of these questions are based on two main topics: the similarities between Macelognathus vagans Marsh, 1884 and Hallopus victor Marsh, 1881; and, the provenance of the latter taxon. The similarities between Macelognathus and Hallopus were noted by Göhlich et al (2005) when they described new postcranial elements assigned to Macelognathus. However most of the similarities noted (e.g., lack of supraacetabular crest) are widely present among noncrocodyliform crocodylomorphs. On the other hand, differences noted by these authors are based on proportions of certain elements that are very difficult to compare, such as the lateromedial development of the calcaneal tuber. The only trait that might shed some light on this matter (a dorsoventrally oriented crest on the medial surface of the calcaneal tuber) is not exposed in Hallopus, precluding any significant comparison. published. As clearly shown by Schuchert (1939) and Walker (1970), neither Marsh nor his collector Baldwin retrieved the specimen themselves. Baldwin bought the specimen from a collector in Colorado Springs (Colorado, USA) and later checked the outcrops for additional material. Based on letters from Baldwin to Marsh, Shuchert (1939) concluded that the type specimen of Hallopus was retrieved from "The Nipple" area, which exposes a horizon assigned to the top of the Morrison Formation. However, subsequently Norell \& Storrs (1989) challenged this view claiming that no beds such as the ones where Hallopus was found were known anywhere in the Morrison Formation. Thus, these authors suggested that it may come from levels 
1409 of the underlying Ralston Formation (Callovian) from Oil Creek Canyon. Finally, Ague,

1410 Carpenter \& Ostrom (1995) revisited "The Nipple” locality and recognized similar brownish/red

1411 levels in the top of the Morrison Formation. Furthermore, petrographic analyses showed that

1412 their samples and the ones from the matrix of the Hallopus specimen were almost identical

1413 (poorly sorted arkosic wackes). As a result they concluded that Hallopus was recovered from the

1414 upper levels of the Morrison Formation (Ague, Carpenter \& Ostrom, 1995). Accepting these

1415 observations makes both taxa (Macelognathus and Hallopus) roughly coincident both in time

1416 and space (although the Fruita specimen is from lower in the upper part of the Morrison

1417 Formation and about $300 \mathrm{~km}$ away from The Nipple), facilitating the synonymy hypothesis.

Unfortunately, from our contribution little new information can be added to solve this

1419 problem as we describe the braincase of Macelognathus, a region unknown in Hallopus.

1420 Nevertheless, our results do find Macelognathus and Hallopus as sister taxa. Given the

1421 similarities and the occurrence of both taxa in the same formation, the potential synonymy

1422 (Macelognathus vagans Marsh, 1884 being a junior synonym of Hallopus, Marsh 1881) has to

1423 be considered. Further preparation of the only known specimen of Hallopus (YPM 1914) or

1424 more material of this taxon, especially crania, would help to solve this uncertainty.

\section{Phylogenetic position of Macelognathus and its implications}

In spite of the low support in our analysis in some nodes of the consensus tree, some conclusions about the general pattern of the results can be extracted. Unlike some other modern crocodylomorph phylogenetic analyses (Clark et al, 2004; Pol et al., 2013) a well resolved phylogenetic hypothesis is here recovered, although with low support values. This is also 
1431 valuable when it is considered that our dataset includes the largest number of non-crocodyliform

1432 crocodylomorphs than in any other analysis (e.g., Clark, Sues \& Berman, 2000; Clark et al.,

1433 2004; Nesbitt, 2011; Pol et al., 2013; Zanno et al., 2013; Drymala \& Zanno, 2016).

Among basal crocodylomorphs, especially near the base of the clade, a general pattern of

1435

1436

1437

1438

1439

1440

1441

1442

1443

1444

1445

1446

1447

1448

1449

1450

1451

1452

1453

small clades that soon go extinct can be recognized. Also these clades have a very important geographic influence, as basically Argentinean (Pseudhesperosuchus + Trialestes) and North American (Hesperosuchus + Dromicosuchus + Kayentasuchus) groups can be recognized. The former is positioned as the most basal clade among crocodylomorphs, while the latter is more closely related to derived crocodylomorphs such as Sphenosuchus and Dibothrosuchus. More basally a clade of mainly European forms is recognized (Terrestrisuchus and Saltoposuchus, which are sometimes synonymized), with the incorporation of the South African taxon Litargosuchus. All these clades represent several diversification pulses that took place in the Late Triassic among crocodylomorphs. While the basal clade formed by Trialestes and Pseudhesperosuchus is restricted to the Late Triassic, the other basal clades extend well into the Early Jurassic, in both cases represented by the most specialized members of the clade (Litargosuchus and Kayentasuchus).

Among the basal crocodylomorphs closest to Crocodyliformes we recovered a clade formed by the Late Jurassic Almadasuchus + Macelognathus + Hallopus, and its monophyly is not sensitive to the position of Thalattosuchia within Crocodylomorpha in the context of our dataset. Although their anatomy is very incompletely known, the Hallopodidae is characterized by a reduction of cranial kinesis (Pol et al., 2013) and several cursorial modifications (as highly elongated radiale, well projected femoral head, presence of additional trochanters on the femora). This clade of derived crocodylomorphs shares many derived traits also present in basal 
1454 crocodyliforms (e.g., wide supraoccipitals, a quadrate laterosphenoid contact [see Phylogenetic

1455 analysis]) and some other traits present in more derived crocodyliforms (such as the presence of

1456 a cranioquadrate passage and the posterior closure of the otic notches). The phylogenetic position

1457 of this group as the sister group of Crocodyliformes implies a large amount of unsampled record

1458 (ghost lineage [Norell, 1992]) due to the presence of the crocodyliform Hemiprotosuchus in the

1459 Late Triassic (Kent et al., 2014). Thus, many traits recovered as synapomorphies of this group of

1460 Late Jurassic crocodylomorphs could be product of parallelisms with Crocodyliformes. More

1461 Jurassic crocodylomorphs remains, especially for the Middle and Late parts of this period, will

1462 be crucial to evaluate the evolution of these forms.

1463

1464 Conclusions

1465

A partial braincase assigned to Macelognathus vagans Marsh, 1884 is described in this

1466

contribution. The use of computed tomography allowed us to study the internal morphology of

1467

this specimen and enabled us to identify structures that otherwise would not be visible.

1468

Furthermore, this study represents the first non-crocodyliform crocodylomorph that has been

1469

subjected to CT scanning. Scans of other crocodylomorph braincases will undoubtedly reveal

1470

similar complexity and should be attempted soon.

1471

Although incomplete, the braincase of Macelognathus has many traits that allowed us to

1472 recognize its affinities among derived crocodylomorphs (e.g., an expanded and pneumatized

1473 basisphenoid; a pneumatized quadrate; a quadrate-otoccipital contact; a wide supraoccipital; a

1474 cranioquadrate passage). In particular, Macelognathus was recovered as a member of a highly

1475 derived group of Late Jurassic crocodylomorphs together with Almadasuchus from Argentina 
1476 and Hallopus from the USA. These forms are highly cursorial, have large otic notches and a

1477 higher integration of the quadrate with their braincases when compared with more basal forms.

1478 Their position as the sister group of crocodyliforms is very interesting, as they allow a better

1479 understanding of the transformations from the typical kinetic skulls of reptiles (Holliday \&

1480 Witmer, 2008) to the typical akinetic skulls of extant crocodylians and crocodyliforms

1481 (Langston, 1973; Pol et al, 2013).

Finally, we compiled a data set incorporating most non-crocodyliform crocodylomorphs

1483

1484

1485

1486

1487

1488

1489

1490

1491

1492

1493

1494

1495

1496

1497

\section{Abbreviations}

AMNH, American Museum of Natural History (Fossil Reptiles), New York, United

States; NHMUK, Natural History Museum, London, U.K.; BSP, Bayerische Staatssammlung fur Palaontologie und Geologie, Munich, Germany; BP, Evolutionary Studies Institute (formerly Bernard Price Institute for Palaeontological Research), University of the Witwatersrand, Johannesburg, South Africa; CM, Carnegie Museum of Natural History, Pittsburg, United 
1498 States; IVPP, Institute of Vertebrate Paleontology and Paleoanthropology, Chinese Academy of

1499 Sciences, Beijing, China; LACM, Natural History Museum of Los Angeles County, Los

1500 Angeles, United States; MACN, Museo Argentino de Ciencias Naturales, Buenos Aires,

1501 Argentina; MCZ, Museum of Comparative Zoology, Cambridge, United States; MLP, Museo de

1502 La Plata, La Plata, Argentina; MPEF, Museo Paleontológico Egidio Feruglio, Trelew,

1503 Argentina; PVL, Museo Miguel Lillo, San Miguel de Tucumán, Argentina; PVSJ, Museo de

1504 Ciencias Naturales, Universidad Nacional de San Juan, San Juan, Argentina; SAM, Iziko South

1505 African Museum, Cape Town, South Africa; SMNS, Staatliches Museum fur Naturkunde,

1506 Stuttgart, Germany; UCMP, University of California Museum of Paleontology, Berkeley, United

1507 States; UFGRS, Universidade Federal do Rio Grande Do Sul, Porto Alegre, Brasil; UFRJ,

1508 Universidade Federal do Rio do Janeiro, Rio do Janeiro, Brasil; NCSM, North Carolina Museum

1509 of Natural Sciences; YPM, Yale Peabody Museum, New Haven, United States.

\section{Acknowledgments}

We would like to thank S. Goldberg, M. Hill and H. Towbin from the Microscopy and Imaging Facility of the American Museum of Natural History for their valuable help during the CT process and M. Norell for arranging for us to use it. The Academic Editor (M. Young) and two anonymous reviewers are thanked, as their suggestions greatly increased the final quality of the resulting manuscript. We are also thankful to L.M. Chiappe for allowing us to study this specimen under his care, and M. Walsh for helping with the loans of the specimen of

1518 Macelognathus. We are grateful to P. Mocho (LACM) for his help with the photos of the type 1519 specimen. Finally, K. Poole and M.A. Ordoñez are thanked for their help in the posterior 
1520 processing of the 3D meshes. TNT is a free program made available by the Willi Hennig Society.

1521 This is J.M.L.'s R-198 contribution to the Instituto de Estudios Andinos Don Pablo Groeber.

1522

1523 References

1524 Ague JJ, Carpenter K, Ostrom JH. 1995. Solution to the Hallopus enigma? American Journal of 1525 Science 295:1-17.

1526

Alcober O. 2000. Redescription of the skull of Saurosuchus galilei (Archosauria: Rauisuchidae).

1527 Journal of Vertebrate Paleontology 20:302-316.

1528

Andrews CW. 1913. A Descriptive Catalogue of the Marine Reptiles of the Oxford Clay. Part II.

1529

London: British Museum (Natural History).

1530

Bakker RT, Galton PM. 1974. Dinosaur monophyly and a new class of vertebrates. Nature 248:

1531

$168-172$.

1532

Baur G. 1891. Remarks on the reptiles generally called Dinosauria. American Naturalist 25:434-

1533 454.

Benton MJ, Clark JM. 1988. Archosaur phylogeny and the relationships of the Crocodylia. In:

1535

Benton MJ, ed. The Phylogeny and Classification of Tetrapods, Volume 1: Amphibians,

1536

Reptiles, Birds. Oxford: Clarendon Press, 295-338.

1537 Bonaparte JF. 1972a. Los tetrápodos del sector superior de la Formación Los Colorados, La

1538 Rioja, Argentina (Triásico Superior). 1 Parte. Opera Lilloana 22:1-183. 
1539 Bonaparte JF. 1972b.Pedeticosaurus leviseuri Van Hoepen, a probable protosuchian. Navorsinge

1540 van die Nasionale Museum, Bloemfontein 2:301-305.

1541 Brazeau MD. 2011. Problematic character coding methods in morphology and their effects.

1542 Biological Journal of the Linnean Society 104:489-498.

1543 Brochu C.A. 1992. Ontogeny of the postcranium in crocodylomorph archosaurs. Ms. Thesis,

1544 University of Texas at Austin, Texas.

1545 Brusatte SL, Muir A, Young MT, Walsh S, Steel L, Witmer LM The braincase and neurosensory

1546 anatomy of an Early Jurassic marine crocodylomorph: implications for crocodilian sinus

1547 evolution and sensory transitions. The Anatomical Record 299:1551-1530.

1548 Busbey ABIII, Gow C. 1984. A new protosuchian crocodile from the Upper Triassic Elliot

1549 Formation of South Africa. Palaeontologia Africana 25:127-149.

1550 Butler RJ, Sullivan C, Ezcurra MD, Liu J, Lecuona A, Sookias RB. 2014. New clade of

1551 enigmatic early archosaurs yields insights into early pseudosuchian phylogeny and

1552 biogeography of the archosaur radiation. BMC Evolutionary Biology. doi:10.1186/1471-2148-

$1553 \quad 14-128$

1554 Carvalho IS, Campos ACA, Nobre PH. 2005. Baurusuchus salgadoensis, a New

1555 Crocodylomorpha from the Bauru Basin (Cretaceous), Brazil. Gondwana Research 8:11-30.

1556 Clark JM. 1986. Phylogenetic relationships of the crocodylomorphs archosaurs. D. Phill. Thesis, 1557 University of Chicago. 
1558 Clark JM. 1994. Patterns of evolution in Mesozoic Crocodyliformes. In Fraser NC, Sues H-D, 1559 eds. In the Shadow of the Dinosaurs, Early Mesozoic Tetrapods. Cambridge: Cambridge 1560 University Press, 84-97.

1561 Clark JM. 2011. A new shartegosuchid crocodyliform from the Upper Jurassic Morrison 1562 Formation of western Colorado. Zoological Journal of the Linnean Society 163:S152-S172.

1563 Clark JM, Sues H-D, Berman DS. 2000. A new specimen of Hesperosuchus agilis from the 1564 Upper Triassic of New Mexico and the interrelationships of basal crocodylomorph archosaurs. 1565 Journal of Vertebrate Paleontology 20:683-704.

1566 Clark JM, Sues H-D. 2002. Two new basal crocodylomorph archosaurs from the Lower Jurassic 1567 and the monophyly of the Sphenosuchia. Zoological Journal of the Linnean Society 136:77-95.

1568 Clark JM, Xu X, Forster CA, Wang Y. 2004. A Middle Jurassic “sphenosuchian” from China 1569 and the origin of the crocodilian skull. Nature 430:1021-1024.

Colbert EH. 1946. Sebecus, representative of a peculiar suborder of fossil Crocodylia from 1571 Patagonia. Bulletin of the American Museum of Natural History 87:2017-270.

Cope ED. 1869. Synopsis of the extinct Batrachia, Reptilia, and Aves of North America. Transactions of the American Philosophical Society 14:1-252.

Crush PJ. 1984. A late Upper Triassic sphenosuchid crocodilian from Wales. Palaeontology 1575 27:131-157.

Drymala SA, Zanno LE. 2016. Osteology of Carnufex carolinensis (Archosauria: Pseudosuchia)

1577 from the Pekin Formation of North Carolina and its implications for Early Crocodylomorph 1578 Evolution. PLoS ONE 11 (6):e0157528. Doi: 10.137/journal.pone.0157528. 
1579 Ezcurra MD, Lecuona A, Irmis RB. 2008. A review of the archosaur Trialestes romeri (Suchia, 1580 Crocodylomorpha) from the Upper Triassic Ischigualasto Formation of Argentina. Libro de 1581 Resúmenes III Congreso Latinoamericano de Paleontología de Vertebrados: 88.

1582 Foster JR. 2003. Paleoecological analyses of the vertebrate fauna of the Morrison Formation 1583 (Upper Jurassic), Rocky Mountain Region, USA. New Mexico Museum of Natural History and 1584 Science Bulletin 23: 1-95.

1585 Gauthier JA. 1986. Saurischian monophyly and the origin of birds. Memoirs of the California 1586 Academy of Science 8:1-55.

1587 Göhlich UB, Chiappe LM, Clark JM, Sues H-D. 2005. The systematic position of the Late 1588 Jurassic alleged dinosaur Macelognathus (Crocodylomorpha: Sphenosuchia). Canadian Journal 1589 of Earth Sciences 42:307-321. DOI: 10.1139/E05-005.

1590 Goloboff P A, Farris JS, Nixon KC. 2008a. TNT, a free program for phylogenetic analysis. 1591 Cladistics 24:774-786.

1592 Goloboff PA, Farris JS, Nixon KC. 2008b. TNT: Tree Analysis Using New Technologies. 1593 Available at http://www.lillo.org.ar/phylogeny. Accessed April 2, 2016.

1594 Hay, OP 1930 Second Bibliography and Catalogue of Fossil Vertebrata of North America. 2 1595 vols. Washington, DC: Carnegie Institute of Washington.

1596 Holliday CM, Witmer LM. 2008. Cranial kinesis in dinosaurs: intracranial joints, protractor 1597 muscles, and their significance for cranial evolution and function in diapsids. Journal of 1598 Vertebrate Paleontology 28:1073-1088. 
1599 Iordansky NN. 1973. The skull of Crocodylia. In: Gans C, Parsons TS, eds. Biology of Reptilia, 1600 Vol. 4. New York: Academic Press, 201-264.

1601

1602

1603

1604

1605

1606

1607

1608

1609

1610

1611

1612

1613

1614

1615

1616

1617

1618

1619
Jouve S. 2009. The skull of Teleosaurus cadomensis (Crocodylomorpha; Thalattosuchia), and phylogenetic analysis of Thalattosuchia. Journal of Vertebrate Paleontology 29:88-102.

Kent DV, Malnis PS, Colombi CE, Alcober OA, Martínez RN. 2014. Age constrains on the dispersal of dinosaurs in the Late Triassic from magnetochronology of the Los Colorados Formation (Argentina). Proceedings of the National Academy of Sciences 111:7958-7963.

Kley NJ, Sertich JW, Turner AH, Krause DW, O’Connor PM, Georgi JA. 2010. Craniofacial morphology of Simosuchus clarki (Crocodyliformes: Notosuchia) from the Late Cretaceous of Madagascar. Society of Vertebrate Paleontology Memoir 10:13-98.

Langston W J. 1973.The crocodylian skull in historical perspective. In Gans C, Parsons TS, eds The Biology of the Reptilia (Volume 4). London: Academic Press, 263-284.

Lecuona A, Desojo JB. 2012. Hind limb osteology of Gracilisuchus stipanicorum (Archosauria: Pseudosuchia). Earth and Environmental Science Transactions of the Royal Society of Edinburgh 102:105-128.

Lecuona A, Ezcurra MD, Irmis RB. 2016. Revision of the early crocodylomorph Trialestes romeri (Archosauria, Suchia) from the lower Upper Triassic of Ischigualasto Formation of Argentina: one of the oldest-known crocodylomorphs. Papers in Palaeontology:1-38.

Leardi JM. 2013. Evolución de la función locomotora durante la diversificación de Archosauria: Patrones de cambio anatómico-funcional de la cintura escapular y el miembro anterior. D. Phill. Thesis, Universidad de Buenos Aires. 
1620

1621

1622

1623

1624

1625

1626

1627

1628

1629

1630

1631

1632

1633

1634

1635

1636

1637

1638

1639

Li J, Wu X-C, Li X. 1994. New material of Hsisosuchus chungkingensis from Sichuan, China. Vertebrata Palasiatica 32:107-126.

Long RA, Murry PA. 1995. Late Triassic (Carnian and Norian) tetrapods from the southwestern United States. New Mexico Museum of Natural History and Science 4:1-254.

Marsh OC. 1881. Principal characters of American Jurassic dinosaurs. Part V. American Journal of Science 21:417-423.

Marsh OC. 1884. A new order of extinct Jurassic reptile (Macelognatha). American Journal of Science 27(3):341.

Mook CC. 1921. Notes on the postcranial skeleton in the Crocodylia. Bulletin of the American Museum of Natural History 44:69-100.

Nascimento PM, Zaher H. 2010. A new species of Baurusuchus (Crocodyliformes, Mesoeucrocodylia) from the Upper Cretaceous of Brazil, with the first complete postcranial skeleton described for the family Baurusuchidae. Papéis Avulsos de Zoologia 50:32-361.

Nash DS. 1975. The morphology and relationships of a crocodilian, Orthosuchus stormbergi, from the Upper Triassic of Lesotho. Annals of the South African Museum 67:227-329.

Nesbitt S. 2007. The anatomy of Effigia okeeffea (Archosauria, Suchia), theropod-like convergence, and the distribution of related taxa. Bulletin of the American Museum of Natural History 302:1-84.

Nesbitt SJ. 2011. The early evolution of archosaurs: relationships and the origin of major clades. Bulletin of the American Museum of Natural History 352:1-292. 
1640 Norell MA. 1992. Taxic origin and temporal diversity: the effect of phylogeny. In Novacek MJ,

1641 Wheeler QD, eds Extinction and Phylogeny. New York: Columbia University Press, 89-118.

1642 Norell MA, Storrs GW. 1989. Catalogue and Review of the Type Fossil Crocodilians in the Yale

1643 Peabody Museum. Postilla 203:1-27.

1644 Ortega F, Buscalioni AD, Gasparini Z. 1996. Reinterpretation and new denomination of

1645 Atacisaurus crassiproratus (Middle Eocene; Issel, France) as cf. Iberosuchus

1646 (Crocodylomorpha, Metasuchia). Geobios 29:353-364.

1647 Ostrom JH. 1971. On the systematic position of Macelognathus vagans. Postilla 153:1-10.

1648 Osmólska H, Hua S, Buffetaut E. 1997. Gobiosuchus kielanae (Protosuchia) from the Late

1649 Cretaceous of Mongolia: anatomy and relationships. Acta Paleontologica Polonica 4:257-289.

1650 Parrish JM. 1993. Phylogeny of the Crocodyotarsi, with reference to archosaurian and

1651 crurotarsan monophyly. Journal of Vertebrate Paleontology 13:287-308.

1652 Peyer K, Carter JG, Sues H-D, Novak SE, Olsen PE. 2008. A new suchian archosaur from the

1653 Upper Triassic of North Carolina. Journal of Vertebrate Paleontology 28:363-381.

1654 Pierce S, Benton MJ. 2006. Pelagosaurus typus Bronn, 1841 (Mesoeucrocodylia:

1655 Thalattosuchia) from the Upper Lias (Toarcian, Lower Jurassic) of Somerset, England. Journal

1656 of Vertebrate Paleontology 26:621-635.

1657 Pierce SE, Williams M, Benson RBJ. 2016. Virtual reconstruction of the brain and sinuses of the

1658 early Jurassic marine crocodylomorph Pelagosaurus typus (Thalattosuchia). PeerJ Preprints:

1659 https://doi.org/10.7287/peerj.preprints.2539v1 
1660 Pol D, Norell MA. 2004. A New Crocodyliform from Zos Canyon, Mongolia. American

1661 Museum Novitates 3445:1-36.

1662 Pol D, Gasparini Z. 2009.Skull anatomy of Dakosaurus andiniensis (Thalattosuchia:

1663 Crocodylomorpha) and the phylogenetic position of Thalattosuchia. Journal of Systematic

1664 Palaeontology 7:163-197.

1665 Pol D, Rauhut OWM, Lecuona A, Leardi JM, Xu X, Clark JM. 2013. A new fossil from the

1666 Jurassic of Patagonia reveals the early basicranial evolution and the origins of Crocodyliformes.

1667 Biological Reviews 88:862-872. DOI: 10.1111/brv.12030.

1668

1669

1670

1671

1672

1673

1674

1675

1676

1677

1678

1679

1680

Pol D, Nascimento PM, Carvalho AB, Riccomini C, Pires-Domingues RA, Zaher H. 2014. A new notosuchian from the Late Cretaceous of Brazil and the phylogeny of advanced notosuchians. PLoS ONE 9:e93105. DOI:20.1371/journal.pone.0093105.

Reig OA. 1963. La presencia de dinosaurios saurisquios en los "estratos de Ischigualasto" (Mesotriásico Superior) de las provincias de San Juan y La Rioja (República Argentina). Ameghiniana 3:3-20.

Schuchert C. 1939. The geological horizon of the dinosaurs Hallopus and Nanosaurus agilis. American Journal of Science 237:19-26.

Sereno PC, Wild R. 1992. Procompsognathus: theropod, "thecodont" or both? Journal of Vertebrate Paleontology 12:435-458.

Simpson GG. 19260 The fauna of quarry nine. American Journal of Science 12:1-11.

Sues H-D, Olsen PE, Carter JG, Scott DM. 2003. A new crocodylomorph archosaur from the Upper Triassic of North Carolina. Journal of Vertebrate Paleontology 23:329-343. 
1681 Trotteyn MJ, Desojo JB, Alcober OA. 2011. Nuevo material postcraneano de Saurosuchus

1682 galilei Reig (Archosauria: Crurotarsi) del Triásico Superior del Centro-Oeste de Argentina.

1683 Ameghiniana 48:13-27.

1684 von Huenne FRF. 1956. Paläontologie und Phylolgenie der Nierderen Tetrapoden. Jena: Gustav

1685 Fischer Verlag.

1686 Walker AD. 1961. Triassic reptiles from the Elgin area: Stagonolepis, Dasygnathus and their

1687 allies. Philosophical Transactions of the Royal Society of London, B 244:103-204.

1688 Walker AD. 1970. A revision of the Jurassic reptile Hallopus victor (Marsh) with remarks on the 1689 classification of the crocodiles. Philosophical Transactions of the Royal Society of London, B $1690 \quad 257: 323-372$.

1691

Walker AD. 1990. A revision of Sphenosuchus acutus Haughton, a crocodylomorph reptile from 1692 the Elliot Formation (late Triassic or early Jurassic) of South Africa. Philosophical Transactions 1693 of the Royal Society of London, B 330:1-120.

1694 Weinbaum JC. 2002. Osteology and relationships of Postosuchus kirkpatricki (Archosauria: 1695 Crurotarsi). Ms. Thesis, Texas Tech University.

Weinbaum JC. 2011. The skull of Postosuchus kirkpatricki (Archosauria: Paracrocodyliformes) from the Upper Triassic of the United States. PaleoBios 30:18-44.

Weinbaum JC, Hungerbühler A. 2007. A revision of Poposaurus gracilis (Archosauria: Suchia) based on two new specimens from the Late Triassic of the southwestern U.S.A.

1700 Palaöntologische Zeitschrift 81/2:131-145. 
1701 Wilberg EW. 2015. What's in an Outgroup? The Impact of Outgroup Choice on the Phylogenetic 1702 Position of Thalattosuchia (Crocodylomorpha) and the Origin of Crocodyliformes. Systematic 1703 Biology. DOI:10.1093/sysbio/syv020.

1704 Wu X-C, Chatterjee S. 1993.Dibothrosuchus elaphros, a crocodylomorph from the Lower 1705 Jurassic of China and the phylogeny of the Sphenosuchia. Journal of Vertebrate Paleontology $1706 \quad 13: 58-89$.

1707 Wu X-C, Sues H-D, Dong Z-M. 1997. Sichuanosuchu shuhanensis, a new ?Early Cretaceous 1708 Protosuchian (Archosauria: Crocodyliformes) from Sichuan (China), and the monophyly of 1709 Protosuchia. Journal of Vertebrate Paleontology 17:89-103.

1710 Zanno LE, Drymala S, Nesbitt SJ, Schneider VP. 2015. Early crocodylomorph increases top tier 1711 predator diversity during rise of dinosaurs. Scientific Reports 5:9276. DOI:10.1038/srep09276 1712 (2015). 


\section{Figure 1}

Posterior region of the skull of Macelognathus vagans (LACM 5572/150148).

A-B, dorsal; and, C-D, lateral view. Scale bar equals $1 \mathrm{~cm}$. Abbreviations: boc, basioccipital; bsf, basisphenoid; cqp, cranioquadrate passage; f, frontal; Isf, laterosphenoid; ota, otic aperture; otc, otic capsule; otoc, otoccipital; p, parietal; prf, prefrontal; pro, protic; q, quadrate; soc, supraoccipital. 
A

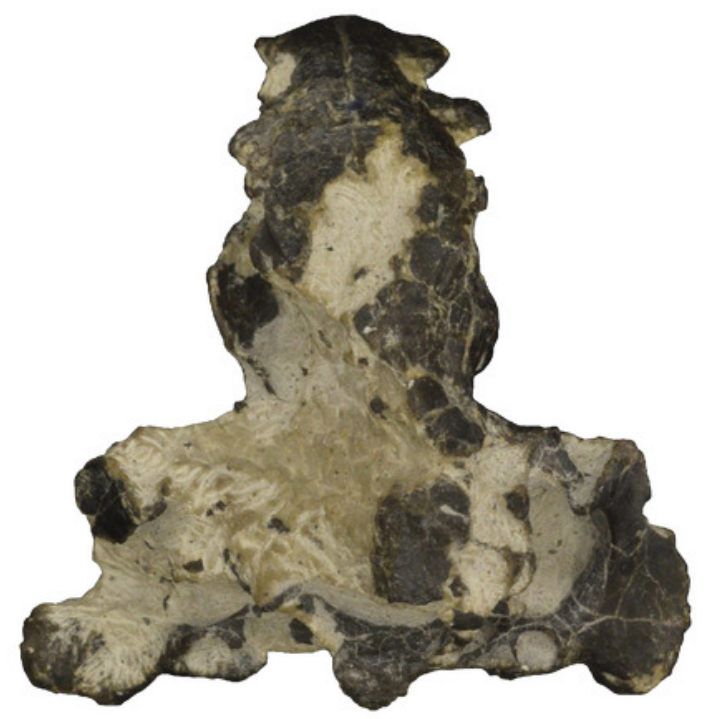

C

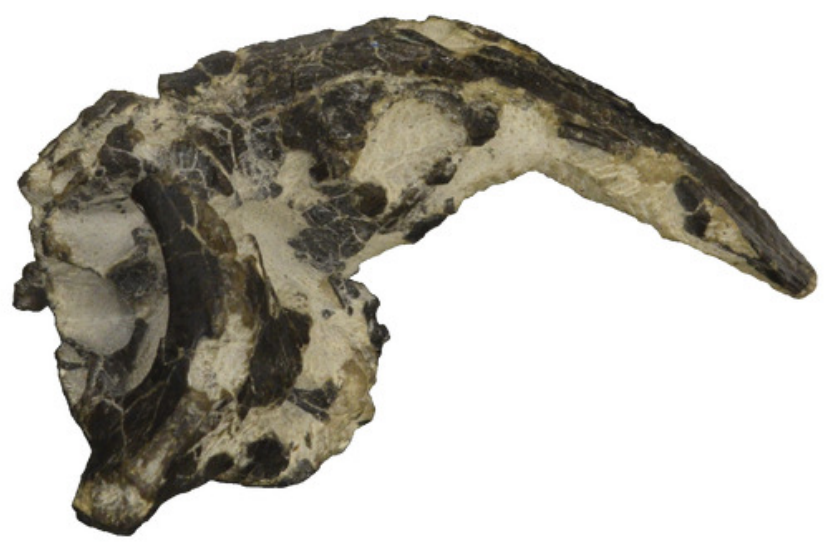

B

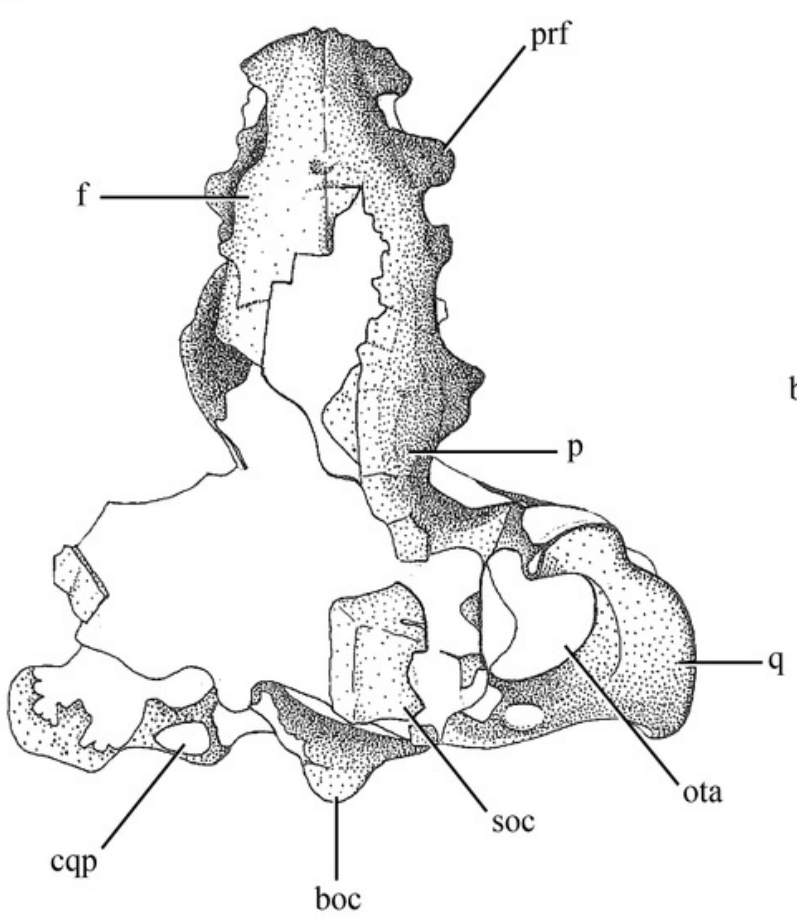

D

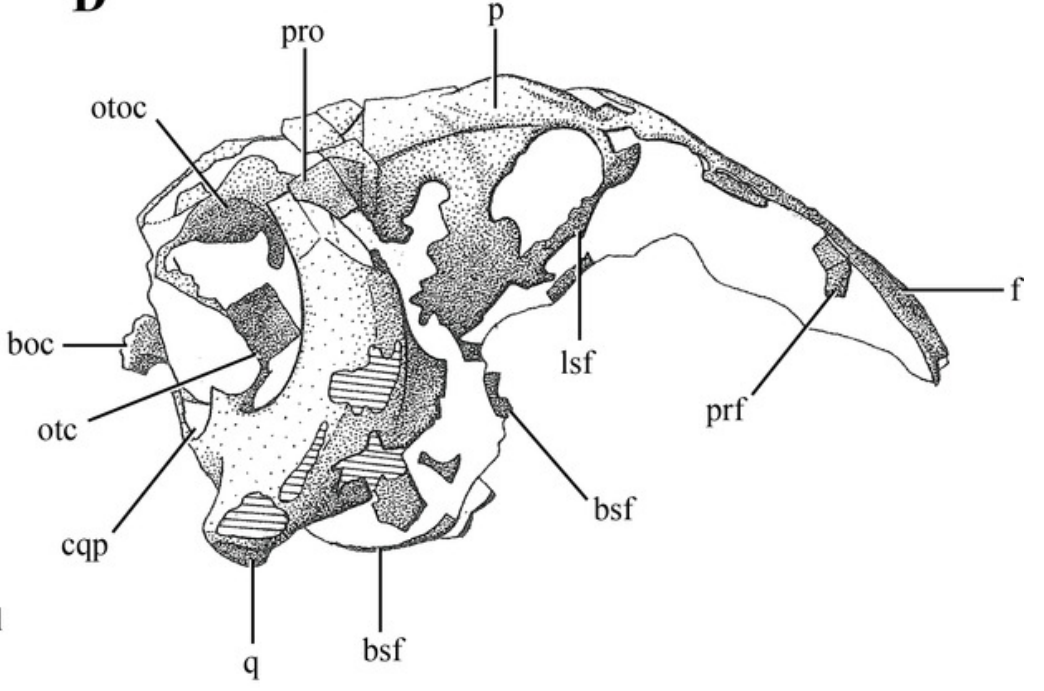


Figure 2

Digital reconstruction of the segmented posterior region of the skull of Macelognathus (LACM 5572/150148).

A, dorsal; B, ventral; C, right lateral; D, anterior; and, E, posterior views. 
A

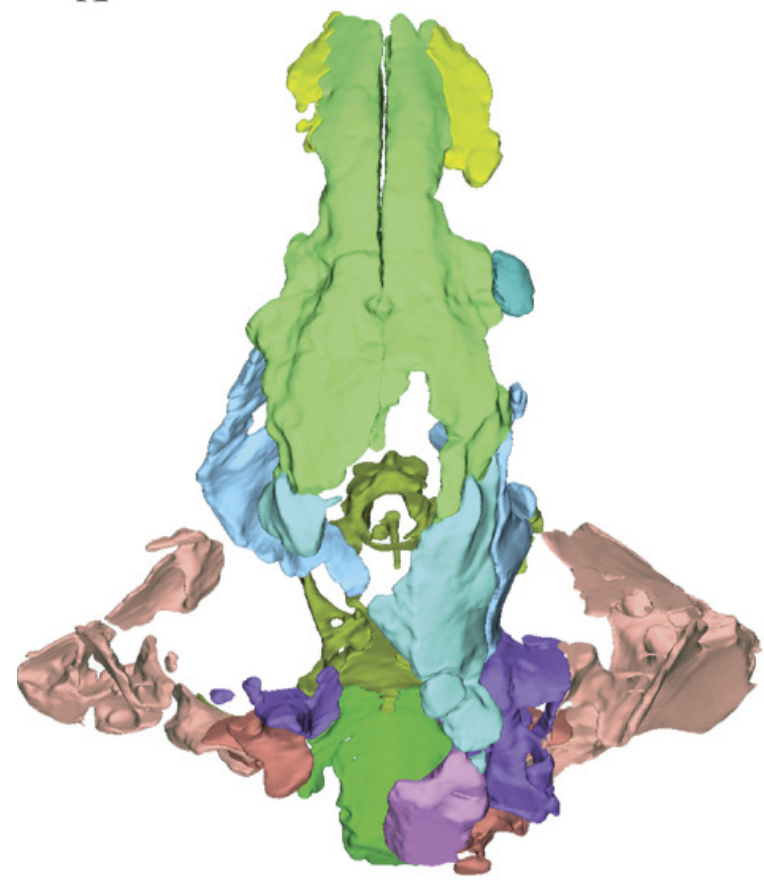

B

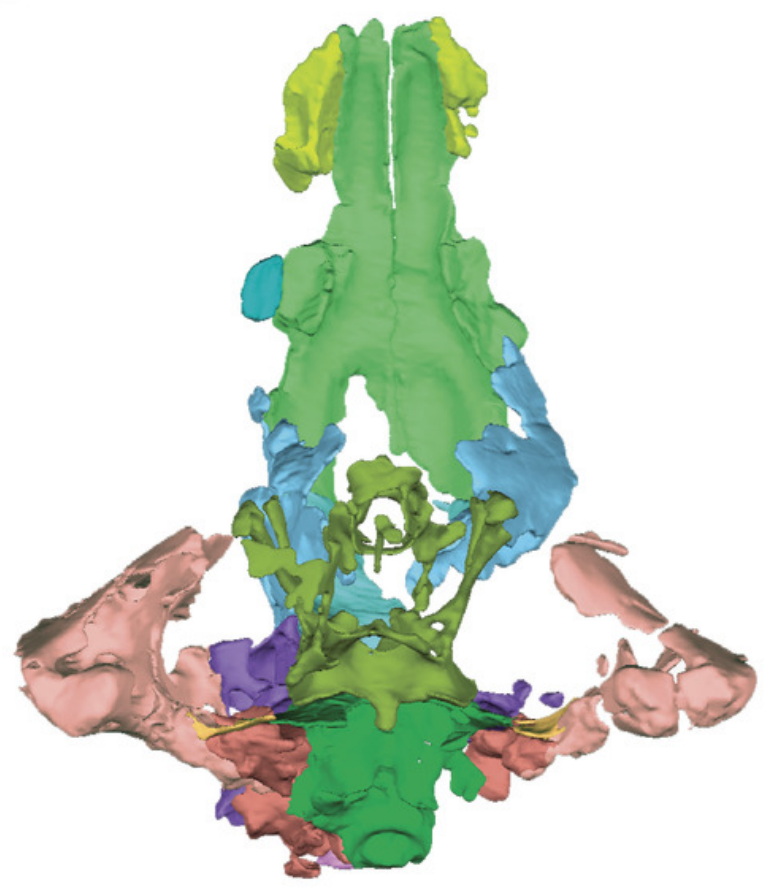

C

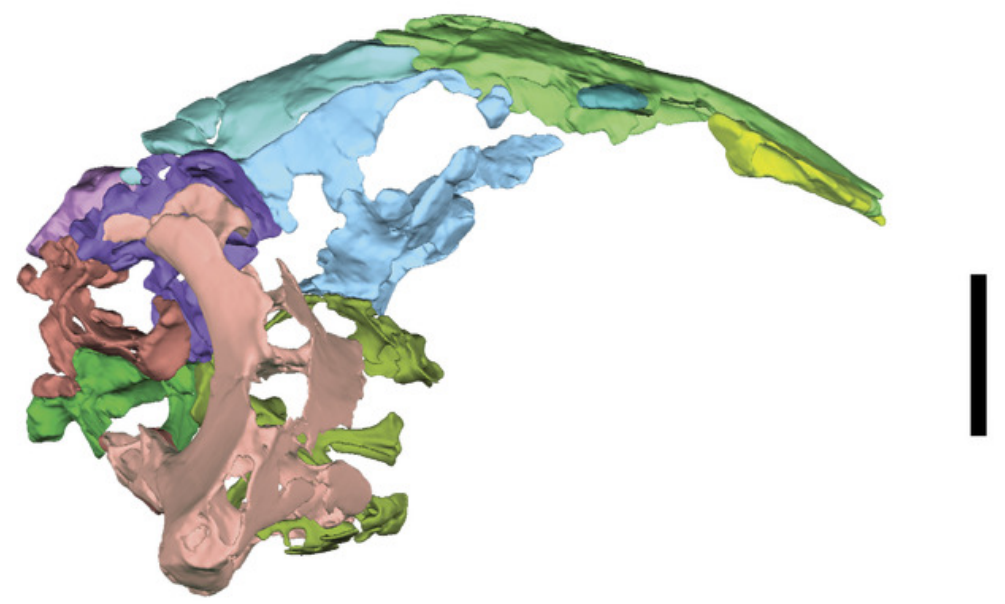

D

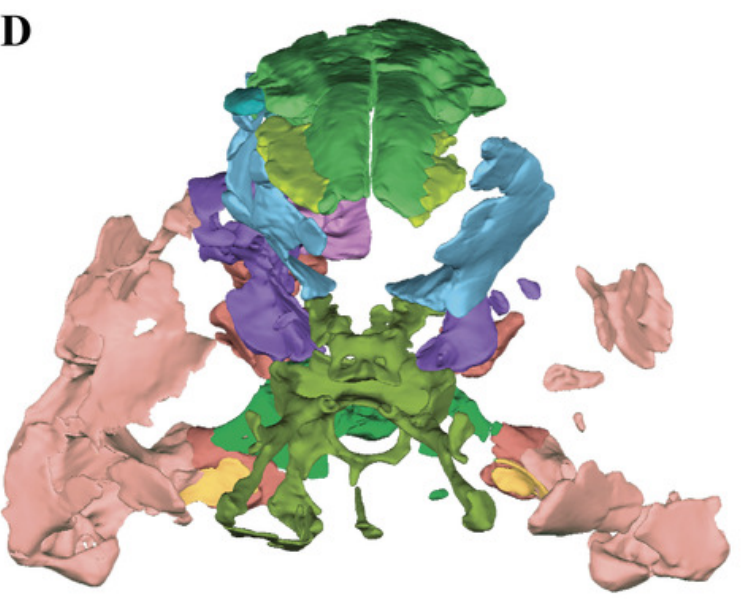

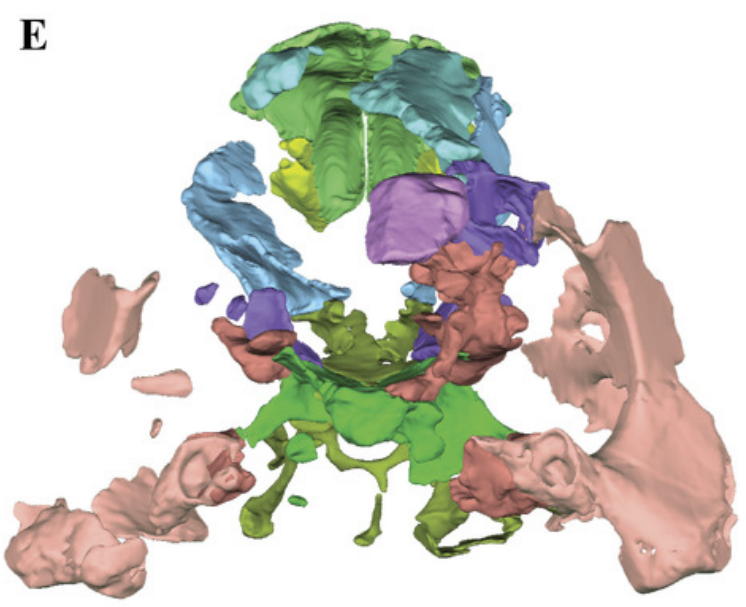

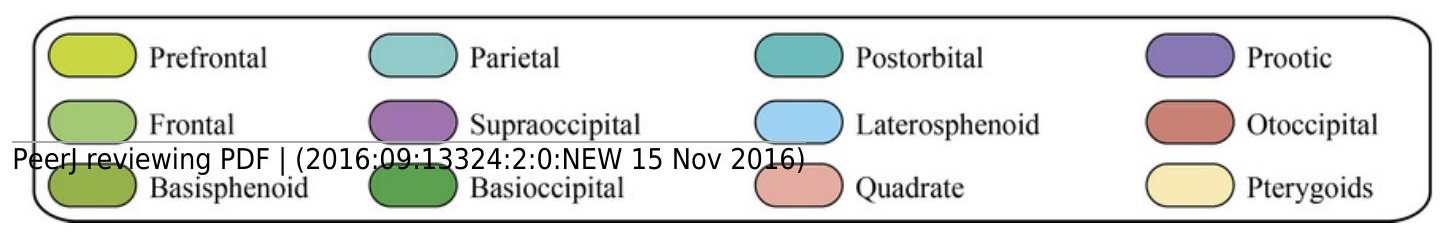




\section{Figure 3}

Digital reconstructions of the frontals, prefrontals and postorbital of Macelognathus.

A, dorsal; B, ventral; and, C, lateral views. D, Close up to the right prefrontal in ventrolateral view. Same color reference as Fig. 2. Abbreviations: cc, crista cranii; ch, depression for the cerebral hemispheres; dob, depression of the olfactory bulb; fr, frontal; ifs, interfrontal suture; om, orbital margin; po, postorbital; prf, prefrontal; prfpc, pneumatic cavity of the prefrontal; prfpp, posterior process of the prefrontal; vp ifs, ventral process of the interfrontal suture. 


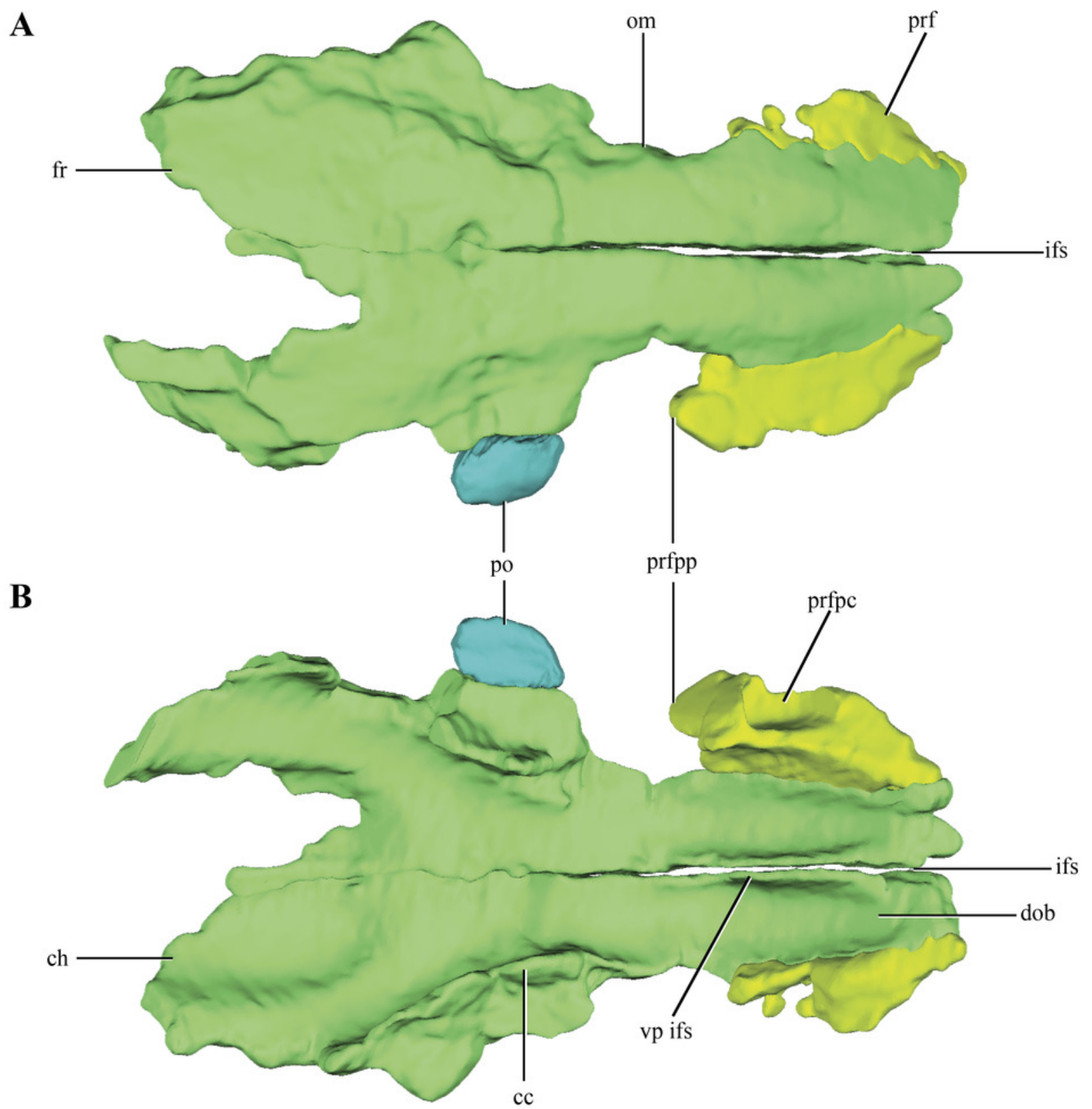

C

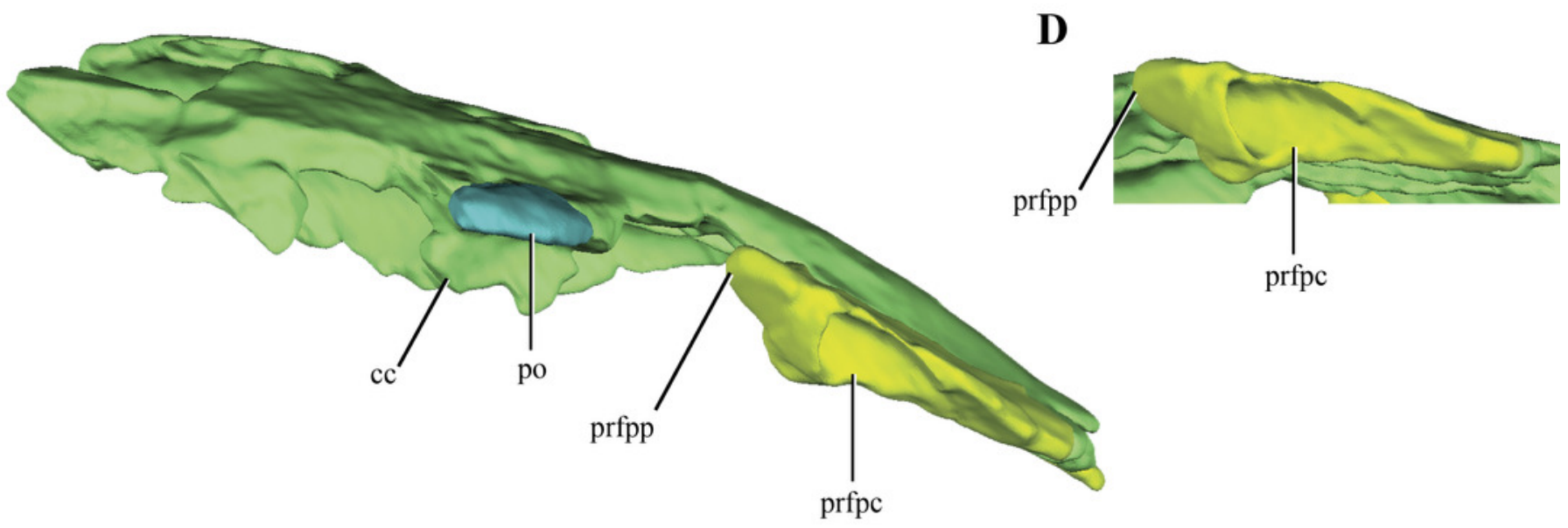




\section{Figure 4}

Digital reconstructions of the parietal of Macelognahus.

A, dorsal; and, B, lateral views. Abbreviations: alpf, anterolateral process of the frontal; dc, dorsal crest; f. Isf, facet for the laterosphenoid; f. pro, facet for the protic; STF, border of the supretemporal fossa.

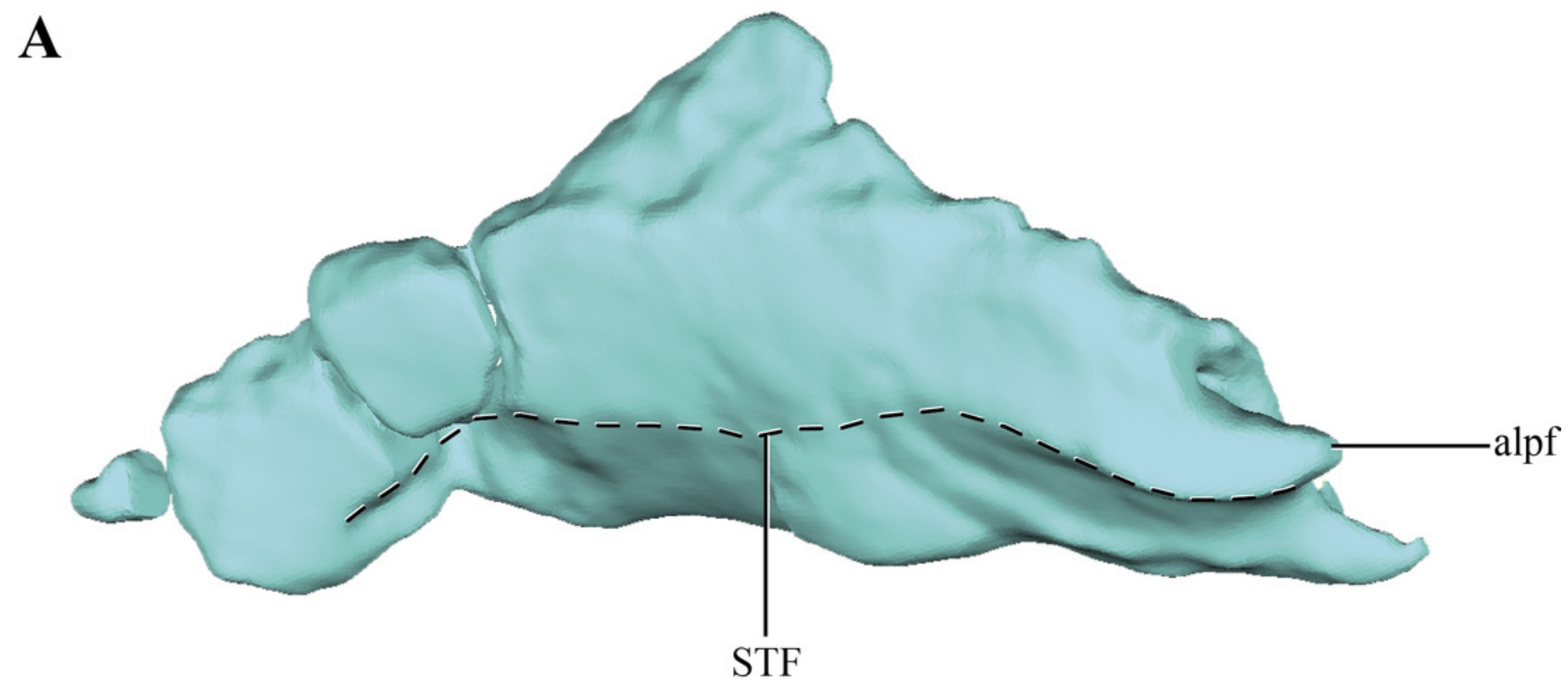

B

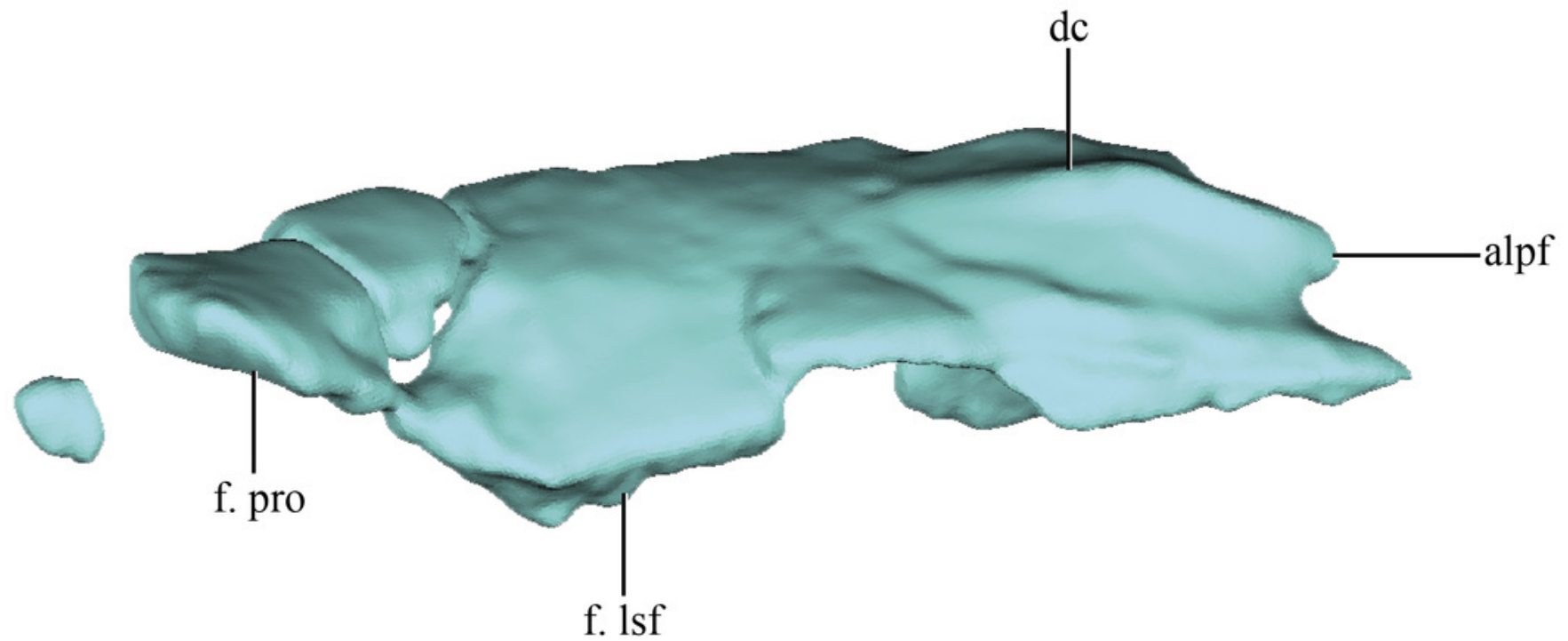




\section{Figure 5}

Digital reconstructions of the right quadrate of Macelognathus.

A, lateral; B, medial; C, anteromedial; and, D, posterior views. Abbreviations: cqp, cranioquadrate passage; dmq, dorsomedial process of the quadrate; f., qj, facet for the quadratojugal; f. otoc, facet for the otoccipital; Icq, lateral condyle of the quadrate; mcq, medial condyle of the quadrate; oj, otic joint; ota, otic aperture; ptq, pterygoid ramus of the quadrate; qf, quadrate fenestra; tc, tympanic crest; 1-5, internal chambers of the quadrate. 
A

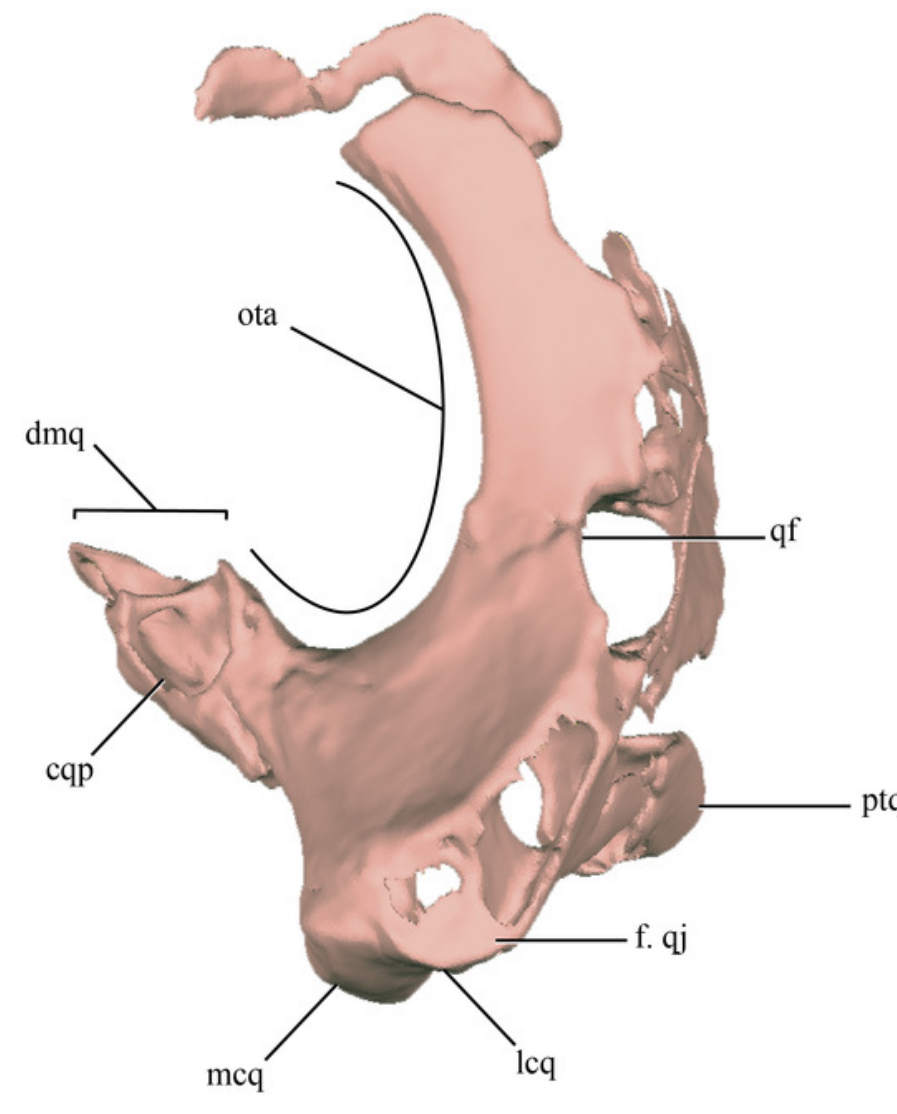

C

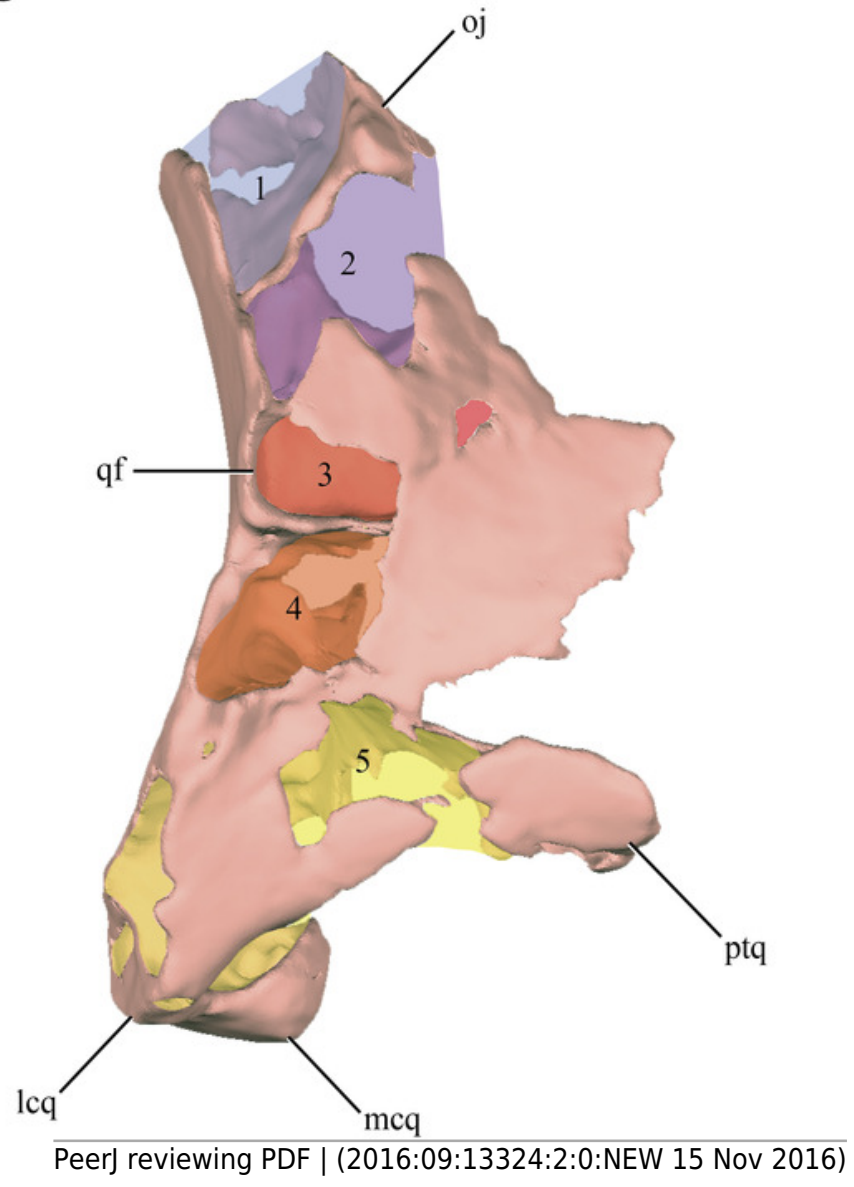

B

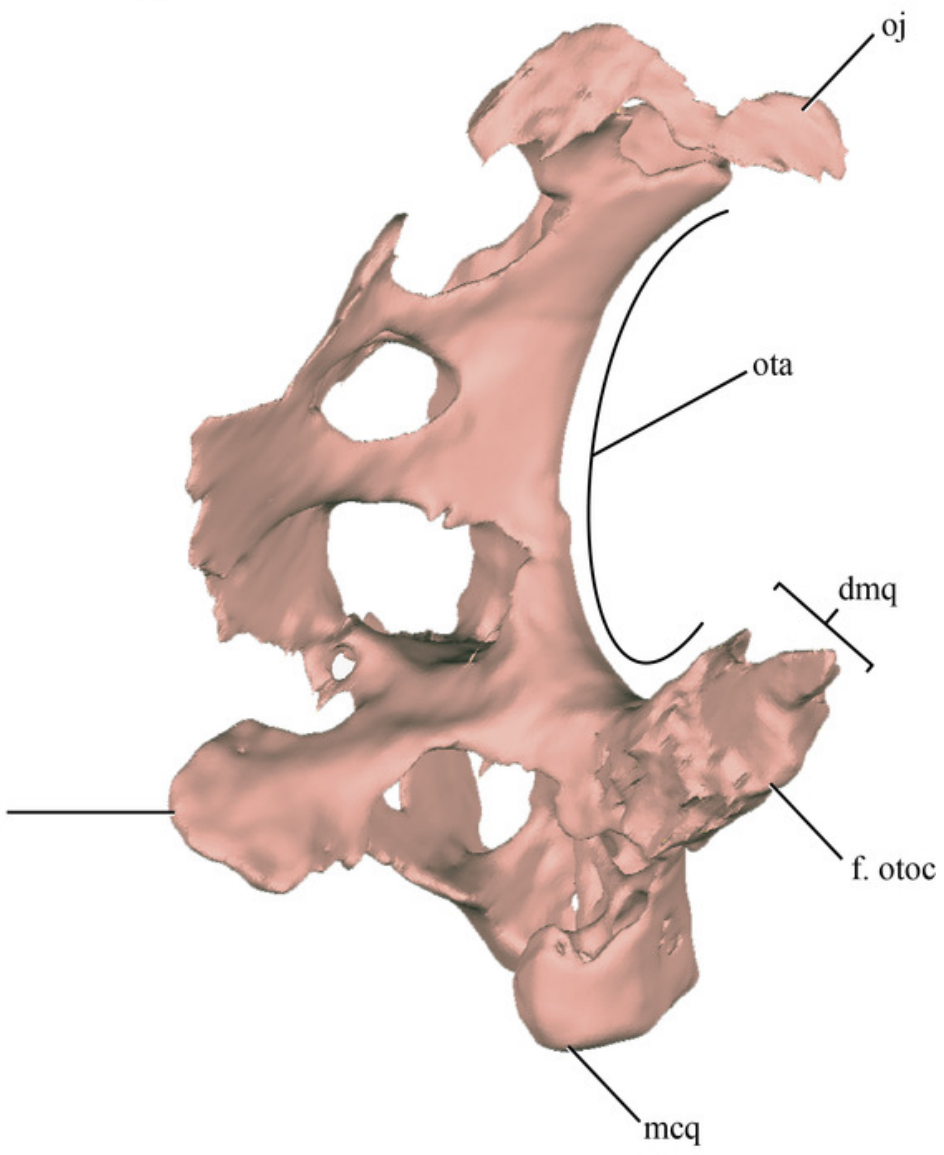

D

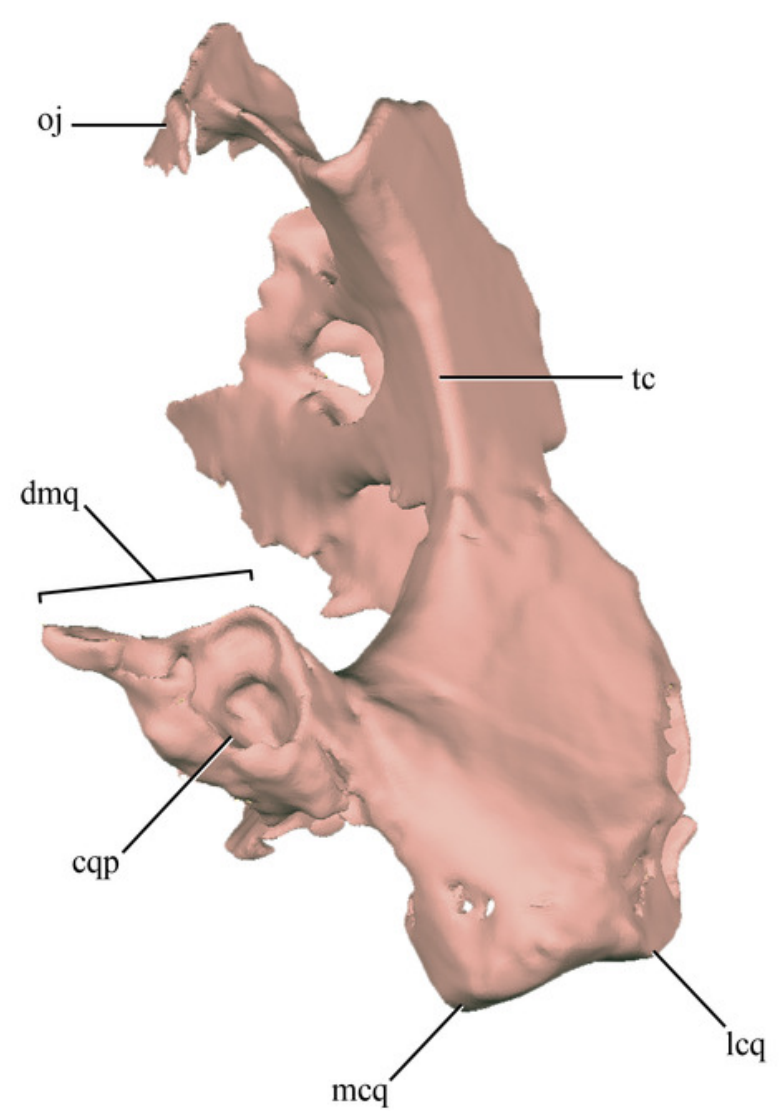




\section{Figure 6}

Digital reconstructions of the braincase of Macelognathus.

A, lateral; and, B, medial views. Same color reference as Fig. 2. Abbreviations: aur, auricular recess; bot, basal tubera; bsf ros, rostrum of the basisphenoid; cif, crista interfenestralis; coc, cochlear recess; con, occipital condyle; cpr, crista prootica; fov, fenestra ovalis; g. csc, groove for the caudal semicircular canal; ma, mastoid antrum; met, metotic fissure; otc, otic capsule; PTR, posterior tympanic recess; paroc, paroccipital processes; vp bsf, ventral plate of the basisphenoid. 
A

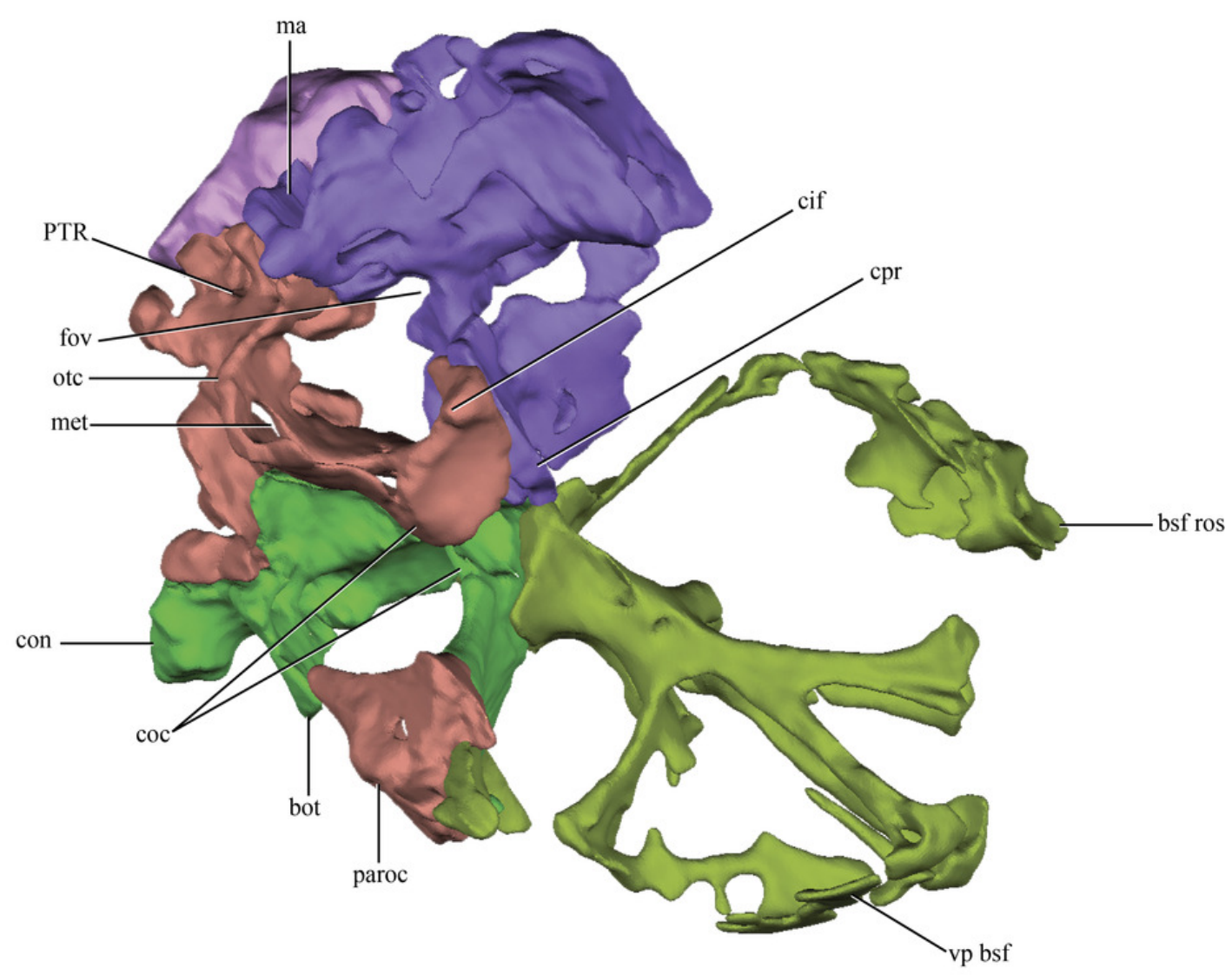

B

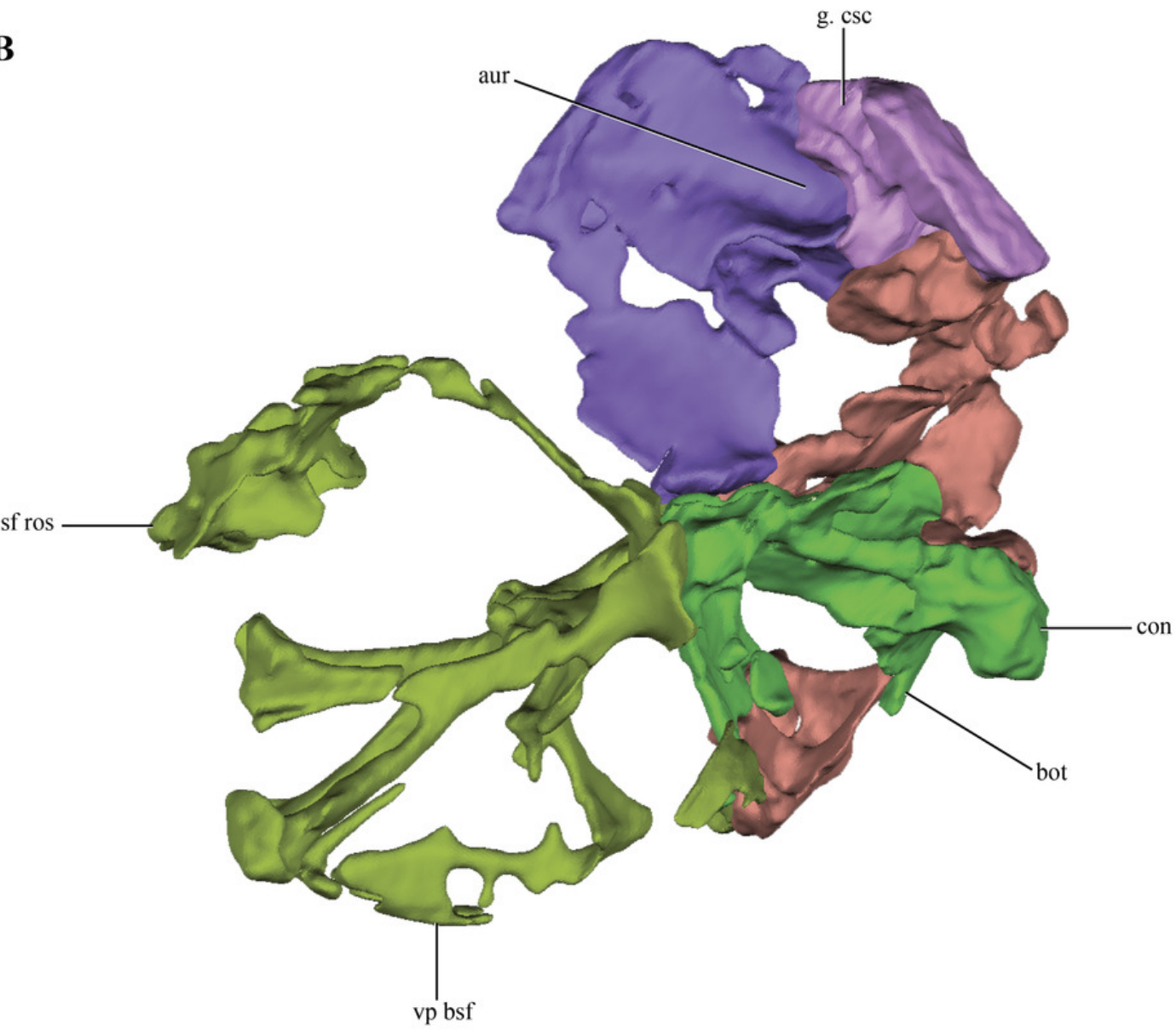




\section{Figure 7}

Digital reconstructions of the right protic of Macelognathus.

A, lateral; B, medial; C, dorsal; and, D, ventral views. Abbreviations: aur, auricular recess; coc, cochlear recess; cpr, crista prootica; f. boc., facet for the basioccipital; fma, foramina of the lateral wall of the mastoid antrum; f. otoc, facet for the otoccipital; f. q, facet for the quadrate; fov, fenestra ovalis; Isc, groove for the lateral semicircular canal; ma, mastoid antrum; VII, exit for the VII cranial nerve. 
A

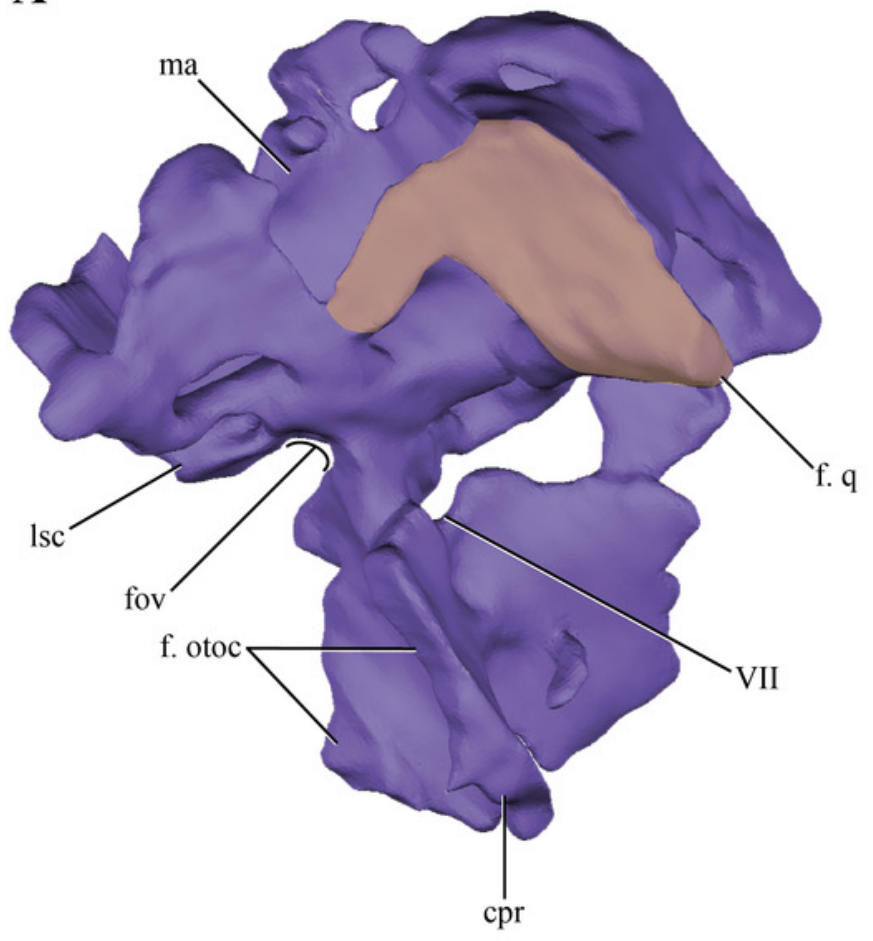

C

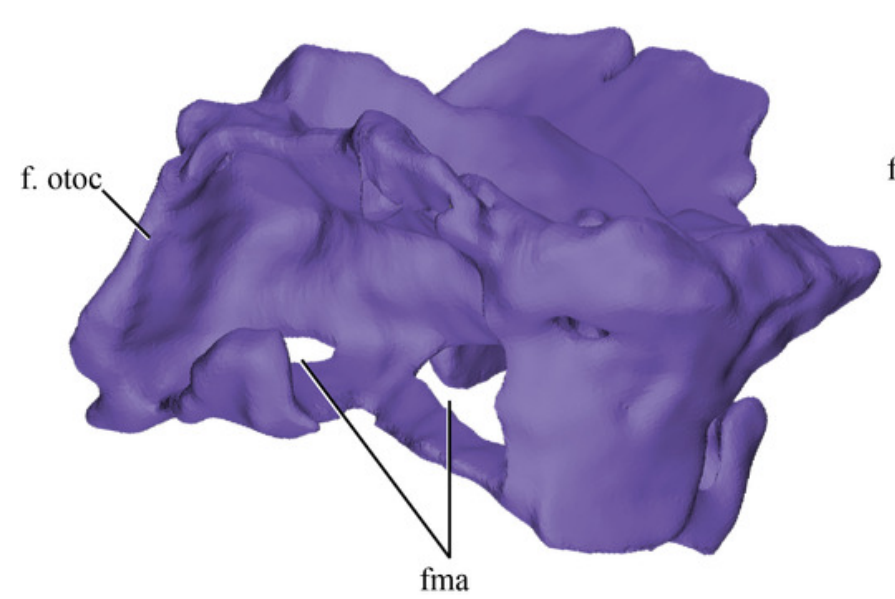

B

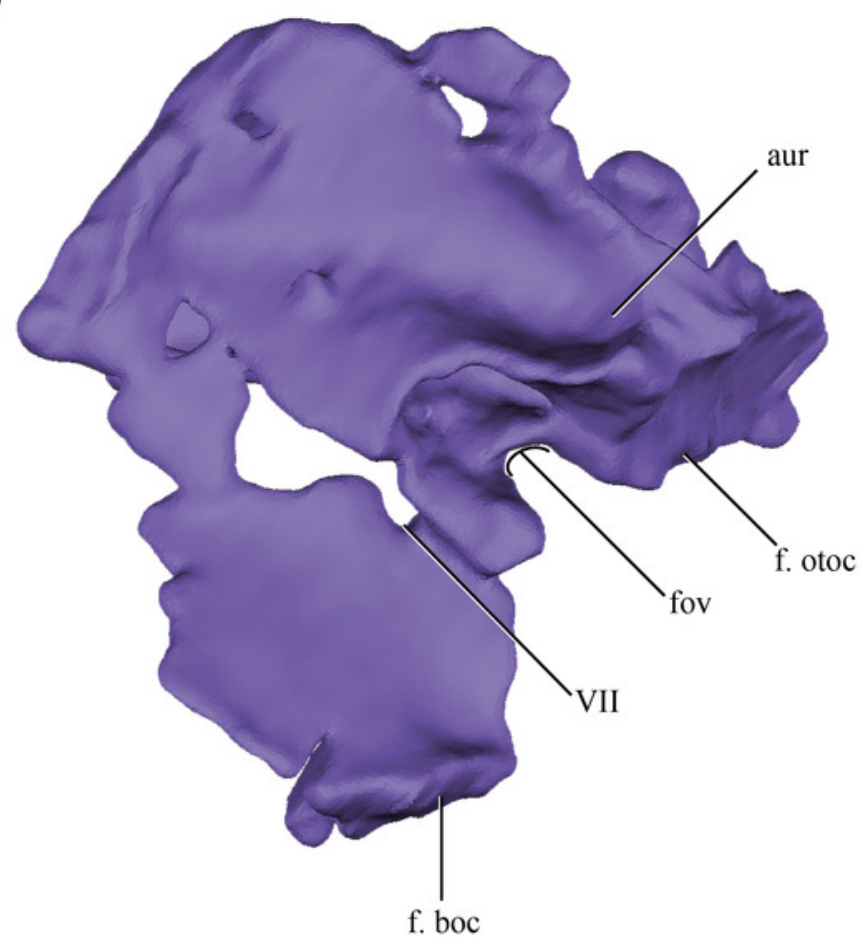

D

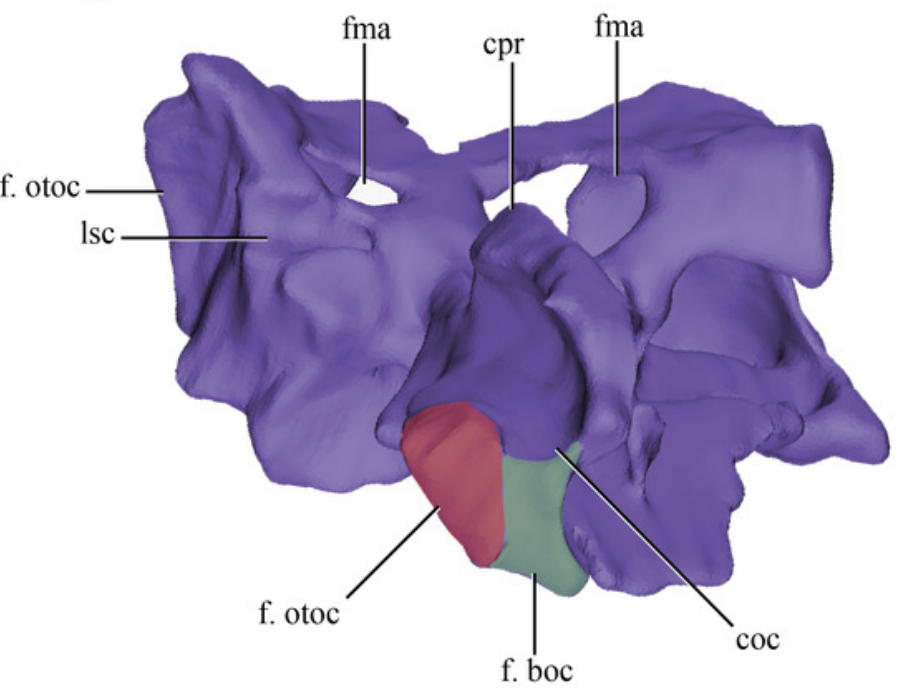




\section{Figure 8}

Digital reconstructions of the right otoccipital (excluding the paroccipital processes) of Macelognathus.

A, posterior; B, lateral; and, C, anterior views. Abbreviations: cif, crista interfenestralis; coc, cochlear recess; dl otc, dorsal lamina of the otic capsule; f. boc, facet for the basioccipital; $f$. pro, facet for the protic; Isc, groove for the lateral semicircular canal; met, metotic fissure; pcv, posterior cerebral vein; PTR, posterior tympanic recess; scb, subcapsular buttress; IX...X, exit for cranial nerves IX...X.

A

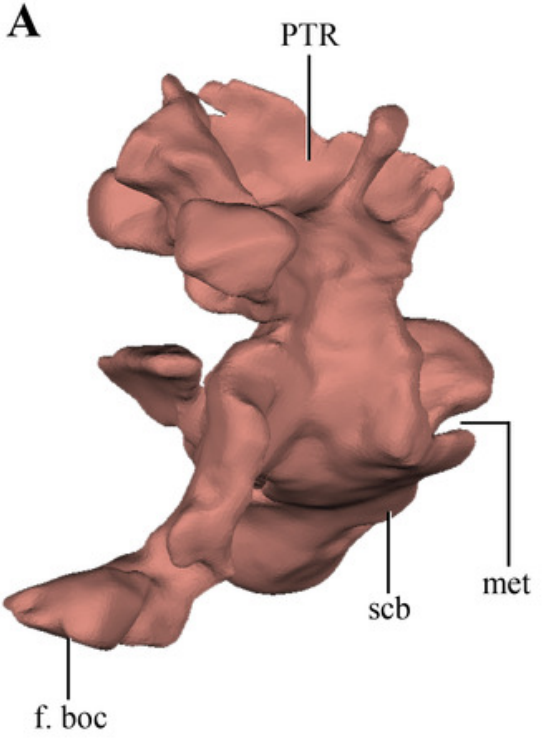

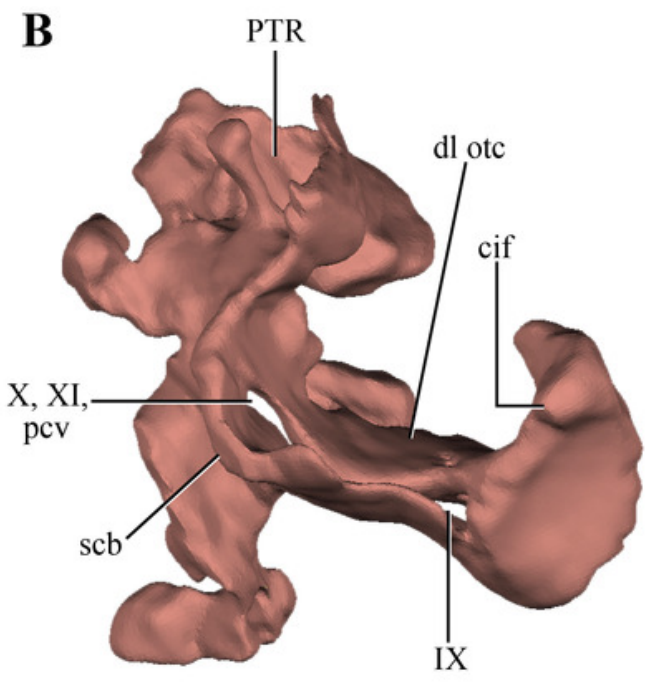

C

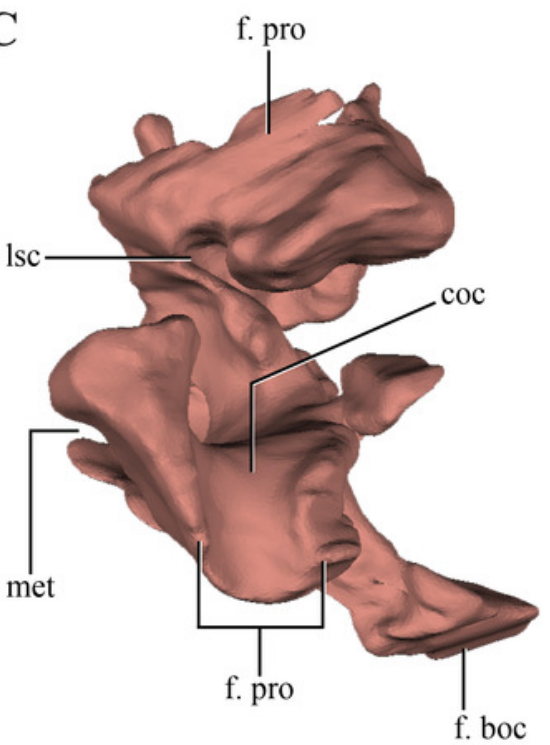




\section{Figure 9}

Digital reconstructions of the supraoccipital of Macelognathus.

A, posterior; B, dorsal; and, C, medial view. Abbreviations: aur, auricular recess; avb, anteroventral bulge of the supraoccipital; csc, groove for the caudal semicircular canal.

A

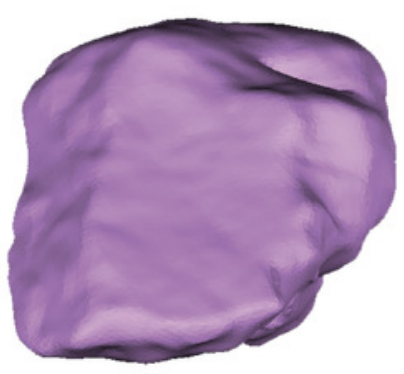

B

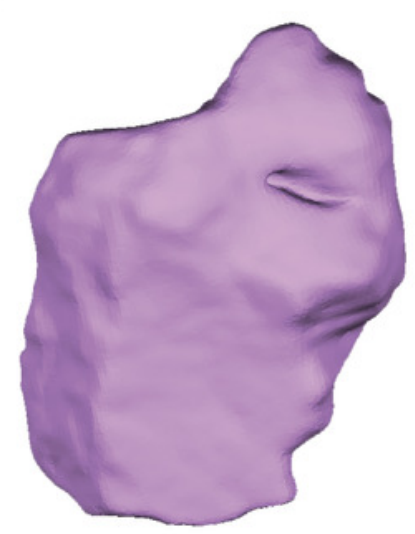

C

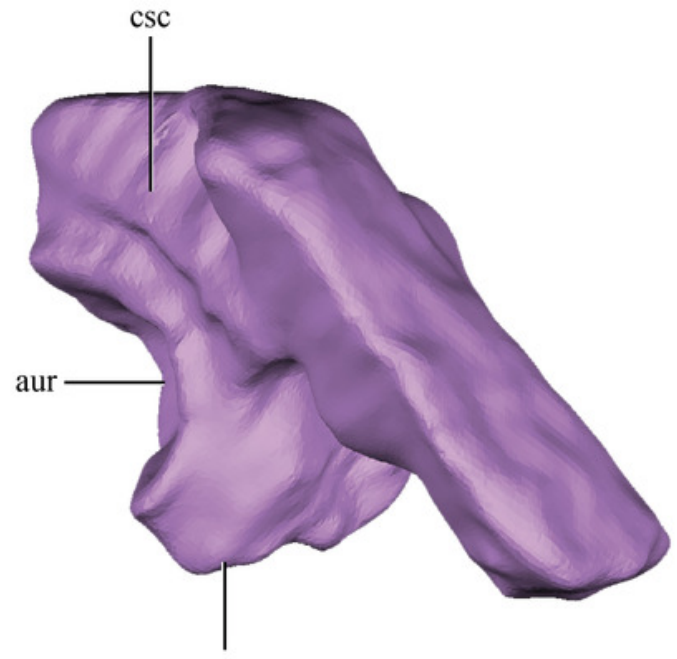




\section{Figure 10}

Digital reconstructions of the basioccipital of Macelognathus.

A, ventral; B, lateral; C, dorsal; and, D, posterior views. Abbreviations: bor, basioccipital recess; bot, basal tubera; bt, blind tubes of the basioccipital; cc bor, central crest of the basioccipital recess; coc, cochlear recess; con, occipital condyle; f end, floor of the endocranial cavity; f. otoc, facet for the otoccipital; f. pro, facet for the protic; If boc, lateral flanges of the basioccipital; $\mathrm{ml}$, medial lamina of the basal tubera; rhom, rhomboidal sinus; vf boc, ventral flanges of the basioccipital.
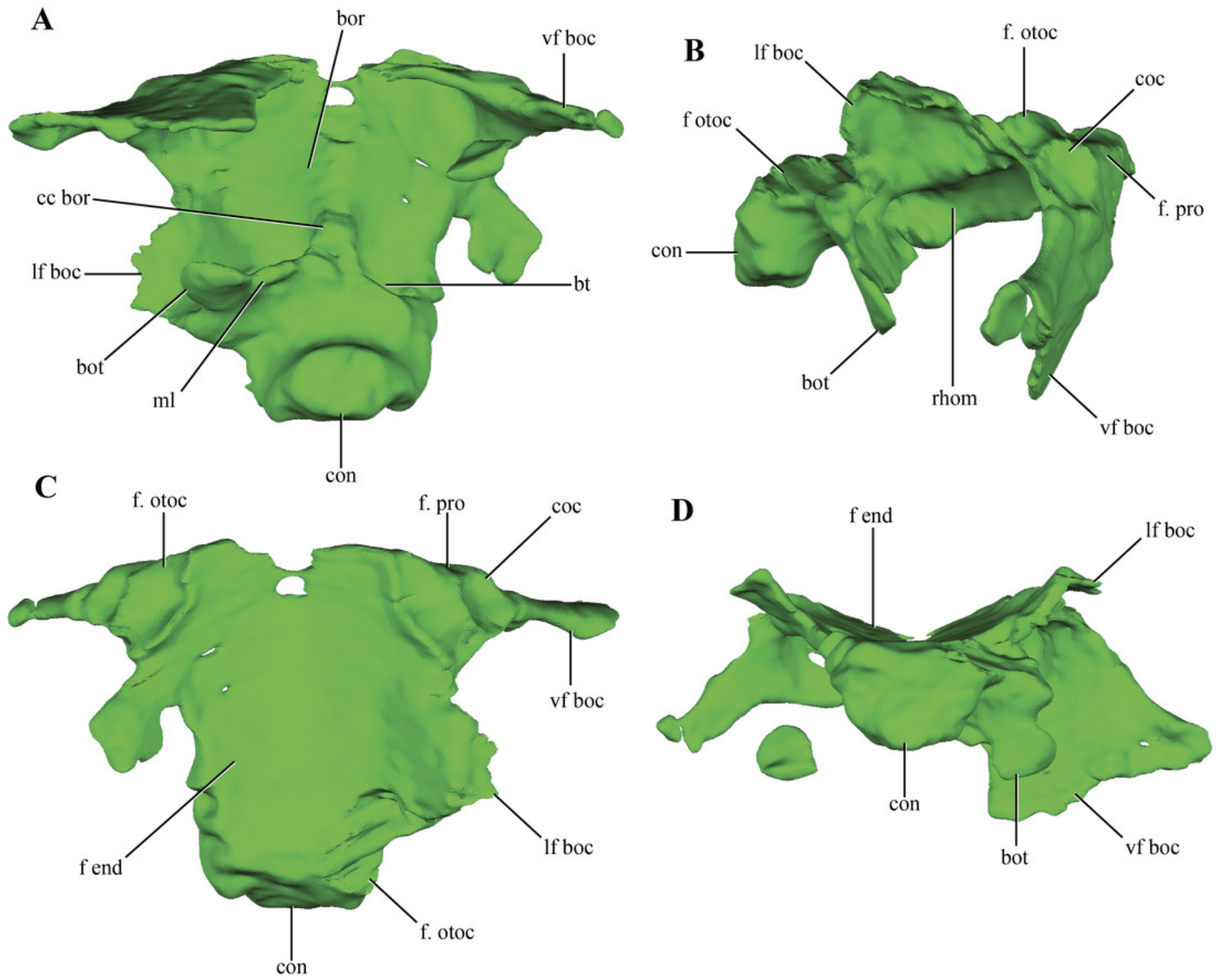


\section{Figure 11}

Digital reconstructions of the basisphenoid of Macelognathus.

A, lateral; B, dorsal; C, anterior; and, D, posterior views. Abbreviations: bsfp, basisphenoid plate; bsf ros, rostrum of the basisphenoid; car, passage for the carotid arteries ;coc, cochlear recess; $c p$, carotid pillar; ds, dorsum sellae; f. boc, facet for the basioccipital; f. Isf, facet for the laterosphenoid; f. pro, facet for the protic; pal; passage for the palatine artery; pp bsf, posterior process of the basisphenoid; ppd, posterior depression of the basisphenoid; pr bsf, posterior "ring" of the basisphenoid; st, sella turica; VI, exit for the VI cranial nerve. 

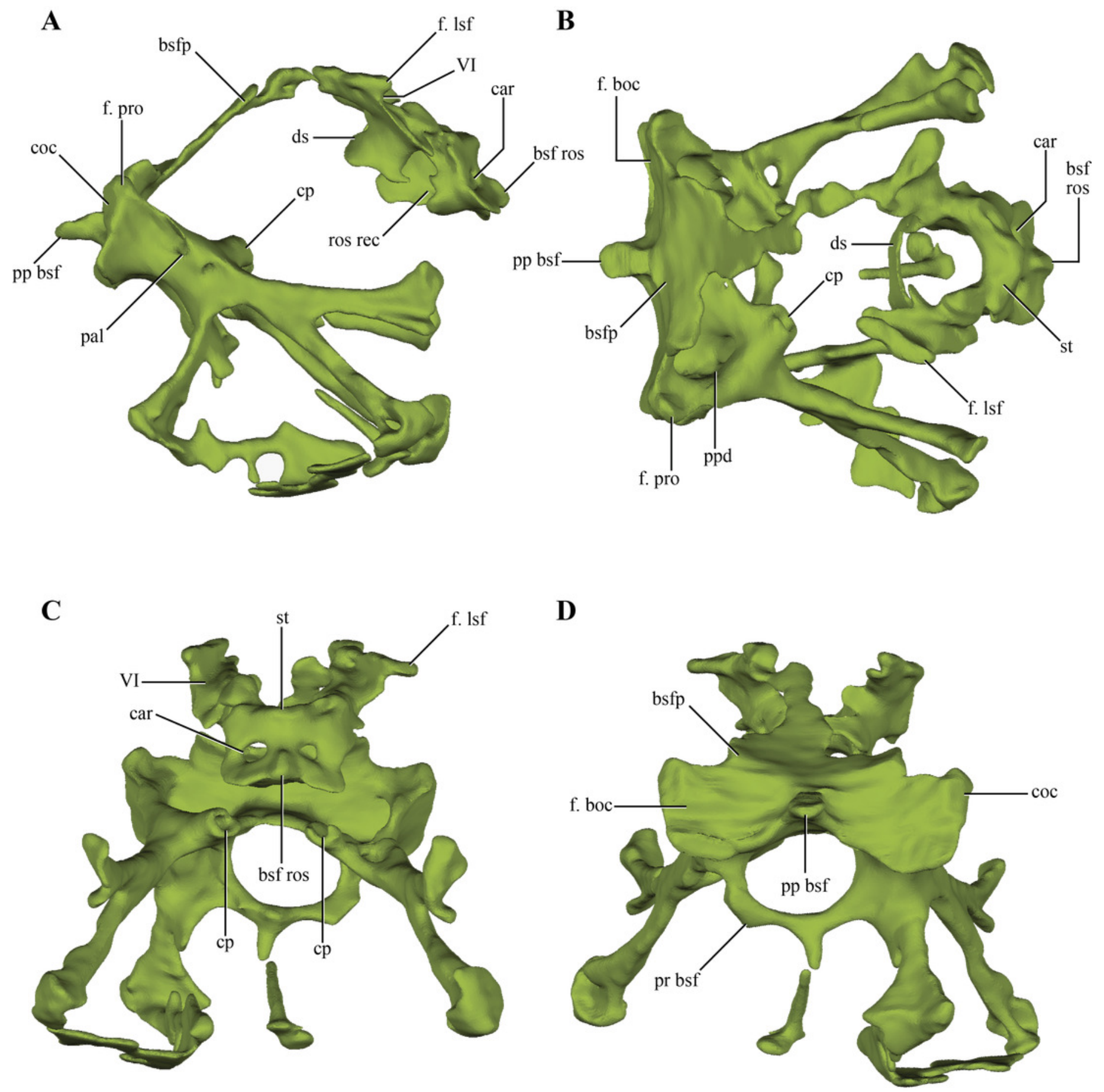


\section{Figure 12}

Digital reconstructions of the left and right laterosphenoids of Macelognathus.

A, lateral; and, C ventral views. Left laterosphenoid in A, lateral; and, B, posterior view.

Abbreviations; cap, capitated processes of the laterosphenoid; f. bsf, facet for the basisphenoid; for?, foramen?; f. par, facet for the parietal; f. pro, facet for the protic; i. cav, internal cavity of the laterosphenoid.

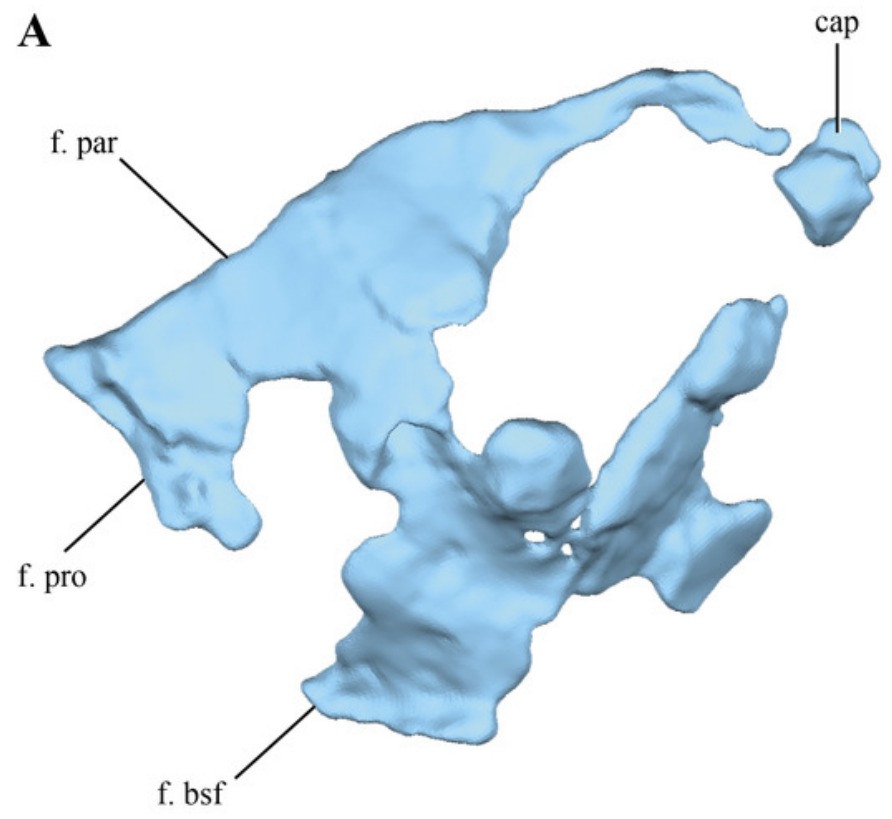

B
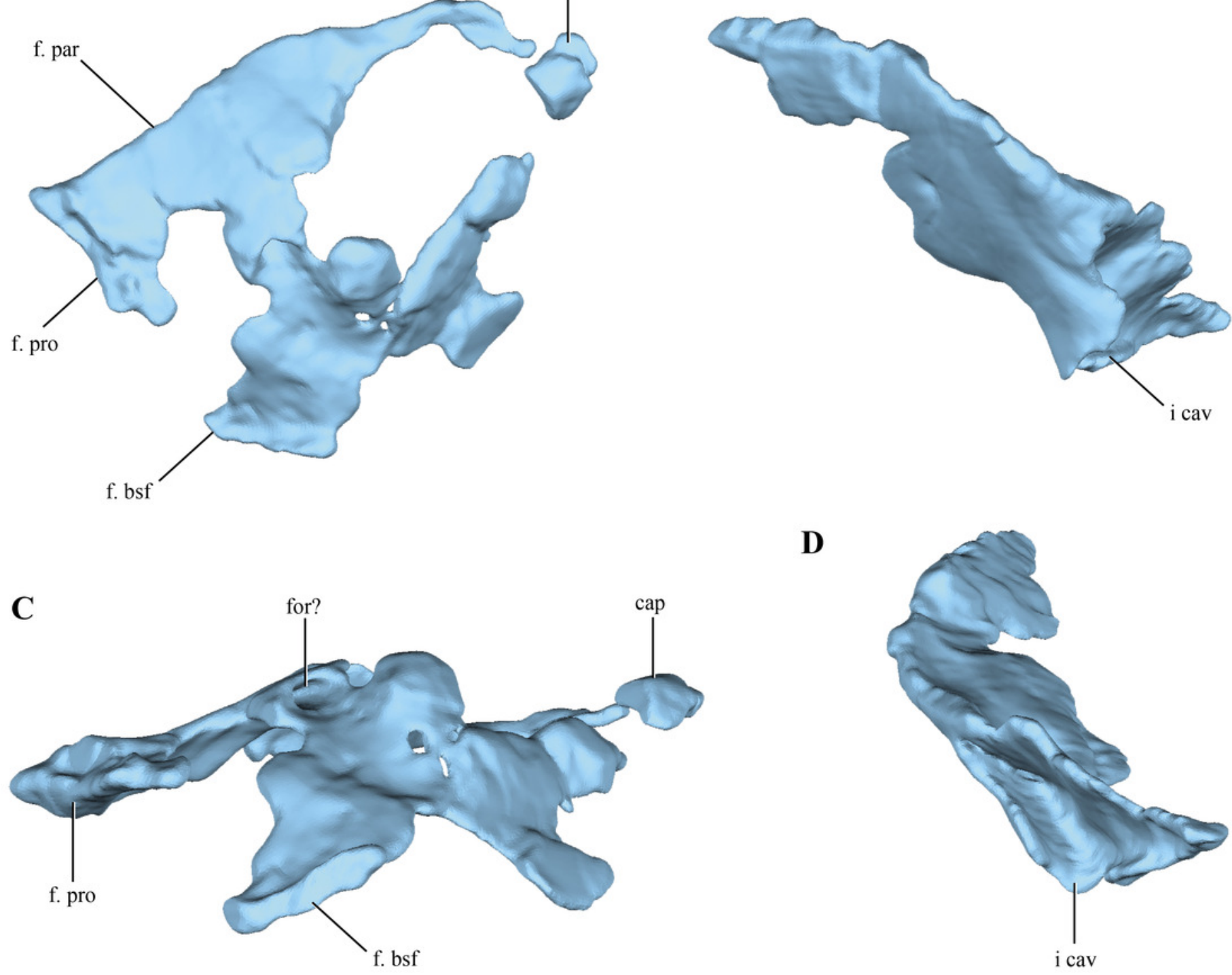

D

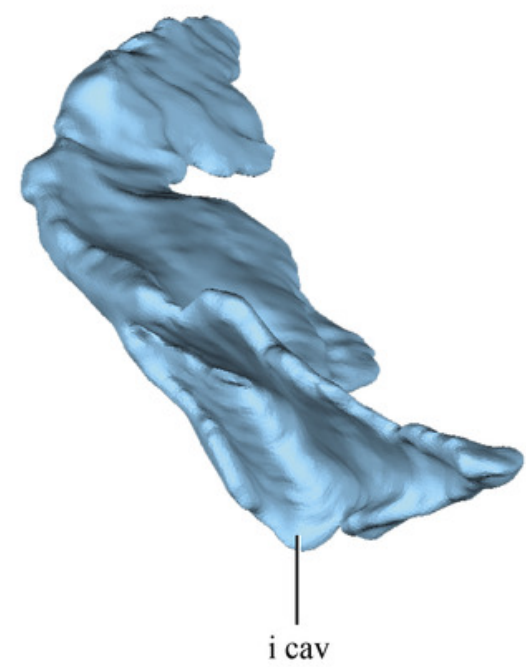




\section{Figure 13}

Selected phylogenetic characters used in this contribution.

Skulls of A, Kayentasuchus walkeri (UCMP 131830); C, Dibothrosuchus elaphros (IVPP V 7907); and, E, Almadasuchus figarii (MPEF PV 3838) in posterior views. Details of the supratemporal fenestra in dorsal view of B, Litargosuchus leptorhynchus (BP/1/5237); D, Hesperosuchus agilis (CM 29894); and, F, Almadasuchus figarii (MPEF PV 3838). See Character Sampling and Supplementary Information for details. 

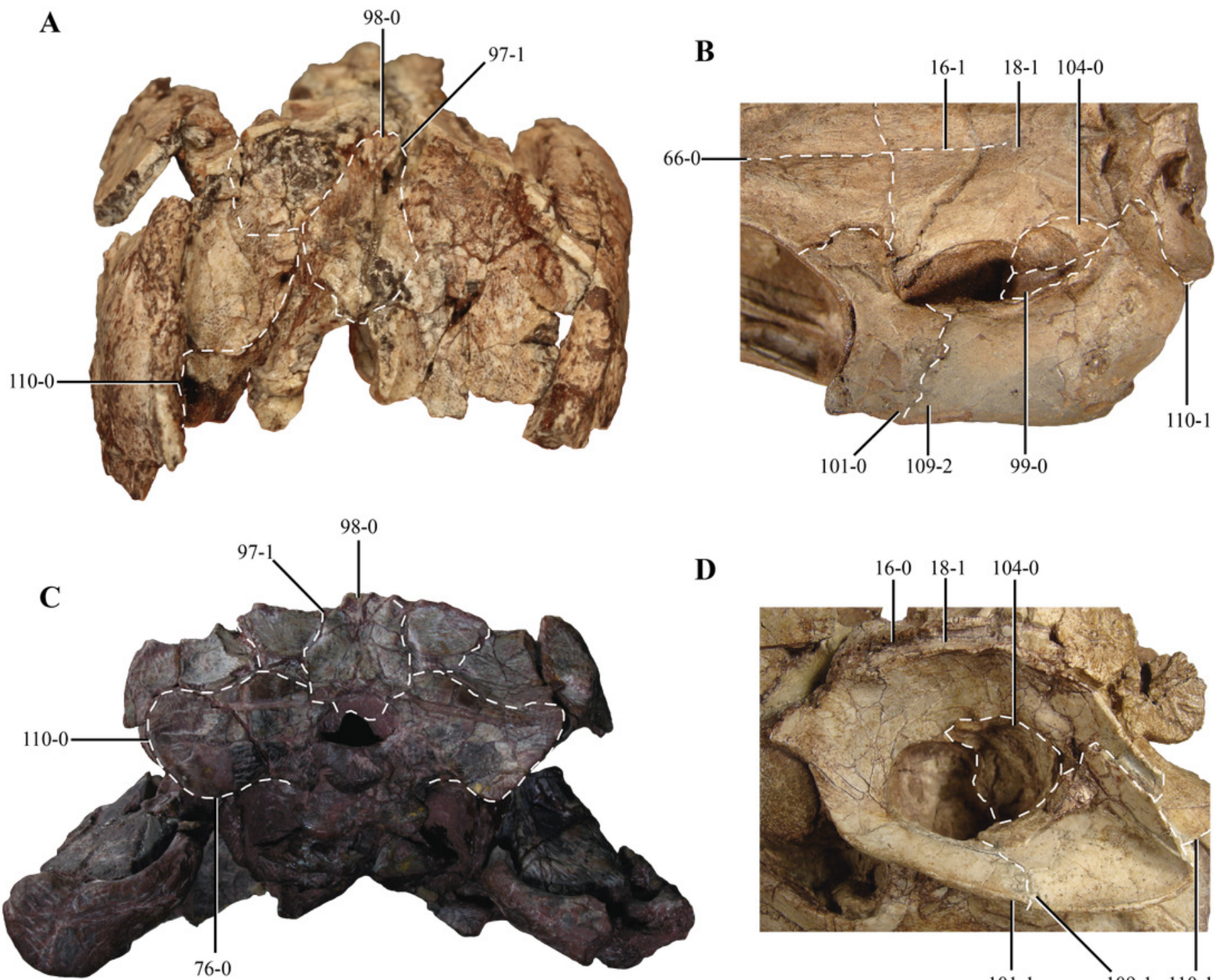

D
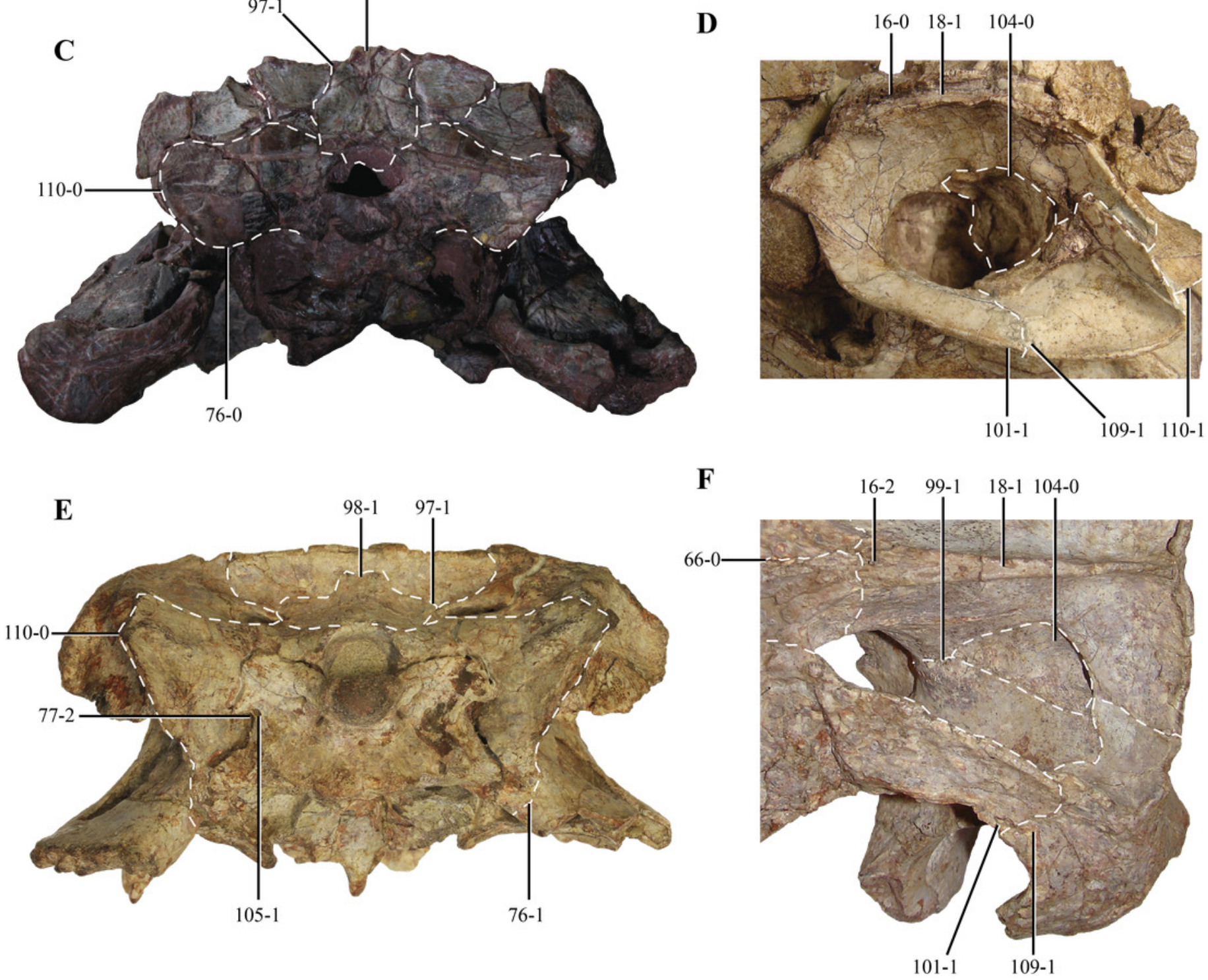


\section{Figure 14}

Selected phylogenetic characters related to Hesperosuchus agilis used in this contribution.

A, Maxilla of the type specimen of Hesperosuchus agilis (AMNH FR 6758) in lateral view. Posterior cervical vertebrae in lateral view of: B, the type (AMNH FR 6758); and, C, the referred (CM 29894) specimen of Hesperosuchus agilis. Proximal radii in anterior view of: D, Pseudhesperosuchus jachaleri (PVL 3830); E,the type specimen of Hesperosuchus agilis (AMNH FR 6758); and, the referred (CM 29894) specimens of Hesperosuchus agilis. See characters 106, 137, and 138. 


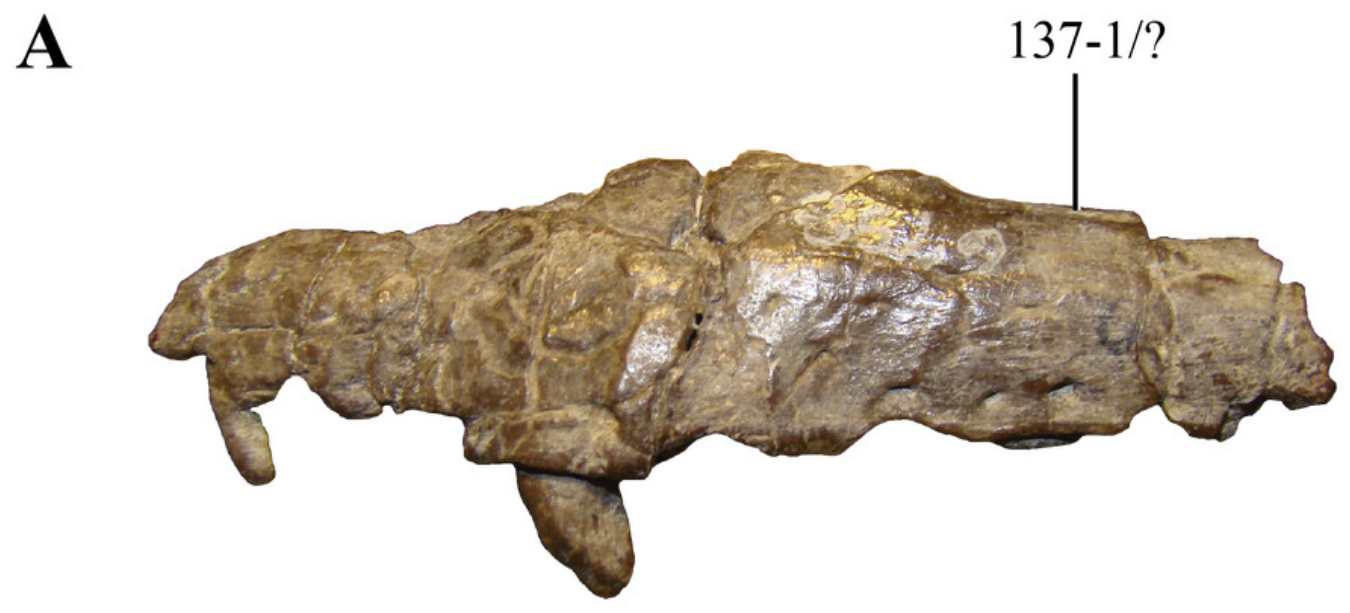

B
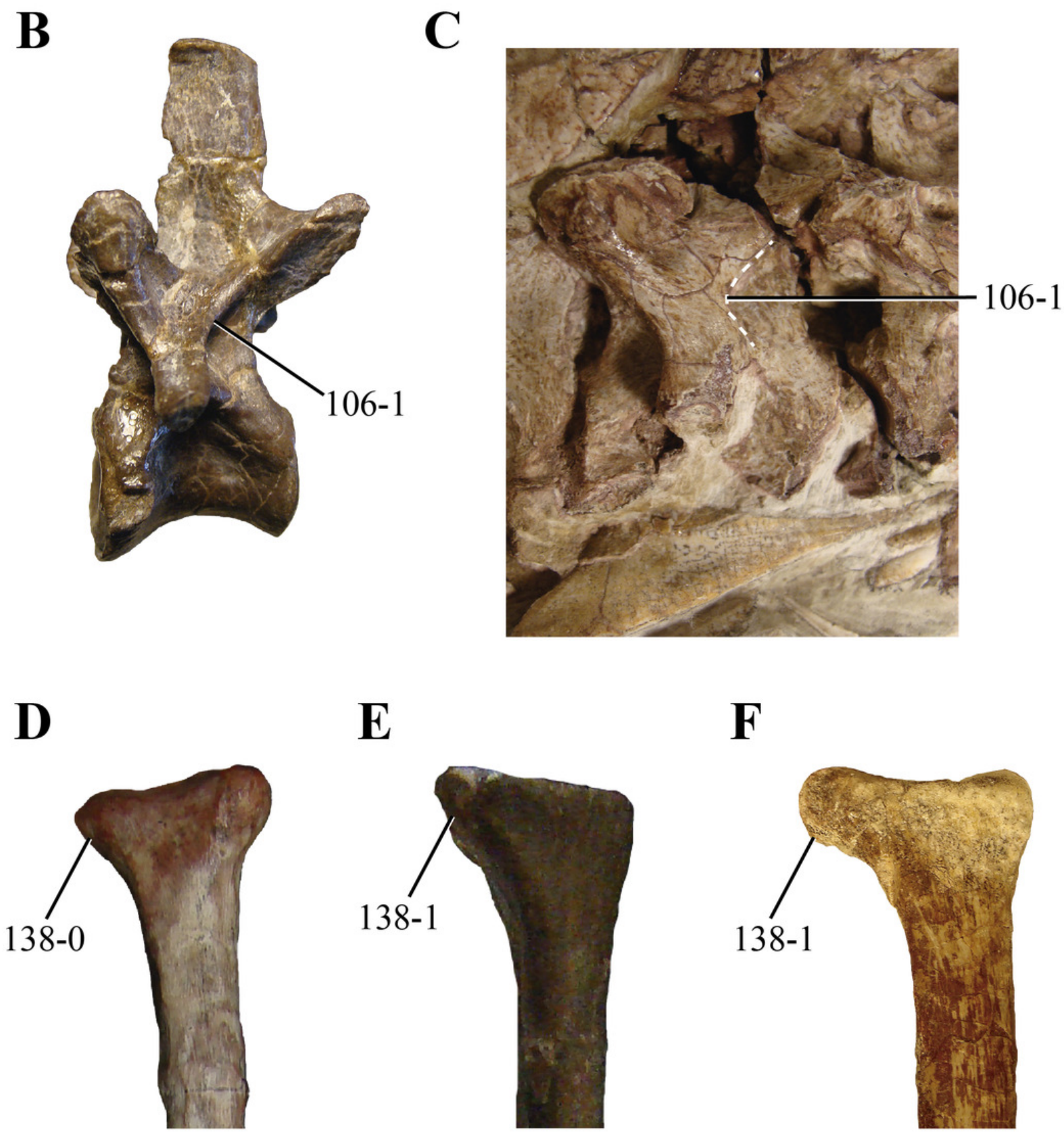

$\mathbf{E}$

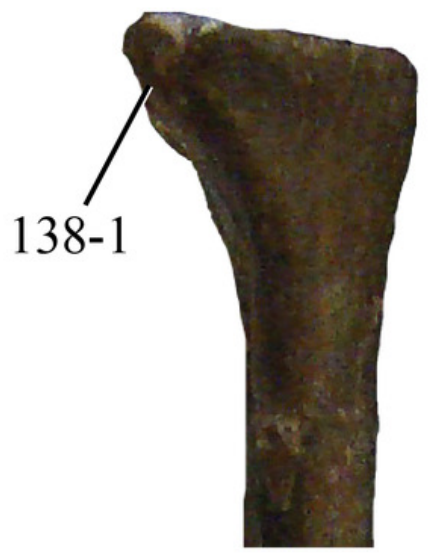

F

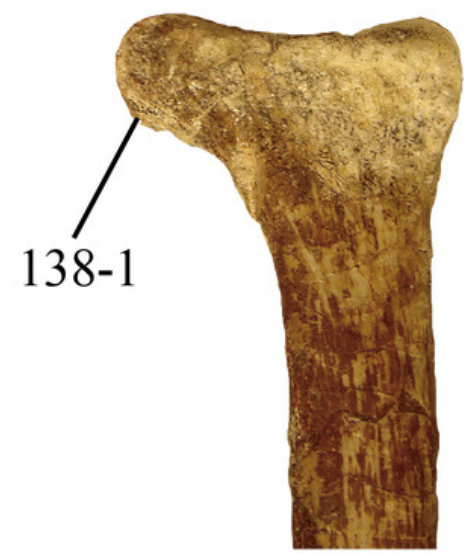




\section{Figure 15}

Detail of the region surrounding the antorbital fenestra with emphasis on the maxilla.

A, Dibothrosuchus (IVPP V 7907); B, Kayentasuchus (UCMP 131830); C, Junggarsuchus (IVPP V 14010); and, Hesperosuchus (CM 29894). The border of the antorbital fossa is marked with a black dashed line, while the anterior and the posterior depths of the maxilla ventral to the antorbital fossa are marked with a white dashed line.

A

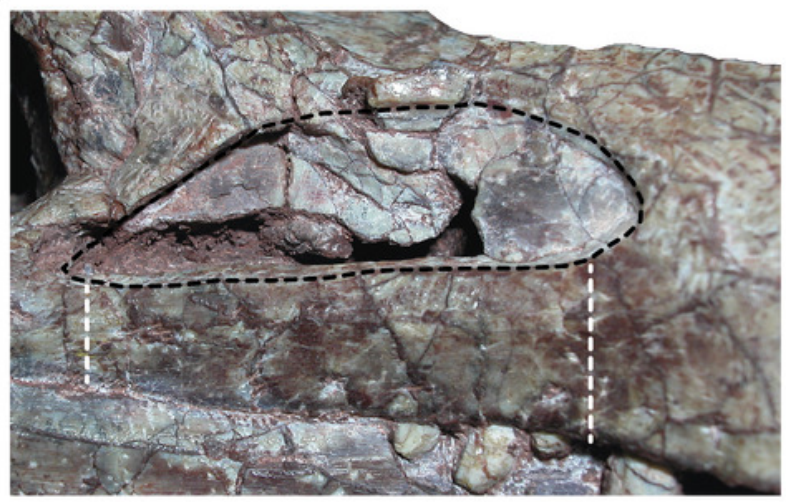

C

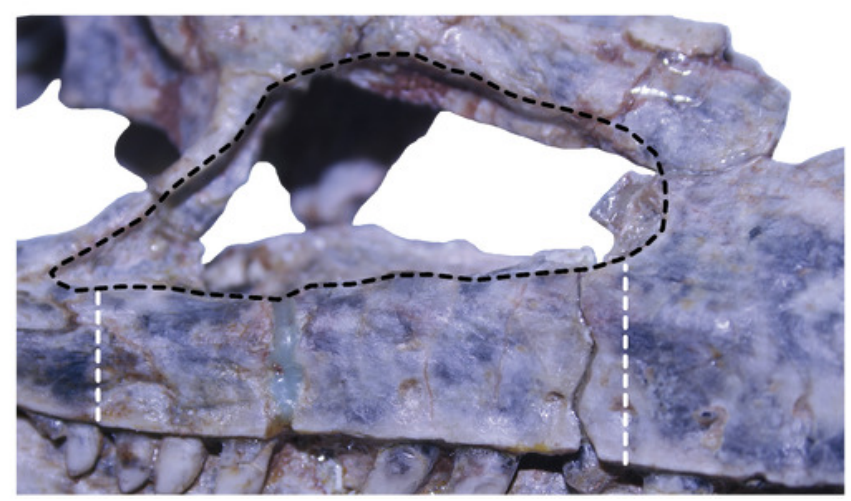

B

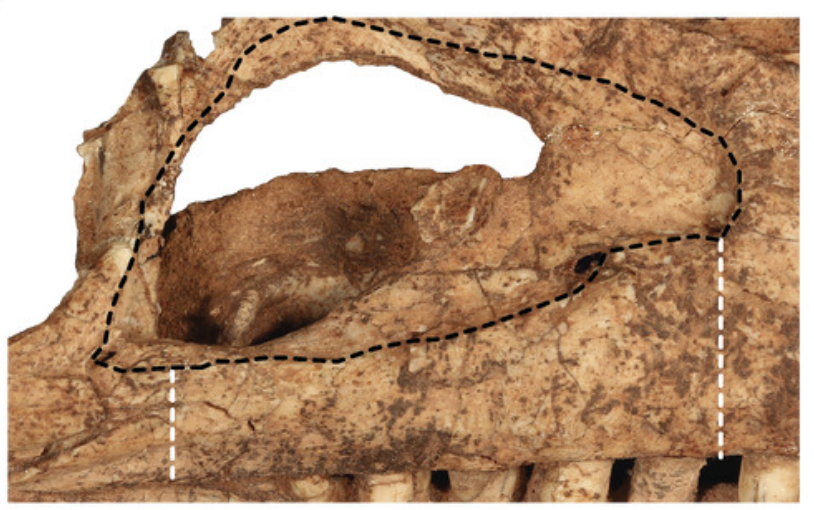

D

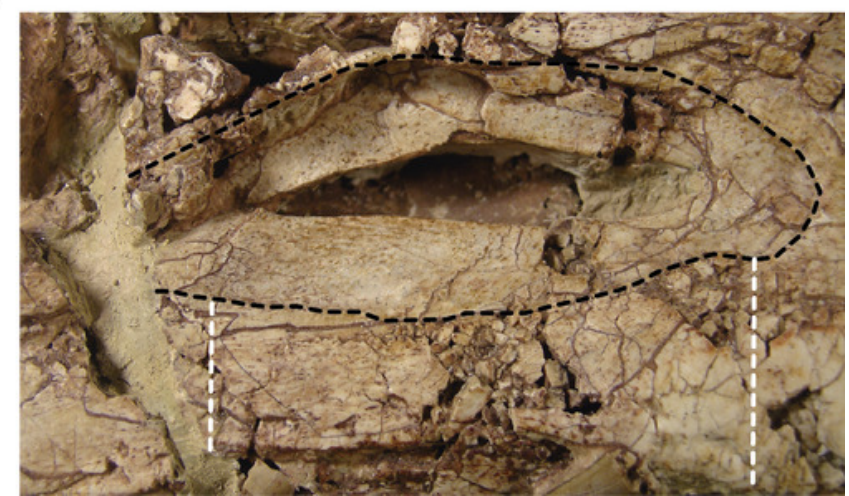


Figure 16

Time calibrated phylogenetic tree of the analysis performed in this contribution.

Strict consensus of the ten MTPs recovered $(\mathrm{L}=348 ; \mathrm{Cl}=0.460 ; \mathrm{RI}=0.778)$, found in 735 of the 1000 replicates.
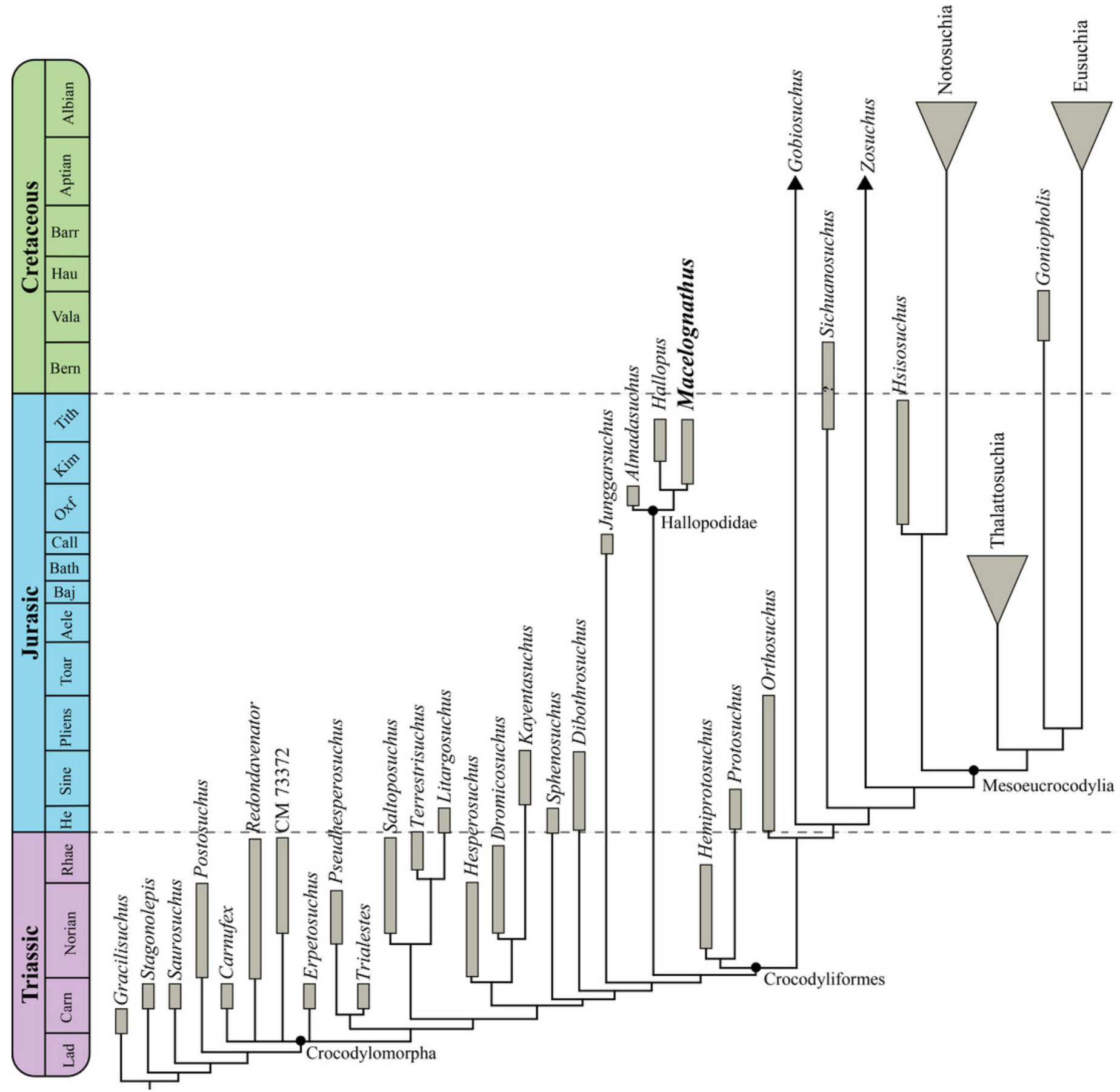